Review

\title{
Greener Synthesis of Nitrogen-Containing Heterocycles in Water, PEG, and Bio-Based Solvents
}

\author{
Joana F. Campos $(\mathbb{D}$ and Sabine Berteina-Raboin * \\ Institute of Organic and Analytical Chemistry (ICOA), University of Orleans, UMR-CNRS 7311, BP 6759, \\ rue de Chartres 45067 Orleans CEDEX 2, France; joana-filomena.mimoso-silva-de-campos@univ-orleans.fr \\ * Correspondence: sabine.berteina-raboin@univ-orleans.fr; Tel.: +33-238-494-856
}

Received: 26 March 2020; Accepted: 9 April 2020; Published: 14 April 2020

check for updates

\begin{abstract}
The solvents used in chemistry are a fundamental element of the environmental performance of processes in corporate and academic laboratories. Their influence on costs, health safety, and nature cannot be neglected. Quantitatively, solvents are the most abundant constituents of chemical transformations; therefore, acting on solvents and replacing standard solvents with safer products can have a great ecological impact. However, not all green solvents are suitable for the wide scope of organic chemistry reactions. A second point to consider is that $50 \%$ of pharmaceutical drugs are nitrogen heterocycles compounds. It therefore appeared important to provide an overview of the more ecological methodologies for synthesizing this class of compounds. In this review, all publications since 2000 that describe green reactions leading to the formation of nitrogen heterocycles using safe solvents were considered. We chose water, PEG, and bio-based solvents for their negligible toxicity. The synthesis of five-, six-, and seven-membered aromatic nitrogen heterocycles using green reactions reported in the literature to date is described.
\end{abstract}

Keywords: bio-based solvents; O,S,N-heterocycles synthesis; catalytic and greener methodology

\section{Introduction}

Even if the chemistry community has made significant efforts towards identifying greener processes by minimizing the quantity of catalysts or using multicomponent reactions and one-pot processes, solvents remain a major portion of the environmental performance of a process, and may have a significant influence on safety and health issues. Green solvents such as water, Poly(ethylene glycol) (PEG) and bio-based solvents hold considerable additional promise to reduce the environmental impact of organic chemistry. The study and search for greener synthetic methods have gained importance over the past two decades (Figure 1).

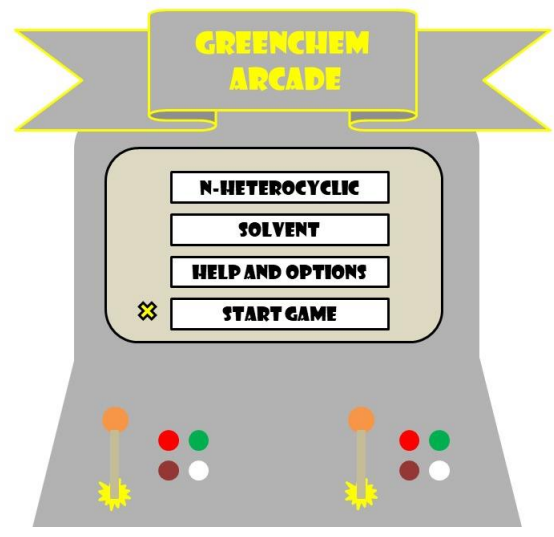

Figure 1. Options for greener synthesis of Nitrogen-Containing Heterocycles. 


\section{Background and Methodology}

After some time dedicated to the search for Green Reactions Leading to the Formation of $\mathrm{N}-\mathrm{Heterocycles,} \mathrm{the} \mathrm{excellent} \mathrm{review} \mathrm{entitled} \mathrm{"More} \mathrm{Sustainable} \mathrm{Approaches} \mathrm{for} \mathrm{the} \mathrm{Synthesis} \mathrm{of}$ N-Based Heterocycles", published by Candeias et al., in 2009 [1] was identified. More recently, other teams also presented well-documented work on green chemistry [2-5] and about the synthesis of heterocyclic compounds [6-16]. The instant review discusses the use of green reactions leading to the formation of nitrogen heterocycles by means of safe solvents, namely water, PEG and various bio-based systems, since 2000. Methyl-THF, which is one of the bio-sourced green solvents widely used today to replace THF, will not be discussed in this review because we did not find any work reporting its use for the synthesis of nitrogen containing heterocycles. Similarly, we will not discuss the use of ionic liquids here since many reviews were already devoted to them. Herein, each of the synthetic strategies and examples are briefly described. We trust this review will be helpful to a broad community of scientists working in medicinal chemistry.

\section{Sustainable Chemistry}

Greener routes are required in the synthesis of N-heterocycles, due to the remarkable importance of these compounds in medicinal chemistry $[17,18]$. Solvents play an important role in the chemical industry and their effectiveness in acting along with reagents and products within chemical processes is a crucial factor. The choice of a solvent will influence the chemical reactivity, selectivity, and yield of the synthesis process. One way to try to minimize safety, toxicity, and emission problems is to find or develop new solvents to replace those commonly used $[19,20]$. In recent years, valid proposals for green solvents have been reported such as water [21-23], and polyethylene glycol for its low price and its low acute toxicity [24-26]. More recently, research teams have demonstrated that the use of bio-based solvents is also a relevant choice [27-30]. All these results in the quest for safer solvents are the best evidence that the concepts of green chemistry have made remarkable progress.

\subsection{Water as Solvent}

The use of water as solvent in reactions is a positive choice from the environmental and economic point of view as it is an inexpensive, nonflammable and widely available resource [31-34]. A report of water used as solvent for the synthesis of heterocycles was published in 1931 for the cycloaddition reaction of furan and maleic anhydride by Diels and Alder [35]. Later, an important example was disclosed by Breslow [36,37], who demonstrated that hydrophobic effects could strongly enhance the rate of several organic reactions. Water has many advantages as reaction solvent for organic synthesis, but the poor solubility of many organic compounds in water limits its use under standard conditions. However, when applied at high temperatures and pressures, it undergoes changes in its properties and can become a good solvent for organic synthesis [16].

\subsection{PEG as Solvent}

In recent years, polyethylene glycols (PEGs) have attracted special attention as green solvents in various chemical transformations [38]. These low-cost compounds are available in a wide range of molecular weights [39]. PEG 400 is presented as a viscous liquid soluble in water and many organic solvents. It has the advantage of being biodegradable, non-toxic, odorless, neutral, non-volatile, and non-irritating, which has allowed its use in a variety of drugs and medications [40-42].

\subsection{Bio-Based Solvents}

Recently, in response to increased concerns about sustainability, emphasis has been placed on biologically based solvents and the need to find alternative solutions to conventional organic solvents. At the moment, the commercial availability supply of this type of solvents is limited because there are some initial barriers, such as their cost of production. Consequently, their market price of bio-based 
solvents is not competitive [43]. We believe that in the near future, and with the progressive increase in the investment of research teams in the study of alternative solvents, these obstacles will be overcome. In this review, we describe biologically based solvents that have been reported as valid alternatives in the synthesis of N-heterocycles, which are; Meglumine, Gluconic acid, Ethyl lactate and Lactic acid. Bio-based solvents or bio-sourced solvents are understood as mean solvents which come from renewable sources, such as for example, vegetable sources which may be agricultural crops rich in carbohydrates, such as corn, wheat, beets, forestry, or aquatic products. Additionally, our last study is described in the present document. This study established for the first time the use of eucalyptol as the new solvent for organic transformations [44].

\section{Five-Membered Aromatic Nitrogen Heterocycles}

\subsection{Formation of the Pyrrole ring}

\subsubsection{Reactions in Water}

In 2013, Reddy et al., developed an effective method to generate 6-substituted-6,6adihydroisoindolo[2,1-a]quinazoline-5,11-diones by the reaction of isatoic anhydride, amine and 2 -formylbenzoic acid 1,2 and 3; in this case, the authors showed that since the multicomponent reaction is less efficient in the absence of $\beta-C D$ (beta-cyclodextrin), the catalyst appears to play an important role in increasing the efficiency of the reaction especially by activating the anhydride carbonyl group of 1 in addition to increasing the water solubility of all the reactants. A subsequent nucleophilic attack by the amine 2 on the activated carbonyl carbon was also facilitated by $\beta-C D$ leading to the generation of the 2-amino- $\mathrm{N}$-arylbenzamide intermediate. This was then reacted with 2-formylbenzoic acid; intramolecular concurrent cyclization involving the carboxylic acid, and the amide group gave the desired product (Scheme 1) [45].<smiles>O=c1[nH]c2cc(I)ccc2c(=O)o1</smiles>

$\mathbf{X}=\mathrm{H}$ or $\mathrm{Cl}$

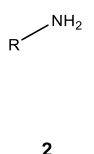

$\mathbf{R}=\mathrm{Me}, \mathrm{Ph}$ or $\operatorname{Het}(\mathrm{Ar})$<smiles>O=Cc1ccccc1C=O</smiles>
$\beta-C D(w / w 10 \%)$<smiles>NC12C(=O)c3ccc(I)cc3N1C(=O)c1ccccc12</smiles>

4, $60-95 \%$

Scheme 1. Reddy et al. (2013).

Suresh et al., obtained polysubstituted pyrroles in good yields from $\alpha$-azido chalcones and 1,3-dicarbonyl compounds in water. Their study showed that $\mathrm{InCl}_{3}$ was an efficient catalyst for this regioselective transformation (Scheme 2) [46].

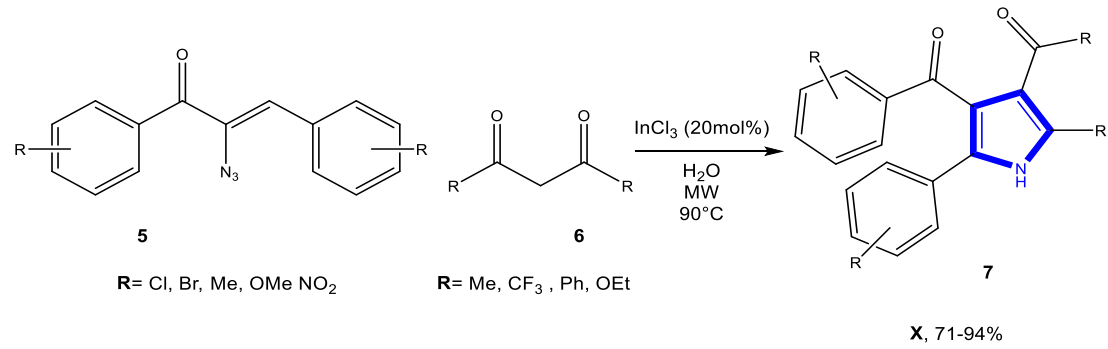

Scheme 2. Suresh et al. (2013). 
The group of Karamthulla reported a direct method for the synthesis of new spiro[indoline-3, 7,9-pyrrolo[1-c]imidazole]-6,9-carbonitrile derivatives 11 via a three-components reaction. The reaction proceeded in good yields using isatin, malononitrile, and hydantoin or thiohydantoin in the presence of $\mathrm{Et}_{3} \mathrm{~N}$ as base (Scheme 3) [47].

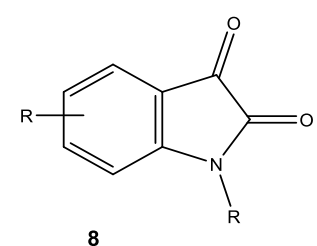

$\mathbf{R}=\mathrm{Cl}, \mathrm{Br}, \mathrm{F}, \mathrm{I}, \mathrm{OMe}$

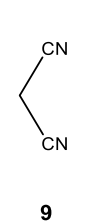

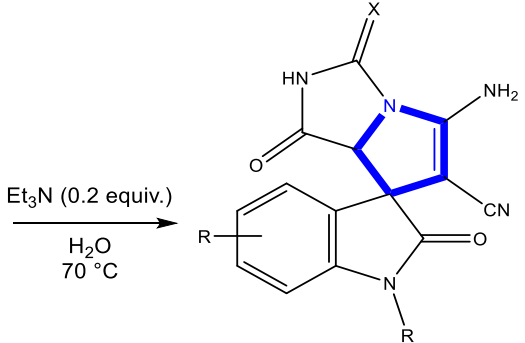

$11,60-90 \%$

Scheme 3. Karamthulla et al. (2013).

Keivanloo et al., synthesized pyrrolo[2- $b$ ]pyrazines by treating 5-(alkyl-arylamino)6-chloropyrazine-2,3-dicarbonitriles 12 with phenylacetylene. This coupling reaction/cyclization is a variant of the Larock indole synthesis and was performed in water using $\mathrm{Pd}\left(\mathrm{Ph}_{3} \mathrm{P}\right)_{2} \mathrm{Cl}_{2}$ and $\mathrm{CuI}$ as catalytic system, sodium lauryl sulfate and $\mathrm{K}_{2} \mathrm{CO}_{3}$ at $70{ }^{\circ} \mathrm{C}$ for $24 \mathrm{~h}$ (Scheme 4) [48].<smiles>Cc1nc(NP)c(Cl)nc1C#N</smiles>

$\mathbf{R}=$ Aryl, $\operatorname{Het}(\mathrm{Ar})$

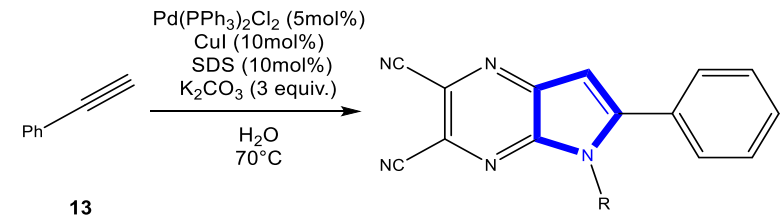

$14,68-96 \%$

Scheme 4. Keivanloo et al. (2012).

Gogoi et al., described a convenient and fast procedure for the synthesis of cycl[3.2.2]azines through a three-component reaction of 2-picoline, $\alpha$-bromoacetophenone and alkyne in aqueous medium under microwave irradiation (Scheme 5) [49].<smiles>[R]c1ccnc(C)c1</smiles>

15 $\mathbf{R}=\mathrm{H}, \mathrm{Me}$

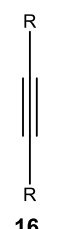

$\mathbf{R}=\mathrm{CO}_{2} \mathrm{Me}, \mathrm{CO}_{2} \mathrm{Et}$

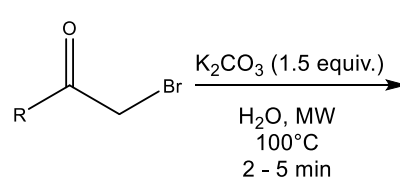

17

$\mathbf{R}=\mathrm{Ph}, \operatorname{Het}(\mathrm{Ar})$

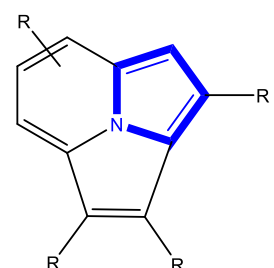

$18,20-92 \%$

Scheme 5. Gogoi et al. (2011).

Yu et al., studied a procedure for the alkynylation coupling of aryl iodides with terminal alkynes catalyzed by a water-soluble copper complex (sulfonato- $\mathrm{Cu}$ (salen)). This reaction was stirred using 2-iodoaniline and aryl acetylene to obtain 2-arylindoles in excellent yields. As expected by the authors, aryl iodides with electron-withdrawing groups afforded much higher isolated yields than those with electron-donating groups (Scheme 6) [50]. 


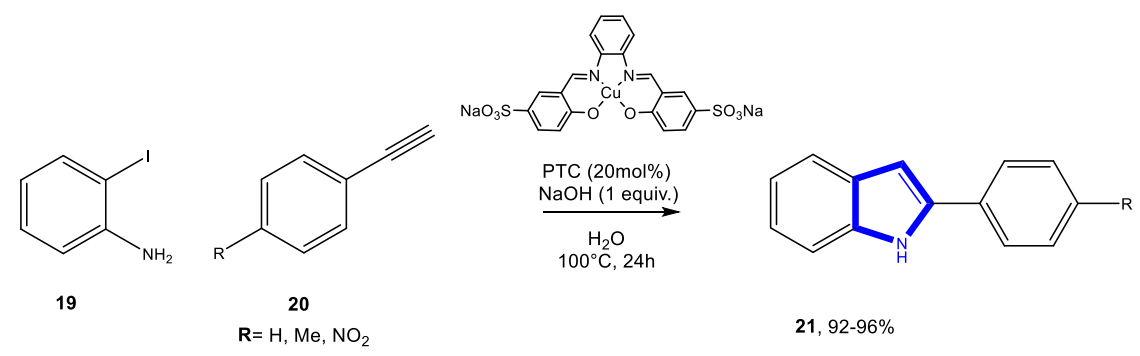

Scheme 6. Yu et al. (2010).

Das et al., developed an efficient approach for the synthesis of polysubstituted pyrrolidin-1, 2-diones. The construction of these compounds was achieved by a one-pot three component reaction of nitroarenes, formaldehyde, and dialkyl acetylenedicarboxylates using indium in dilute aqueous $\mathrm{HCl}$ at room temperature (Scheme 7) [51].

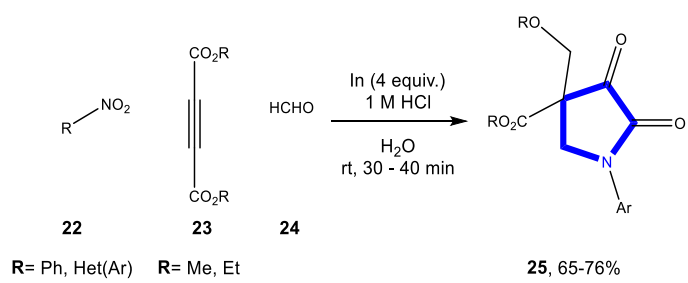

Scheme 7. Das et al. (2010).

Barnard et al., adopted greener $N$-heterocyclizations with water as solvent and no transition metal catalysts and showed good yields in a fraction of the time needed for the conventional synthesis of isoindolines (Scheme 8) [52].

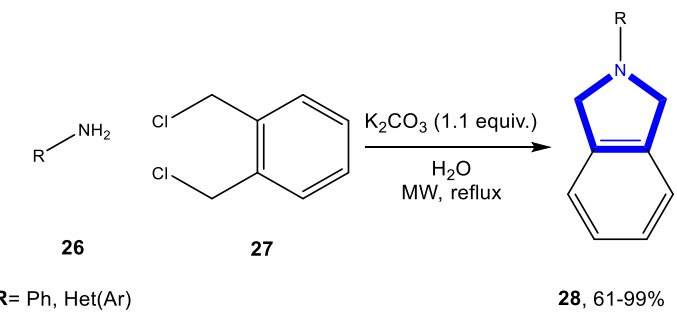

Scheme 8. Barnard et al. (2006).

The Demir group successfully employed a catalyzed amination-annulation strategy for the synthesis of 2-aminopyrrole-4-carboxylates. This work developed a $\mathrm{Zn}\left(\mathrm{ClO}_{4}\right)_{2}$ catalyzed protocol to generate pyrrole ring-formation in high yields via $\alpha$-cyanomethyl-ketoesters (Scheme 9) [53].

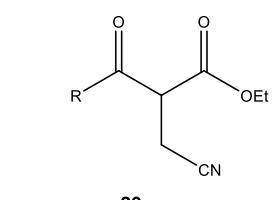

$\mathbf{R}=\mathrm{Me}, \mathrm{CH}\left(\mathrm{CH}_{3}\right)_{2}, \mathrm{Ph}, \operatorname{Het}(\mathrm{Ar})$

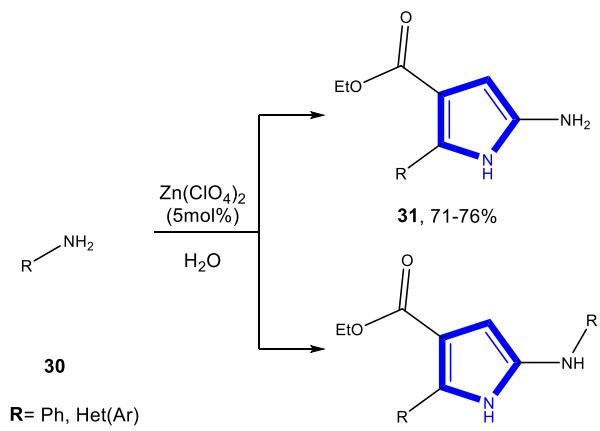

32, $70-83 \%$

Scheme 9. Demir et al. (2006). 


\subsubsection{Reactions in PEG}

The group of Yedukondalu performed the synthesis of substituted tetrahydrocarbazoles. By heating phenyl hydrazine hydrochlorides or 4-piperidone hydrochloride with substituted cyclohexanones or piperidone in PEG, the team was able to synthesize several derivatives, as shown in Scheme 10 [54].

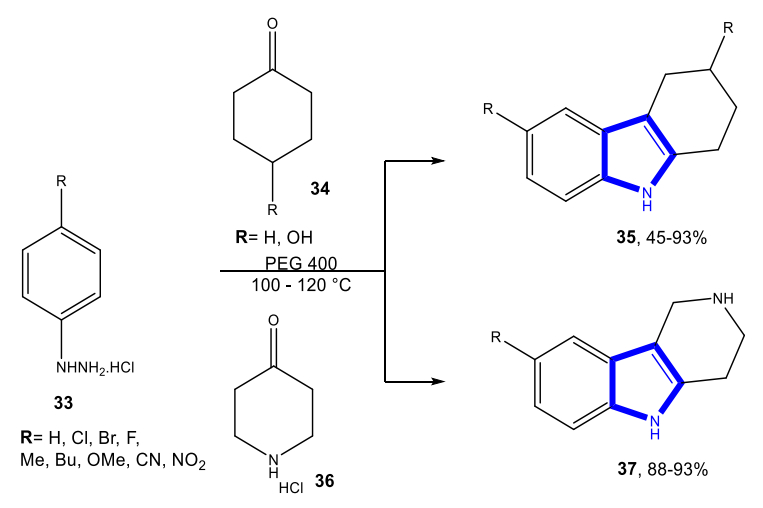

Scheme 10. Yedukondalu et al. (2014).

Mishra et al., employed a one-pot synthesis protocol for the preparation of aminoindolizine. The results were achieved using pyridine- or quinoline-2-carboxaldehydes with secondary amines and terminal alkynes via tandem $\mathrm{C}-\mathrm{H}$ activation, coupling, and cyclization reactions using copper chloride (Scheme 11) [55].<smiles>O=Cc1cc2ccccc2cn1</smiles><smiles>[R]NC</smiles>

morpholine piperidine piperazine

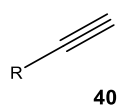

$\mathbf{R}=\mathrm{Ph}, \operatorname{Het}(\mathrm{Ar})$ $\mathrm{N}$-methylaniline

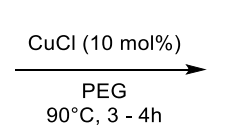

$90^{\circ} \mathrm{C}, 3-4 \mathrm{~h}$<smiles>[R]c1cc(N([R])[R])c2cc3ccccc3cn12</smiles>

41, $63-96 \%$

Scheme 11. Mishra et al. (2012).

\subsubsection{Reactions in Bio-Based Solvents}

Dandia et al., reported the first ever 1,3-dipolar cycloaddition synthetic protocol for the synthesis of spirooxindole derivatives using ethyl lactate as bio-based solvent. The reaction proceeded in high yield with the 1,3-dipolar cycloaddition reaction of substituted isatin and proline with napthaquinone (Scheme 12) [56].
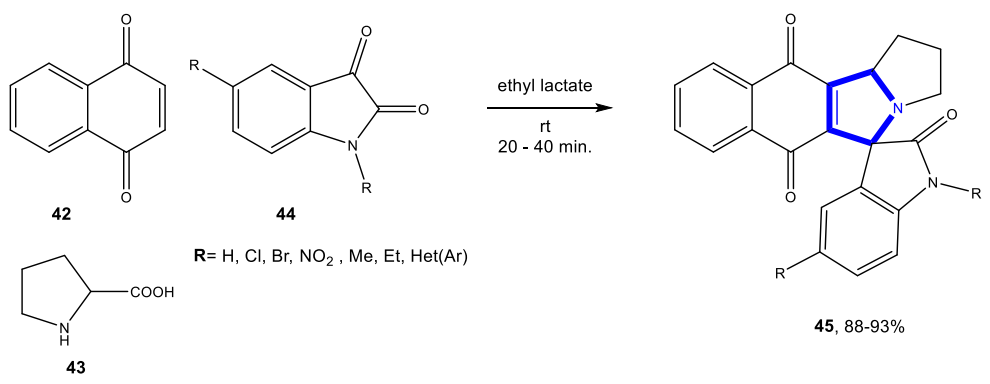

Scheme 12. Dandia et al. (2013). 
In 2015, Wang et al., reported an efficient novel and scalable process for the synthesis of pyrrole derivatives in lactic acid under ultrasonic irradiation. The synthesis, which gave excellent yields, consisting of several pyrrole derivatives, was achieved from the Knorr condensation reaction. The authors demonstrated that the condensation reaction in lactic acid under ultrasonication avoids the shortcomings of causticity, volatility, and recycling difficulties, when compared with traditional Knorr condensation using acetic acid as solvent (Scheme 13) [57].

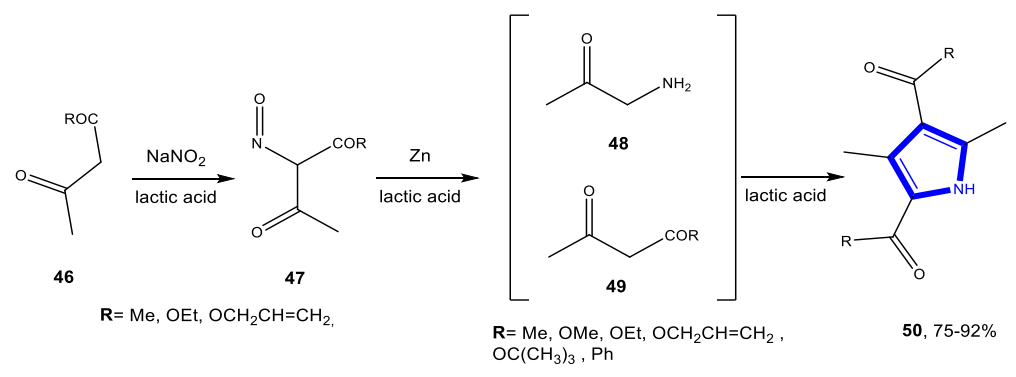

Scheme 13. Wang et al. (2015).

Yang et al., investigated the use of lactic acid in three-component condensation of benzaldehydes, anilines and diethyl acetylene dicarboxylate to obtain polysubstituted pyrrolidinones. This team showed that the application of this bio-based solvent resulted in several improvements; the products were isolated in good yields using a single step and in a shorter time (Scheme 14) [58].

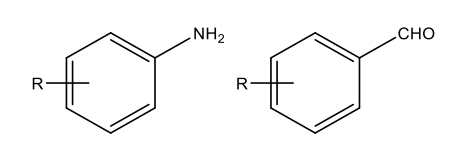

51

$\mathrm{R}=\mathrm{H}, \mathrm{Me}, \mathrm{OMe}, \mathrm{NO}_{2}$

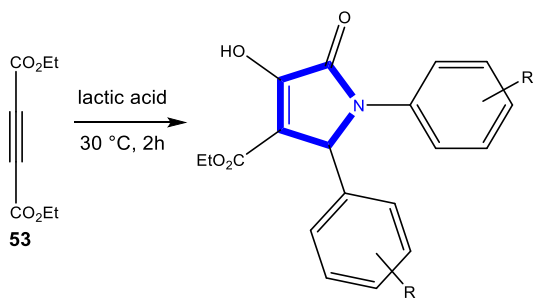

54, $52-83 \%$

Scheme 14. Yang et al. (2012).

Li et al., employed a four-component coupling of amines, aldehydes, 1,3-dicarbonyl compounds, and nitromethane to obtain pyrrole derivatives. Compounds were prepared using a gluconic acid aqueous solution as an efficient and reusable promoting medium. This methodology demonstrated excellent functional group tolerance, short reaction time, and high yield of products (Scheme 15) [59].

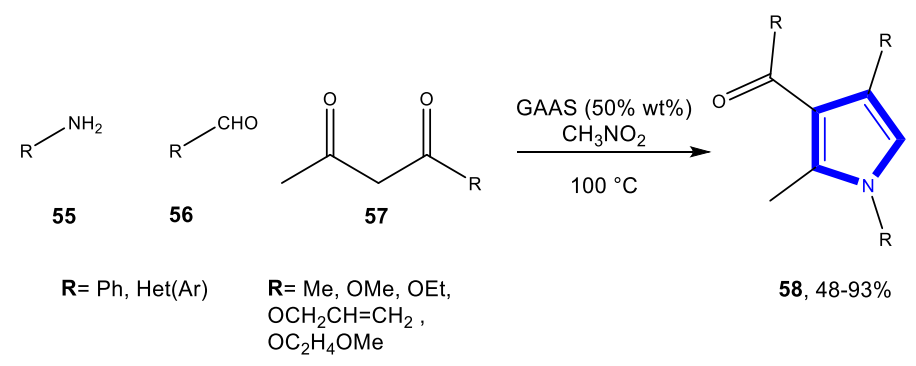

Scheme 15. Li et al. (2013).

\subsection{Formation of the Pyrazole Ring}

\subsubsection{Reactions in Water}

Recently, Muthusamy and Gangadurai published the synthesis of benzopyranopyrazoles through a 1,3-dipolar cycloaddition approach involving an in situ generated aryl diazomethane 
from propargylated salicyl aldehydes and their intramolecular [3+2]-cycloaddition reaction with a suitably placed terminal alkyne/alkene. Aryl diazomethanes were generated by base-mediated decomposition of the corresponding aryl sulfonyl hydrazones; in addition, hydrazones were readily accessed from the corresponding aldehydes (Scheme 16) [60].

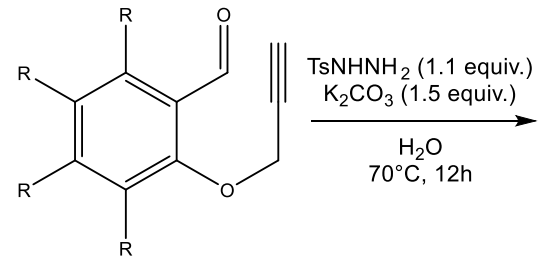

59<smiles>[R]c1c([R])c([R])c2c(c1[R])OCc1c[nH]nc1-2</smiles>

$60,77-96 \%$

$\mathbf{R}=\mathrm{H}, \mathrm{Cl}, \mathrm{Br}, \mathrm{I}, \mathrm{OMe}, \mathrm{OEt}$, $\mathrm{NO} 2, \mathrm{tBu}, \mathrm{CH}=\mathrm{CH}-\mathrm{CH}=\mathrm{CH}$

Scheme 16. Muthusamy and Gangadurai (2018).

The group of Eswararao achieved the rapid synthesis of $1 H$-pyrazolo[1- $b]$ phthalazine-5,10-diones using $\mathrm{InCl}_{3}$ catalyzed reaction of phthalic anhydride, hydrazine hydrate, benzaldehydes and malononitrile/ethyl cynoacetate at reflux in good yields (Scheme 17) [61].<smiles>O=C1OC(=O)c2ccccc21</smiles>

61<smiles>[R]CN</smiles>

$\mathbf{R}=\mathrm{CN}, \mathrm{CO}_{2} \mathrm{Et}$<smiles>C=O</smiles>

63

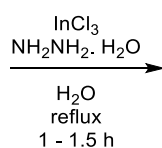

$1-1.5 \mathrm{~h}$<smiles>[R]C1=C(N)n2c(=O)c3ccccc3c(=O)n2C1[R]</smiles>

$64,82-85 \%$

Scheme 17. Eswararao et al. (2017).

Sagir et al., achieved a one-pot four-component reaction catalyzed by iodine in water. This reaction protocol involved the formation of pyrazolo-pyrido-pyrimidines and their spiro analogues from hydrazine, ethylacetoacetate, 6-amino-1-methyluracil, and isatin or aldehyde and iodine as catalyst (Scheme 18) [62].
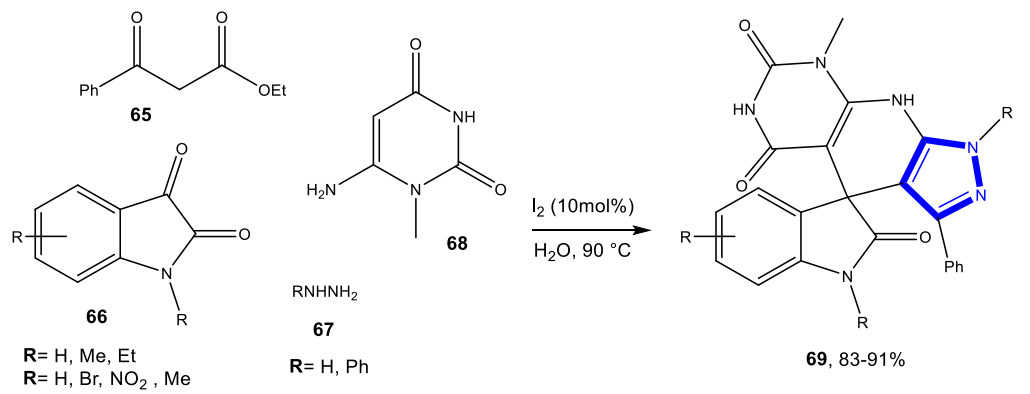

Scheme 18. Sagir et al. (2017).

Maleki et al., worked on the preparation of pyrano[2,3-c]pyrazoles. These reactions were conducted with a one-pot, four-component synthesis process catalyzed by nano-structured diphosphate in water. The library of pyrano[2,3-c]pyrazoles was successfully synthesized with this method, which proved to be effective for aromatic aldehydes bearing either electron-donating or electron-withdrawing substituents as well as for the heterocyclic aldehyde (Scheme 19) [63]. 


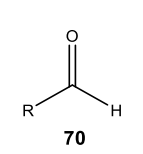

$\mathbf{R}=\mathrm{Ph}, \operatorname{Het}(\mathrm{Ar})$<smiles>N#CCC#N</smiles><smiles>CCOC(=O)CC(C)=O</smiles>

71<smiles>CC1=C(C)C(C)C(C)=C(C)c2c(C)n[nH]c2O1</smiles>

72, $85-92 \%$

Scheme 19. Maleki et al. (2016).

Bakherad et al., demonstrated a reaction protocol using magnetized water as solvent. The water was prepared using a static magnetic system of $6000 \mathrm{G}$ field strength with a flow rate of $500 \mathrm{~mL} \mathrm{~s}-1$ at different magnetization times. The generation of pyrano[2,3-c]pyrazoles and pyrano[ $\left[4^{\prime}, 3^{\prime}: 5,6\right]$ pyrazolo[2,3- $\left.d\right]$ pyrimidines proceeded through a one-pot four-component catalyst-free protocol (Scheme 20) [64].

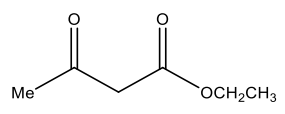

73<smiles>[R]C=O</smiles>

74

$\mathrm{R}=\mathrm{Me}, \mathrm{CH}\left(\mathrm{CH}_{3}\right)_{2}, \mathrm{CH}_{2} \mathrm{CH}\left(\mathrm{CH}_{3}\right)_{2}$ $\mathrm{Ph}, \operatorname{Het}(\mathrm{Ar})$
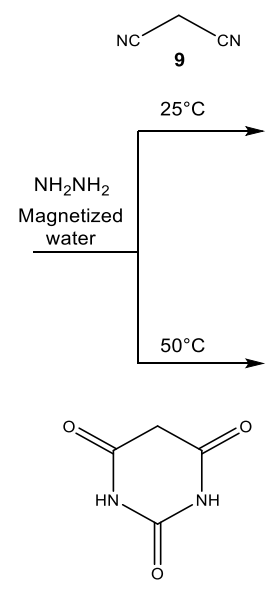

75<smiles>CC1=C(C)C(C)C2C(C)NNC2O1</smiles>

76, $86-98 \%$<smiles>[R]C1c2c(C)n[nH]c2Oc2[nH]c(=O)[nH]c(=O)c21</smiles>

$77,85-98 \%$

Scheme 20. Bakherad et al. (2017).

Marković and Joksović reported a methodology for the construction of the ethyl 5-aryl- $1 \mathrm{H}$ pyrazole-3-carboxylate ring system from 4-aryl(hetaryl,alkyl)-2,4-diketoesters and 1,3-diketones with semicarbazide hydrochloride. This approach did not require toxic hydrazine and product purification, eliminating the use of toxic liquid chemicals (Scheme 21) [65].

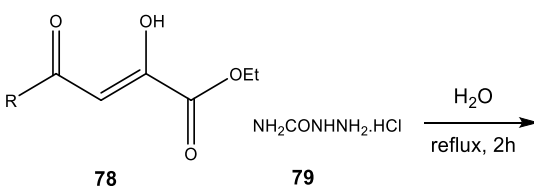

$\mathbf{R}=\mathrm{Ph}, \operatorname{Het}(\mathrm{Ar})$

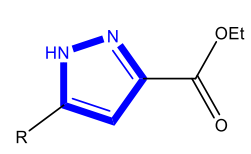

$80,85-98 \%$

Scheme 21. Marković and Joksović (2015).

Dam et al., achieved a super-paramagnetic nanoparticle supported L-proline catalyst (nano-FDP) for the construction of the pyrazole ring. The strategy adopted was under ultrasonic irradiation. The various derivatives were prepared in excellent yields at room temperature (Scheme 22) [66]. 


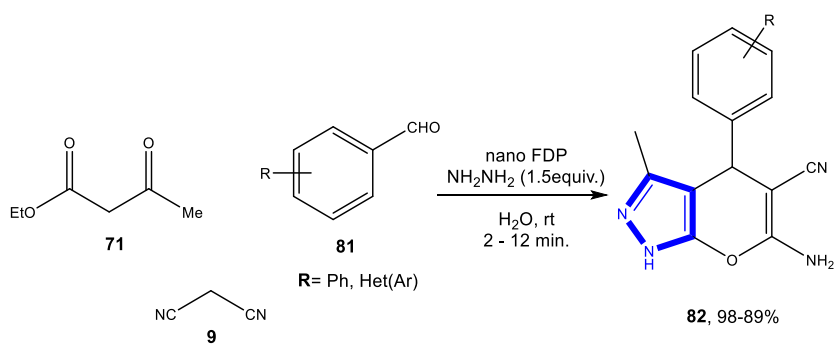

Scheme 22. Dam et al. (2015).

The team of Srivastava reported an iodine-catalyzed sequential process to access pyrazole series from phenyl hydrazine, malanonitrile, and a diverse range of aldehydes. The strategy was performed using water as solvent and no purification by column chromatography was required (Scheme 23) [67].

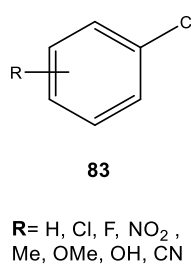

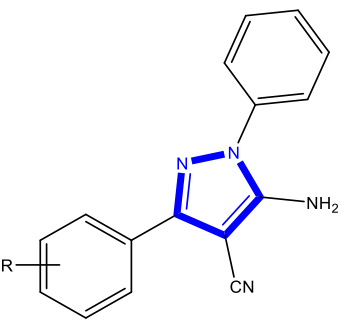

84, $86-94 \%$

Scheme 23. Srivastava et al. (2014).

Khoraamabadizad et al., designed the synthesis of pyrazolo[1,2-a]pyridazine under ultrasonication in water using triethanolamine as catalyst. This approach involved a one-pot reaction of maleic hydrazide, with aromatic aldehydes and malononitrile. The catalyst applied participated both in the Knoevenagel condensation of malononitrile with substituted benzaldehydes and in the reaction of the condensation product with maleic hydrazide (Scheme 24) [68].<smiles>O=c1cc[nH][nH]c1=O</smiles><smiles>O=Cc1cccc(Br)c1</smiles>

86 $\mathrm{R}=\mathrm{H}, \mathrm{Cl}, \mathrm{Br}, \mathrm{NO}_{2}$,<smiles>CCOC#N</smiles>

9<smiles>N#CC1=C(N)n2c(=O)ccc(=O)n2C1c1ccccc1</smiles>

$87,40-95 \%$

Scheme 24. Khoraamabadizad et al. (2014).

In 2014, Heravi et al., published the synthetic protocol to obtain pyrazolopyranopyrimidines. They reported access to the derivatives via a one-pot, four-component reaction from ethyl acetoacetate, hydrazine hydrate, benzaldehydes, and barbituric acid catalyzed by DABCO in water (Scheme 25) [69]. 


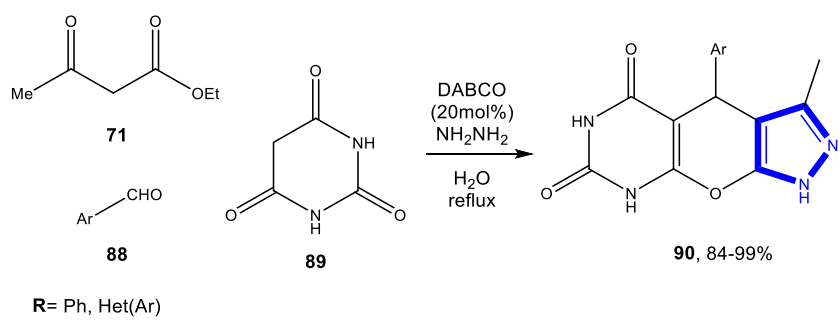

Scheme 25. Heravi et al. (2014).

Sachdeva and Rekha studied a catalytic protocol to obtain pyranopyrazoles using $\mathrm{ZnO}$ nanoparticles. This procedure comprised the reaction of hydrazine hydrate, methylacetoacetate, substituted aromatic aldehydes, and ethylcyano acetate in the presence of a catalytic amount of $\mathrm{ZnO}$ nanoparticle as catalyst under stirring at room temperature in the presence of water (Scheme 26) [70].

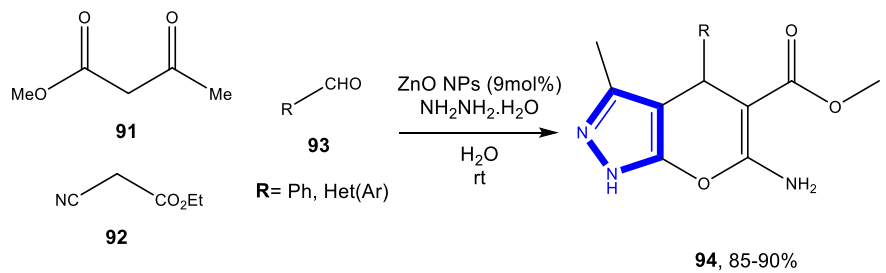

Scheme 26. Sachdeva and Rekha (2013).

$\mathrm{Wu}$ et al., reported a synthetic approach for the synthesis of pyranopyrazole using cetyltrimethylammonium chloride $(\mathrm{CTACl})$ as catalyst. The catalyst applied showed high activity, high stability and the desired products were obtained in good to excellent yields from ethyl acetoacetate, hydrazine hydrate/phenylhydrazine, aromatic aldehydes, and malononitrile, using water as solvent at $90{ }^{\circ} \mathrm{C}$ (Scheme 27) [71].
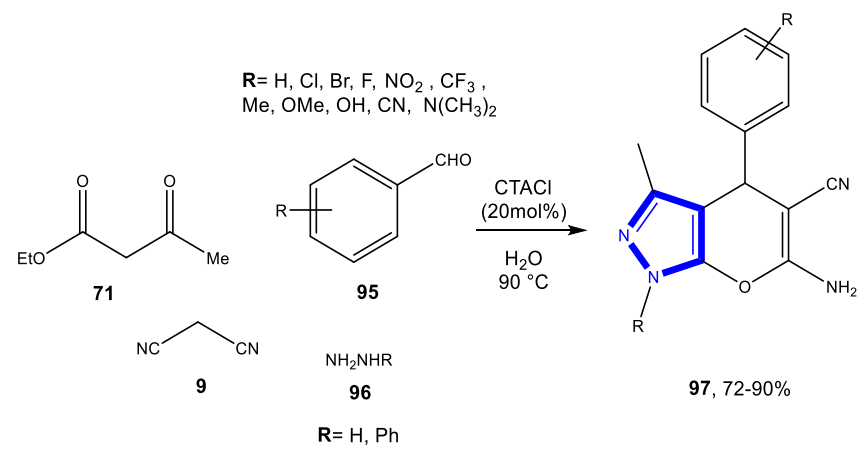

Scheme 27. Wu et al. (2013).

Zonouz et al., presented a catalyst-free methodology for the synthesis of methyl 6-amino-5-cyano4-aryl-2,4-dihydropyrano[2,3-c]pyrazole-3-carboxylates in water using a one-pot, four-component reaction. The key steps in the synthesis were the formation of benzylidine malononitrile via Knoevenagel condensation between aldehyde and malononitrile; then the formation of pyrazolone by reaction of hydrazine hydrate with dimethyl acetylenedicarboxylate; and lastly, the Michael addition of the formed intermediates, followed by cyclization and tautomerization (Scheme 28) [72]. 


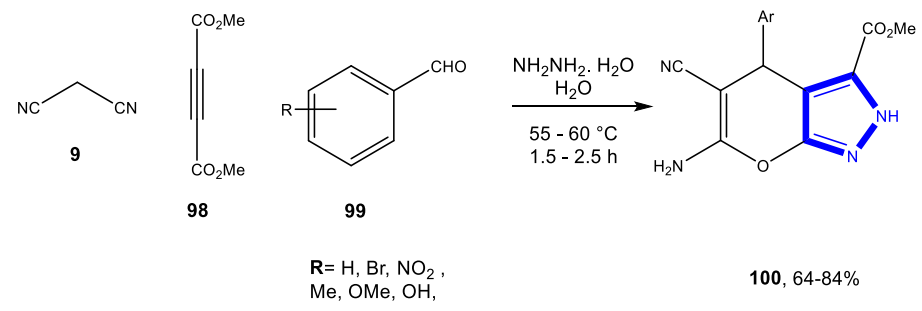

Scheme 28. Zonouz et al. (2012).

Madje et al., accomplished the synthesis of $2 H$-indazolo[2,1-b]phthalazinetrione derivatives in good yields by three-component condensation reaction of phthalhydrazide, dimedone, and aromatic aldehydes using alum $\left[\mathrm{KAl}\left(\mathrm{SO}_{4}\right)_{2} \cdot 12 \mathrm{H}_{2} \mathrm{O}\right]$ as catalyst in water (Scheme 29) [73].

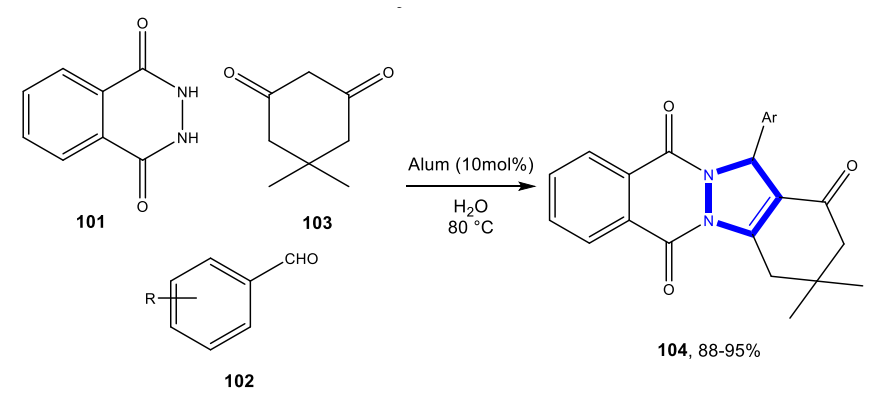

$\mathbf{R}=\mathrm{H}, \mathrm{Cl}, \mathrm{Br}, \mathrm{F}, \mathrm{NO}_{2}$,

Scheme 29. Madje et al. (2012).

Savant et al., obtained trisubstituted pyrazoles via a sequential condensation of various R-acylketene dithioacetals with hydrazine hydrate, followed by the oxidation of sulfide to sulfone using water as solvent. The derivatives were successfully achieved using water as solvent and with a short reaction time. (Scheme 30) [74].

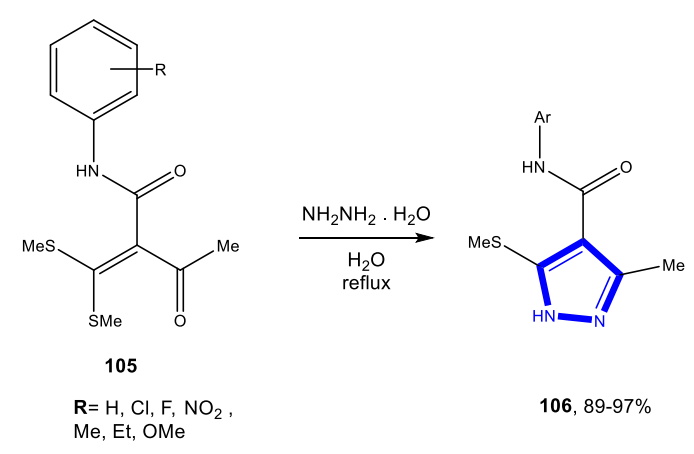

Scheme 30. Savant et al. (2010).

The team of Mali performed a condensation of 2-chloro-3-formyl quinolines and hydrazine hydrate/phenyl hydrazine for the synthesis of pyrazolo[3,4-b]quinolines. This protocol was carried out in aqueous medium and using thermal/microwave energy resources (Scheme 31) [75]. 
<smiles>O=Cc1cc2cc(Br)cc(P)c2nc1Cl</smiles>

107

$\mathrm{R}=\mathrm{H}, \mathrm{Me}, \mathrm{OMe}$ $R=H, E t$

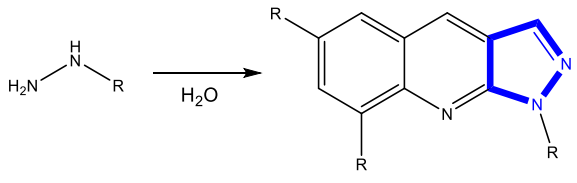

96

$\mathrm{R}=\mathrm{H}, \mathrm{Ph}$

$108,87-93 \%$

Scheme 31. Mali et al. (2010).

\subsubsection{Reactions in PEG}

Karnakar et al., synthesized spiro pyranopyrazole derivatives in good to excellent yields using PEG as solvent. This one-pot four-component reaction promoted by a Knoevenagel condensation occurred between isatin and malononitrile, which reacted with the pyrazolone intermediate formed by the condensation of dialkyl acetylene dicarboxylate and hydrazine hydrate. The sequential strategy was finalized with the Michael addition, followed by enolization and ring closure to provide the desired product (Scheme 32) [76].

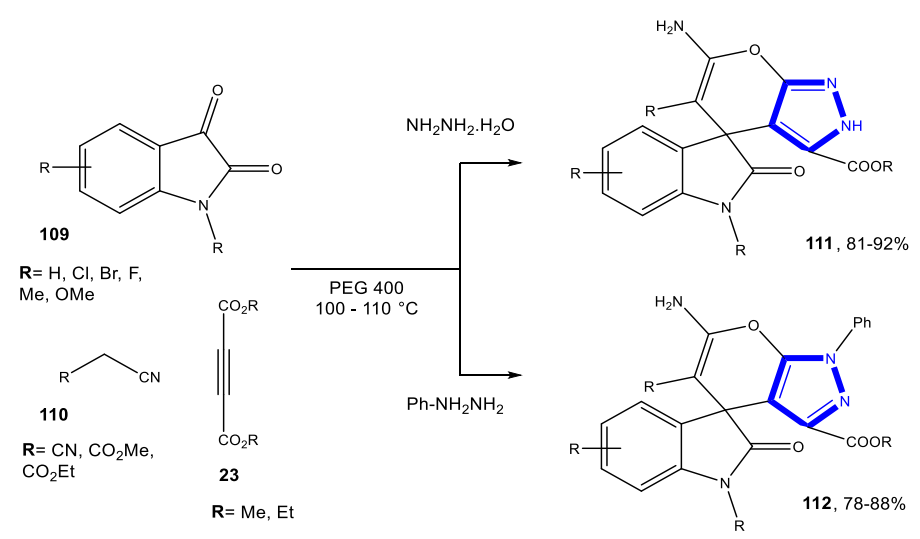

Scheme 32. Karnakar et al. (2015).

The group of Lavania performed the synthesis of 2-pyrazolines by their condensation with hydrazine hydrate in PEG. The strategy was applied to the preparation of pyrazolines in good to excellent yields (Scheme 33) [77].<smiles>O=C(/C=C/P)c1c2ccccc2cc2ccccc12</smiles>

113
PEG 400

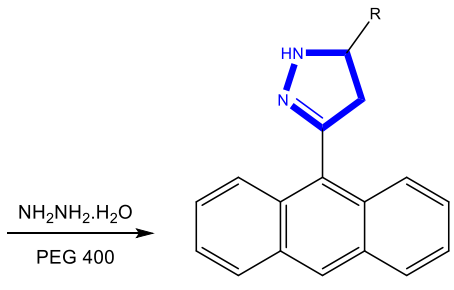

$114,81-84 \%$

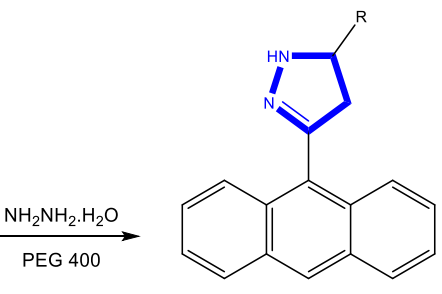

Scheme 33. Lavania et al. (2013).

Kidwai et al., prepared 1H-indazolo[1,2-b]-phthalazine-1,6,11-triones using ceric ammonium nitrate (CAN) as catalyst. The library was obtained from a one-pot reaction of phthalhydrazide, cyclic- $\beta$-diketone and an aldehyde in polyethylene glycol (Scheme 34) [78]. 


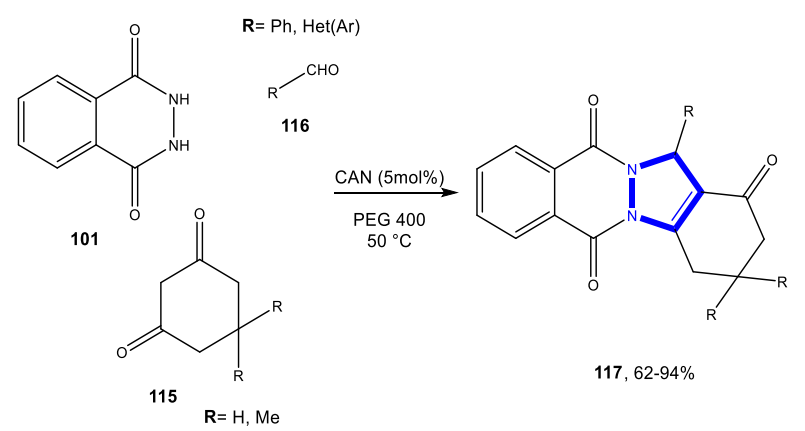

Scheme 34. Kidwai et al. (2012).

\subsubsection{Reactions in Bio-Based Solvents}

Bhat et al., achieved the synthesis of 2-pyrazoline derivatives by applying a reaction approach catalyzed by cerium chloride heptahydrate $\left(\mathrm{CeCl}_{3} \cdot 7 \mathrm{H}_{2} \mathrm{O}\right)$ and ethyl lactate as solvent. The team was able to successfully prepare 1,3,5-triaryl-2-pyrazoline from the condensation reaction between chalcones and phenyl hydrazine (Scheme 35) [79].

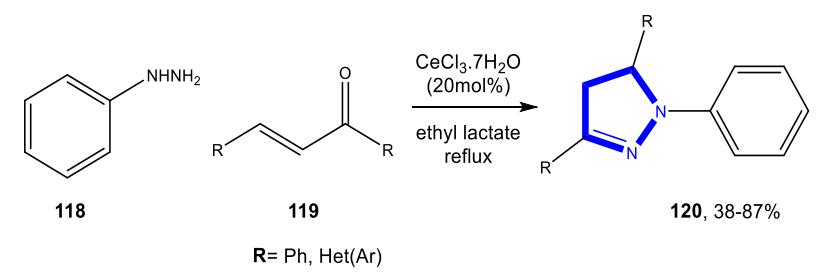

Scheme 35. Bhat et al. (2017).

\subsection{Formation of the Imidazole Ring}

\subsubsection{Reactions in Water}

Dheer et al., studied the regioselective synthesis of 2-iodo-imidazo[1,2-a]pyridines and 2-iodobenzoimidazo[2,1- $b$ ]thiazoles catalyzed by $\mathrm{CuI} / \beta-\mathrm{CD}$. This methodology showed efficient synthesis of imidazo derivatives in good yields using water as solvent (Scheme 36) [80].

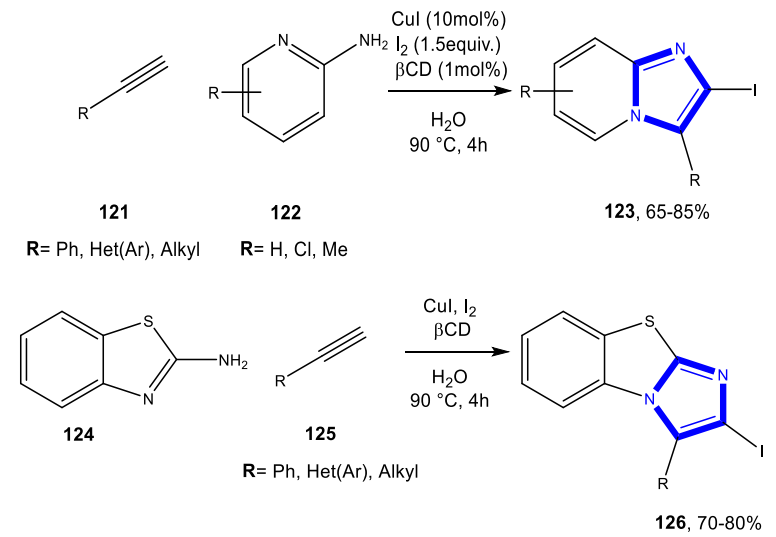

Scheme 36. Dheer et al. (2017).

Bhagat and Telvekar described the synthesis of imidazo[1-a]pyridines, imidazo[1,2-a]pyrimidines, and imidazo[2,1-b]thiazole using NBS in aqueous medium. The series were accomplished with 2-aminopyridines, or 2-aminopyrimidines, or 2-aminothiazole, with $\beta$-keto esters, or 1,3-diones, or aryl ketones (Scheme 37) [81]. 


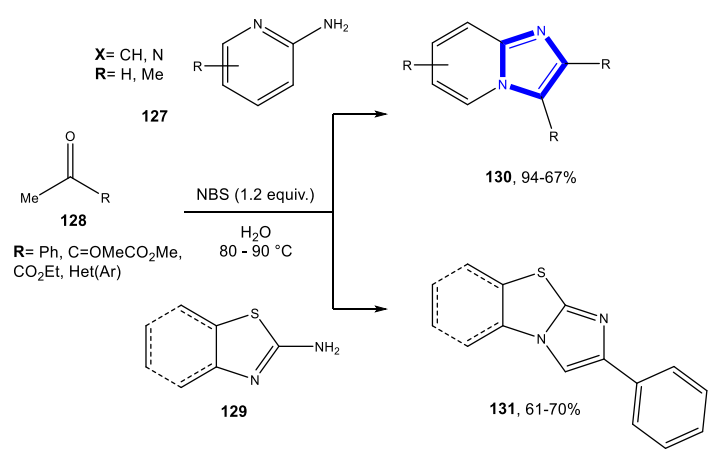

Scheme 37. Bhagat and Telvekar (2017).

Wagare et al., developed an efficient microwave-assisted one-pot process for the synthesis of azaindolizines in PEG 400 and water. The construction of these compounds was achieved from 2-aminopyridines and in-situ generated phenacyl bromides. This protocol avoided the use of lachrymatory $\alpha$-haloketones as well as volatile toxic organic solvents and reduced the reaction time to obtain excellent yield (Scheme 38) [82].

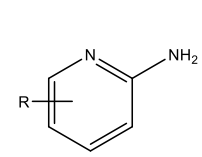

132<smiles>CCC(=O)c1ccccc1</smiles>

133

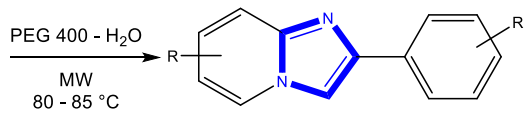

$134,84-89 \%$

$\mathbf{R}=\mathrm{H}, \mathrm{Cl}, \mathrm{Br}, \mathrm{Me}$

$\mathbf{R}=\mathrm{H}, \mathrm{Cl}, \mathrm{Br}, \mathrm{Me}, \mathrm{OMe}$

Scheme 38. Wagare et al. (2016).

Nikoofar et al., reported a catalytic system to be used for the synthesis of 2,4,5-triaryl- $1 \mathrm{H}$-imidazoles in water under reflux conditions. The use of $\mathrm{ZnO}$ nanorods ( $\mathrm{ZnO} \mathrm{NRs}$ ) as catalyst was developed. The authors showed that they were mild, benign, and effective catalysts for the preparation of tri-substituted imidazoles in high yield from a one-pot, three-component protocol (Scheme 39) [83].

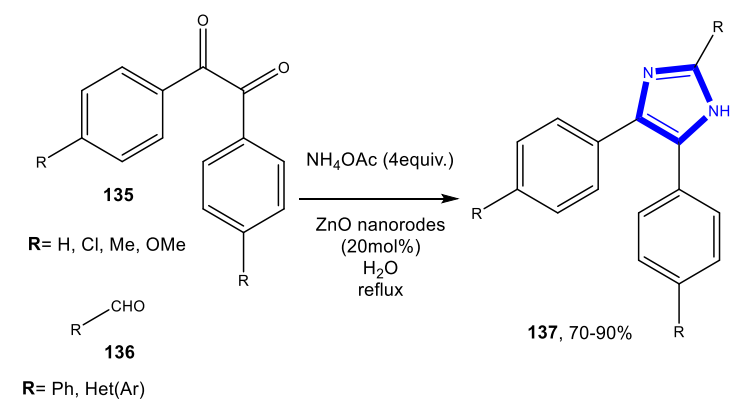

Scheme 39. Nikoofar et al. (2015).

Chanu et al., employed a one-pot, three-component reaction approach with $\alpha$-oxoketenedithioacetals, diamines and DMAD to prepare tetrahydroimidazo[1,2-a]pyridines. The various derivatives were achieved under aqueous reaction conditions. The reaction involved SNAr intramolecular cyclization (Scheme 40) [84]. 


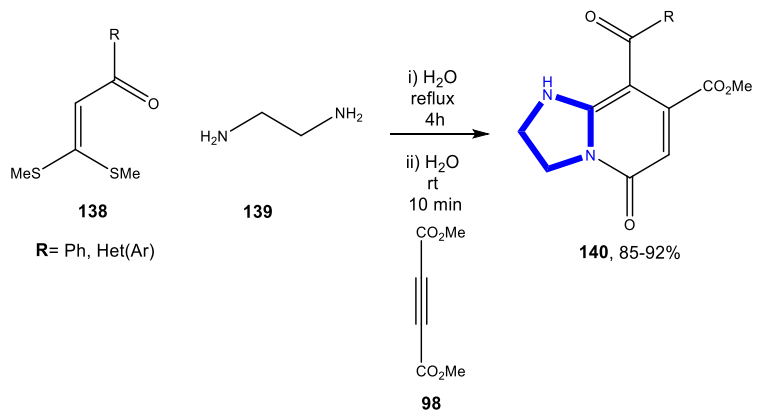

Scheme 40. Chanu et al. (2014).

Siddiqui et al., carried out the preparation of imidazo[1,2-a]pyridine through the three-component conversion of 2-aminopyridine, aldehyde, and alkyne, in imidazo[1,2-a]pyridine by employing iodine as catalyst under aqueous conditions. The synthesis involved the in-situ formation of imines followed by the addition of alkyne to give the desired products in excellent yield (Scheme 41) [85].

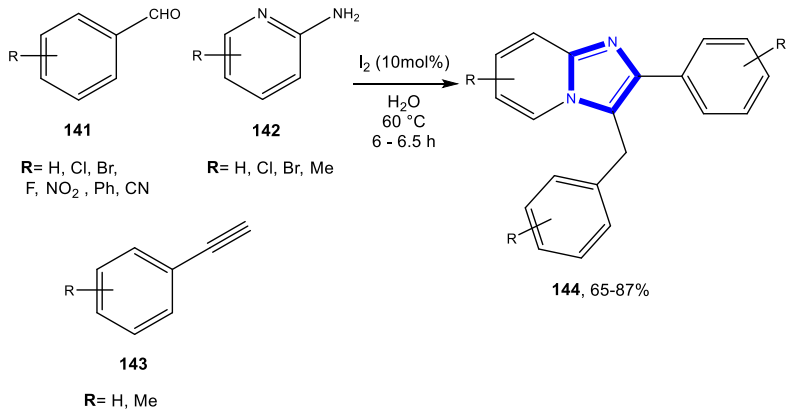

Scheme 41. Siddiqui et al. (2014).

Peshkov et al., prepared imidazo[1,2-a]azine derivatives via the three-component reaction of 2-aminoazine, 2-oxoaldehyde, and cyclic 1,3-dicarbonyl. The synthetic route studied was successfully achieved via a Biginelli-type multicomponent process in water (Scheme 42) [86].

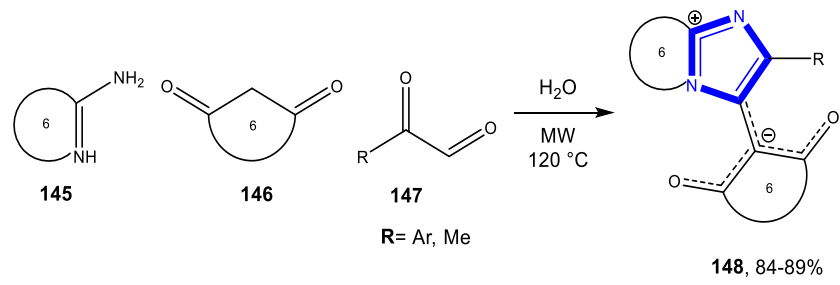

Scheme 42. Peshkov et al. (2014).

Bangade et al., succeeded in preparing 3-aryl imidazo[1,2-a]pyridines, 5-aryl imidazo[2,1- $b$ ] thiazoles and 3-aryl benzo[d]imidazo[2,1-b][1,3]thiazoles from the reaction of phenacyl bromide with heterocyclic amine in presence of DABCO in aqueous medium (Scheme 43) [87]. 


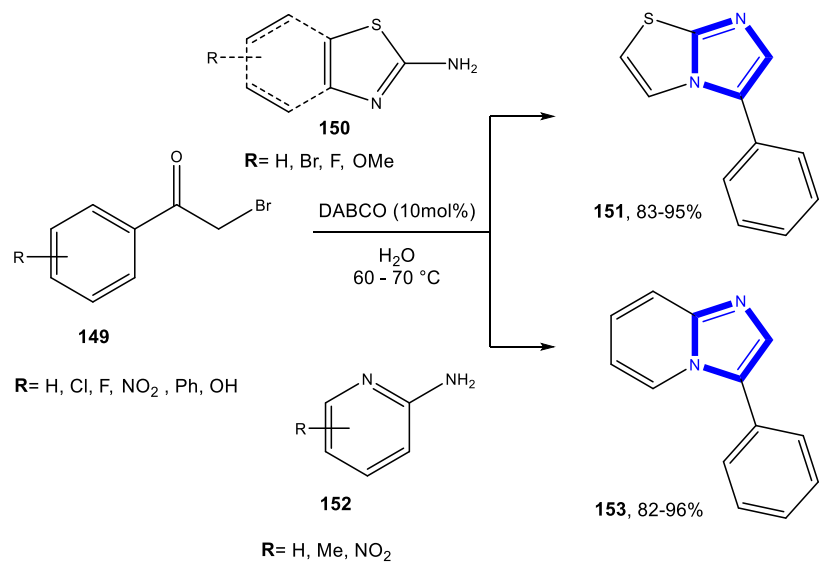

Scheme 43. Bangade et al. (2013).

Rustagi et al., obtained various fused benzimidazo[2,1-a]isoquinolines performing a one-pot approach to the regioselective tandem from $o$-alkynylaldehydes and arylamines with tethered nucleophiles using AgI as catalyst in water. This protocol was shown to have a broad substrate scope, good functional group tolerance, and high efficiency (Scheme 44) [88].

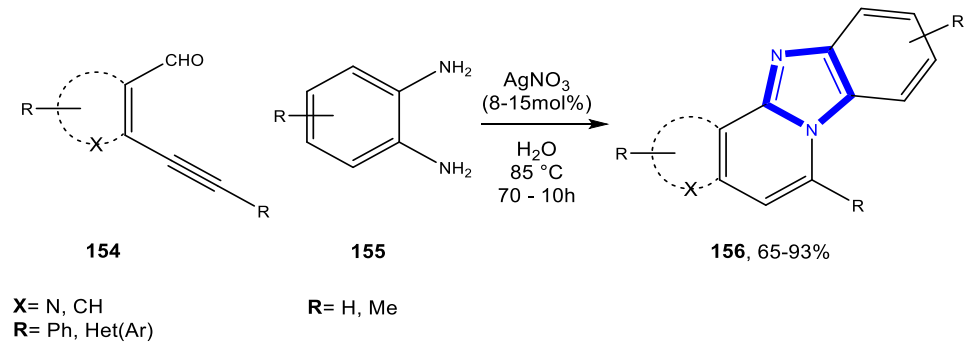

Scheme 44. Rustagi et al. (2012).

Kumar et al., accomplished the synthesis of diarylimidazoles using water as solvent by reacting $\alpha$-tosyloxy ketones with a variety of amidines. This methodology demonstrated several advantages such as good yields, no metal reagents, avoidance of toxic, volatile, and corrosive organic solvents (Scheme 45) [89].<smiles>[R]C(=O)C(C)O</smiles>

157 $\mathbf{R}=\mathrm{Ph}, \operatorname{Het}(\mathrm{Ar})$ $\mathbf{R}=\mathrm{Ph}, \mathrm{Het}(\mathrm{Ar})$
$\mathbf{R}=\mathrm{H}, \mathrm{COMe}$<smiles>N=C(N)N</smiles>

158

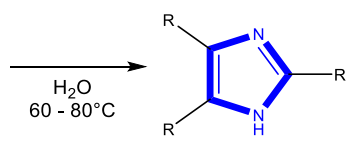

$159,50-93 \%$

Scheme 45. Kumar et al. (2011).

Rustagi et al., adopted a tandem reaction for the synthesis of substituted benzimidazoles. This protocol was conducted in aqueous media from o-alkynyl aldehydes and amines having an $\mathrm{N}$-tethered nucleophile using $\mathrm{Ag}(\mathrm{I})$ as the catalyst. The sequential strategy involved the formation of two new carbon-nitrogen bonds and one new carbon-carbon bond, thereby leading to the formation of two heterocyclic rings in a one-pot reaction giving fused polycyclic heterocycles (Scheme 46) [90]. 


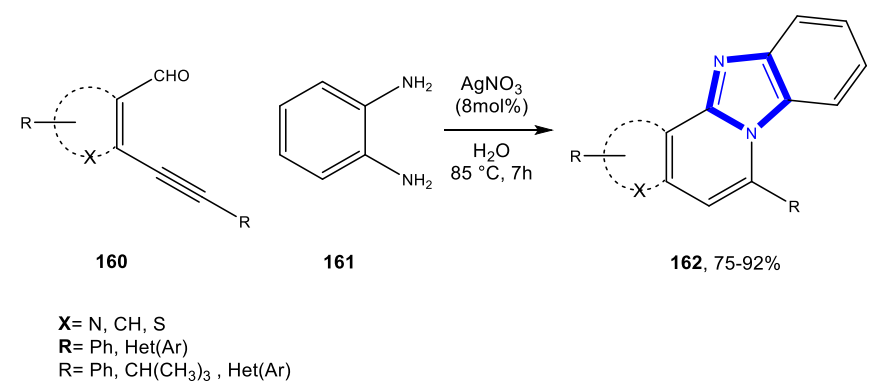

Scheme 46. Rustagi et al. (2011).

Peng et al., reported a study to obtain benzimidazole in water. For this process, they developed a $\mathrm{Cu}_{2} \mathrm{O} / \mathrm{DMEDA}$ system to achieve intramolecular $\mathrm{C}-\mathrm{N}$ Bond formation and consequently the benzimidazole ring system in high yields (Scheme 47) [91].

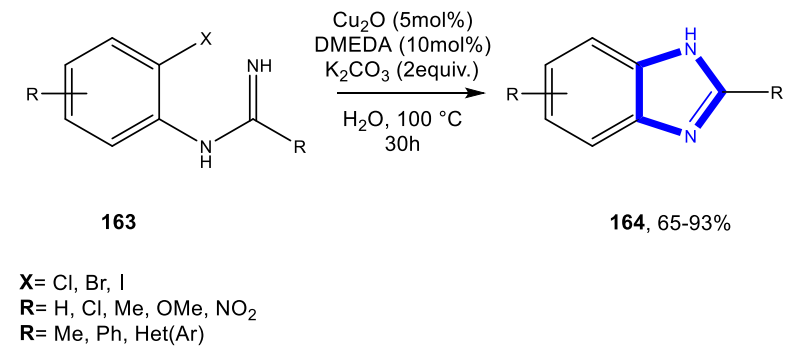

Scheme 47. Peng et al. (2011).

Chanu et al., reported a synthesis of heterocyclic $N, N$-acetals in water. The compound was synthesized efficiently from ketene dithioacetal with ethane-1,2-diamine in the absence of any acid/base catalyst (Scheme 48) [92].<smiles>CC(C)=CC(=O)c1ccccc1</smiles>

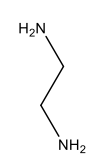

16<smiles>CC(C)=C1CCc2ccccc2C1=O</smiles><smiles>[111InH]</smiles><smiles>[2H]C=C(C)C</smiles>

170<smiles>NCCN</smiles>

166

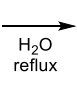<smiles>COc1cccc2c1CCC1C2=NN2CCN[C@@H]12</smiles><smiles></smiles>

$169,90 \%$

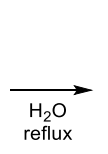<smiles>[Y]C([2H])=C1NCCN1</smiles>

$171,70-93 \%$

$\mathbf{R}=\mathrm{CN}, \mathrm{CO}_{2} \mathrm{Me}$
$\mathbf{R}=\mathrm{CN}, \mathrm{CO}_{2} \mathrm{Me}, \mathrm{CO}_{2} \mathrm{C}_{2} \mathrm{H}_{5}, \mathrm{PhCO}$

Scheme 48. Chanu et al. (2010).

Boeini and Najafabadi prepared benzimidazole through 1,2-diaminobenzene and a suitable S-methylthioamidinium salt in the presence of a catalytic amount of hexadecyl trimethylammonium bromide (HTAB) (Scheme 49) [93]. 


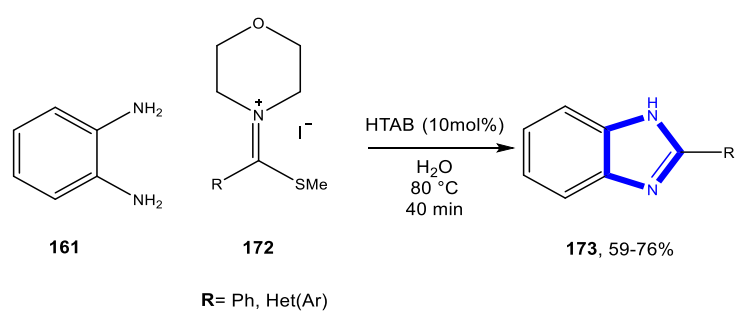

Scheme 49. Boeini and Najafabadi (2009).

Barbero et al., employed a copper-catalyzed intramolecular N-arylation of 2-bromoarylureas for the preparation of benzoimidazolones. The synthesis of several derivatives was achieved by using $\mathrm{CuI}$ and TMEDA acting both as the ligand and as the base in a water solution. In addition, the authors related that although $\mathrm{CuI}$ provides the best results in this novel protocol, other copper salts $(\mathrm{CuCl}, \mathrm{CuBr}$, $\mathrm{Cu}(\mathrm{OAc})_{2} \cdot \mathrm{H}_{2} \mathrm{O}, \mathrm{Cu}(\mathrm{OTf})_{2}$ and $\left.\mathrm{Cu}\left(\mathrm{ClO}_{4}\right)_{2} \cdot 6 \mathrm{H}_{2} \mathrm{O}\right)$ could be used with similar efficiency (Scheme 50) [94].

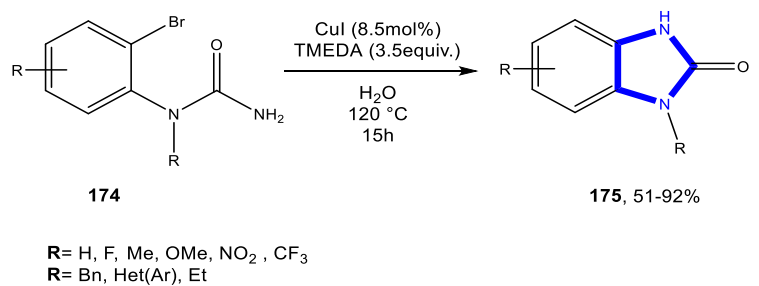

Scheme 50. Barbero et al. (2008).

\subsubsection{Reactions in PEG}

Mekala et al., carried out an efficient procedure for the synthesis of 1,2-disubstituted benzimidazoles. The construction of these compounds was achieved by the nucleophilic attack of the phenylenediamine on the carbonyl carbon. The electrophilicity of the carbonyl carbon was enhanced in the PEG 400 medium compared to the other solvents, and hence accelerated the reaction by removing the liberated water, which was soluble in PEG 400. It enabled its conversion to the corresponding benzimidazole (Scheme 51) [95].

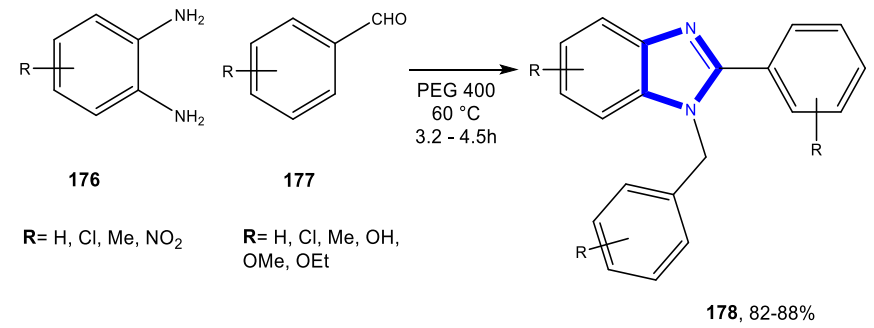

Scheme 51. Mekala et al. (2015).

In 2014, Berteina-Raboin et al., generated 2-arylimidazo[1,2-a]pyridines in good yields within 10 minutes from readily available 2 -amino pyridines and $\alpha$-bromo ketones. A one-pot procedure was engineered to achieve 2,3-diarylimidazo[1,2-a]pyridines using a reduced amount of palladium catalyst without ligand for the $\mathrm{C}-\mathrm{H}$ arylation step in the same environmentally sound medium (Scheme 52) [96]. 


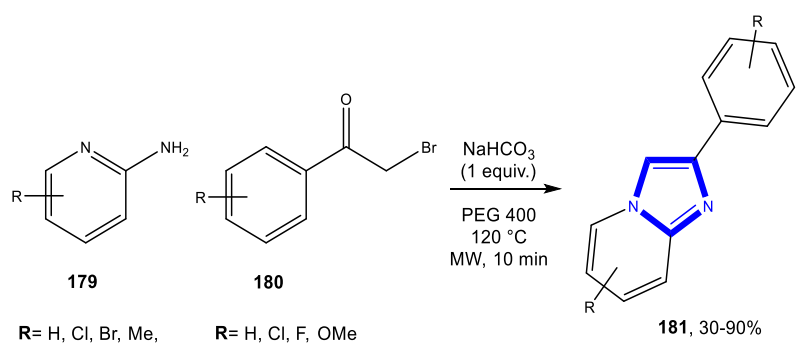

$\mathrm{R}=\mathrm{H}, \mathrm{Cl}, \mathrm{Br}, \mathrm{Me}$
$\mathrm{CO}_{2} \mathrm{Me}, \mathrm{CF}_{3}, \mathrm{OBn}$

$\mathbf{R}=\mathrm{H}, \mathrm{Cl}, \mathrm{F}, \mathrm{OM}$

$181,30-90 \%$

Scheme 52. Berteina-Raboin et al. (2014).

Guchhait and Madaan studied the scope and limitations of an Ugi-Type Multicomponent Reaction mediated by Zirconium(IV) Chloride in PEG. The construction of these compounds was carried out using reaction of heterocyclic amidines with aldehydes and isocyanides. The team reported that the combination of catalyst and solvent was crucial for the regioselectivity and versatility of the method (Scheme 53) [97].

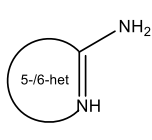

182<smiles>O=Cc1ccc(Cl)cc1</smiles>

183

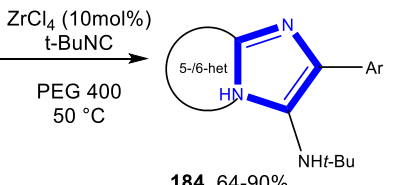

$184,64-90 \%$

Scheme 53. Guchhait and Madaan (2009).

\subsubsection{Reactions in Bio-Based Solvents}

Berteina-Raboin et al., demonstrated, for the first time, that eucalyptol could be used as solvent for organic synthesis. They have shown that it could be an interesting alternative to conventional solvents for the one-pot synthesis of 2,3-diarylimidazol[1,2-a]pyridines involving a condensation between 2-aminopyridine and bromoacetophenones, followed by a C-H activation at $\mathrm{C}-3$. This solvent, derived from biomass and recyclable, was also effective for various transformations of heteroatom-containing heterocycles such as oxygen, sulfur, or nitrogen (Scheme 54) [44].

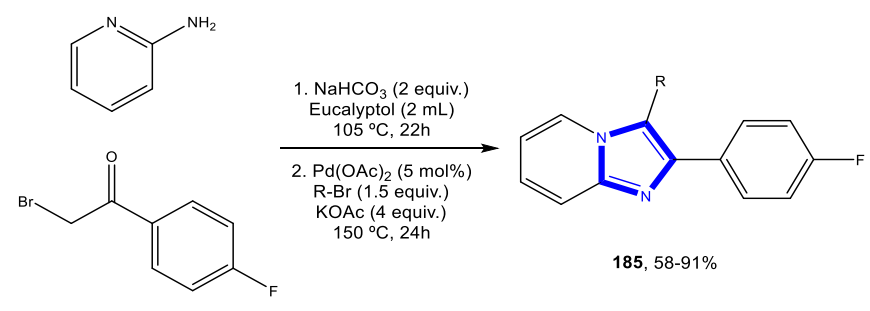

Scheme 54. Berteina-Raboin et al. (2019).

\subsection{Formation of the Triazole Ring}

\subsubsection{Reactions in Water}

In 2017, Dheer et al., reported the synthesis of iodo substituted 1,2,3-triazoles. The scope of the reaction was explored by using substituted benzyl bromides and acetylenes in water at $90{ }^{\circ} \mathrm{C}$. The desired products, 5-iodo-1,4-disubstituted-1,2,3-triazoles were obtained in major quantity with 1,4-disubstituted-1,2,3-triazoles as minor product. In general, substituted phenylacetylene reacted smoothly with in-situ synthesized benzyl azide to furnish the triazole derivatives. It was observed that aliphatic halides were moderately reactive as compared to benzyl halides and furnished the products in moderate to lower yields (Scheme 55) [80]. 


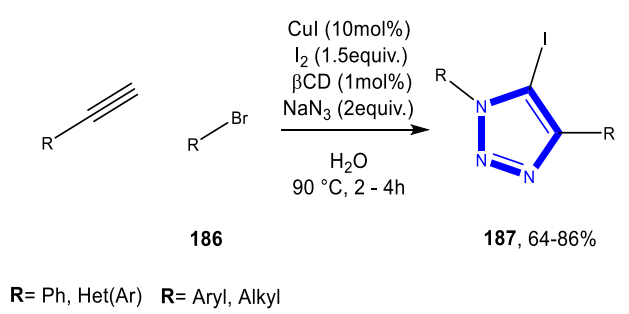

Scheme 55. Dheer et al. (2017).

Hiroki et al., adopted a copper(I) chloride catalyzed reaction using 2-ethynylpyridine as catalyst, and were able to synthesize 1,4-disubstituted 1,2,3-triazoles in good yields from azides and alkynes at room temperature (Scheme 56) [98].

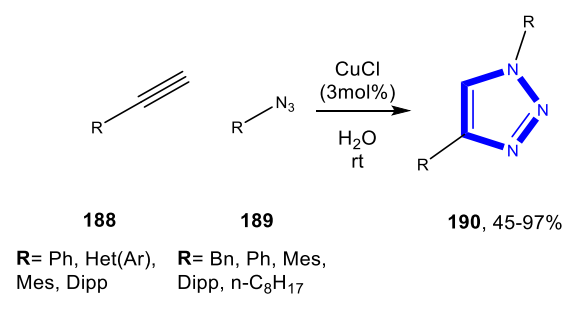

Scheme 56. Hiroki et al. (2013).

Kshirsagar et al., performed a multicomponent reaction to obtain a library of triazole substituted trans-beta-lactams from the copper-catalyzed three-component click reaction of 4-acetoxy beta-lactam, sodium azide, and alkynes without isolation of the azide intermediates (Scheme 57) [99].

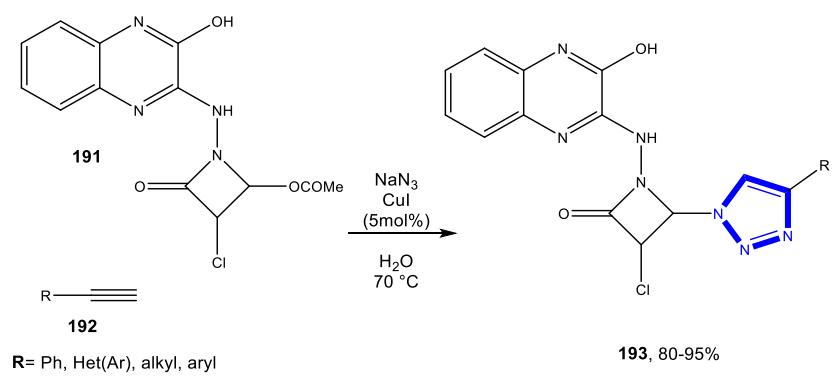

Scheme 57. Kshirsagar et al. (2013).

Kumar et al., employed an Intramolecular Huisgen [3+2] cycloaddition in water for the preparation of pyrrolidine-triazole derivatives. Compounds were prepared with complete 1,5-regioselectivity and no metal catalyst. Azido-alkynes derived from amino acid/tartaric acid were used, and an alkyne attached to an electron withdrawing group provided the final product with a better yield and stability (Scheme 58) [100].

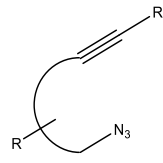

194

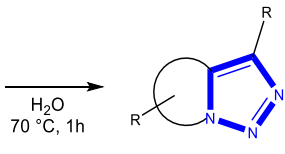

195

Scheme 58. Kumar et al. (2012).

Anil et al., prepared 1,4-disubstituted 1,2,3-triazoles through magnetically separable and reusable copper ferrite nanoparticles in a one-pot reaction, in tap water. This protocol was successfully 
achieved from the initial substitution of benzyl halides with sodium azide to generate in situ benzyl azides, followed by copper ferrite catalyzed cycloaddition reaction with alkynes in water at $70{ }^{\circ} \mathrm{C}$ (Scheme 59) [101].

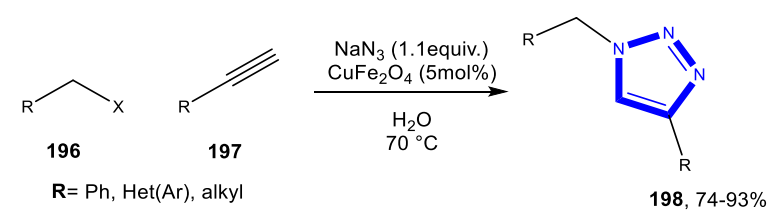

Scheme 59. Anil et al. (2012).

\subsubsection{Reactions in PEG}

Reddy's group reported the synthesis of triazolo-1,2,4-benzothiadiazine-1,1-dioxides via a copper-catalyzed tandem cyclisation of ynamides. This approach was crucial because fused triazolo ring system could be prepared through an intermolecular $\mathrm{C}-\mathrm{N}$ bond formation followed by subsequent cycloaddition between ynamide and azide. Thus, three new $\mathrm{C}-\mathrm{N}$ bonds were formed in a single step (Scheme 60) [102].

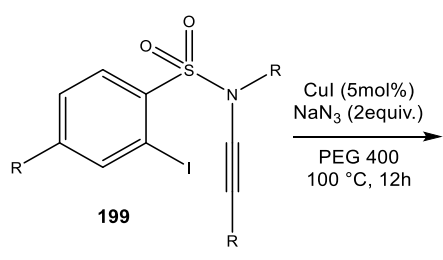

$\mathbf{R}=\mathrm{tBu}, \mathrm{Me}, \mathrm{OMe}, \mathrm{Ph}$ $\mathbf{R}=\operatorname{Het}(\mathrm{Ar})$

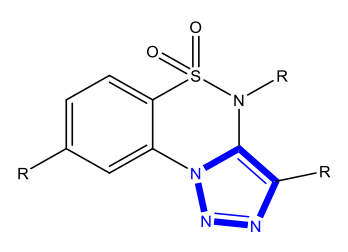

$200,48-84 \%$

Scheme 60. Reddy et al. (2014).

\subsection{Formation of the Tetrazole Ring}

Reactions in Water

Saiprathima et al., reported a direct method for the synthesis of tetrazole derivatives via a metal-free azide-nitrile [2+3] cycloaddition. 3-(1H-tetrazol-5-yl)indolin-2-ones were produced easily with excellent yields at room temperature (Scheme 61) [103].

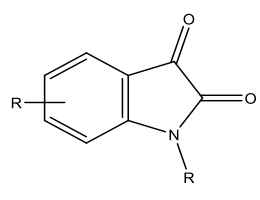

201

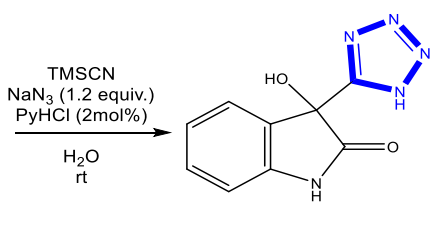

202, $83-98 \%$

$\mathbf{R}=\mathrm{H}, \mathrm{Cl}, \mathrm{Br}, \mathrm{F}, \mathrm{I}, \mathrm{Me}$

$\mathrm{NO}_{2}, \mathrm{OCF}_{3}$
$\mathbf{R}=$ aryl, alkyl

Scheme 61. Saiprathima et al. (2013).

Khalili et al., developed an effective method to obtain 5-amino-1-aryl- $1 H$-tetrazoles using secondary arylcyanamides. With this greener approach, the team successfully achieved the desired products in most cases, avoiding the generation of unwanted products (Scheme 62) [104]. 


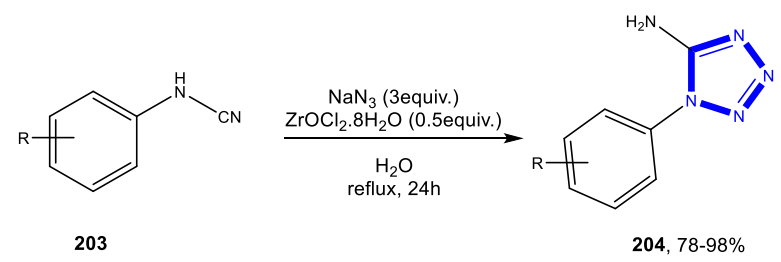

$\mathbf{R}=\mathrm{Cl}, \mathrm{Br}, \mathrm{Me}, \mathrm{OMe}, \mathrm{NO}_{2}$

Scheme 62. Khalili et al. (2013).

Habibi et al., described a convenient procedure for the synthesis of arylaminotetrazoles in water. The construction of these compounds was carried out using reaction of arylcyanamides and sodium azide in the presence of $\mathrm{ZnCl}_{2}$. The method was shown to have various advantages such as high yields and no need for purification (Scheme 63) [105].

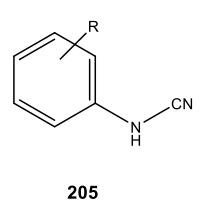

205

$$
\mathbf{R}=\mathrm{H}, \mathrm{Cl}, \mathrm{Br}, \mathrm{NO}_{2}
$$

$\mathrm{Me}$

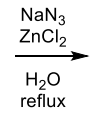

reflux

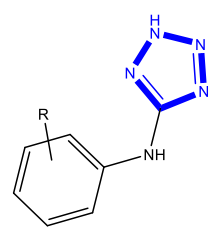

206, $61-84 \%$

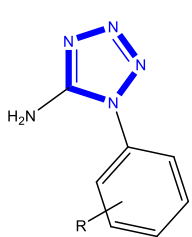

207, $84-90 \%$

Scheme 63. Habibi et al. (2010).

\subsection{Formation of the Isothiazole Ring}

\section{Reactions in Water}

Wang et al., investigated a Cu catalyzed tandem reaction of o-bromobenzamide derivatives with potassium thiocyanate in water. The reaction involved a tandem protocol with $\mathrm{S}-\mathrm{C}$ bond and $\mathrm{S}-\mathrm{N}$ bond formation (Scheme 64) [106].

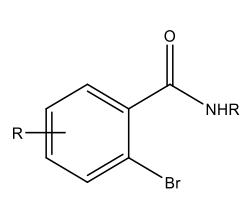

208

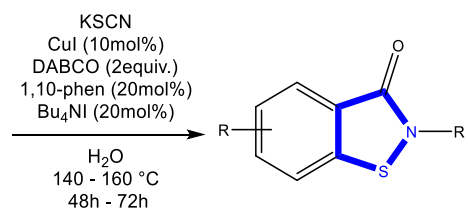

209, $35-60 \%$

$\mathbf{R}=\mathrm{H}, \mathrm{Br}, \mathrm{F}, \mathrm{Me}$

$\mathbf{R}=\mathrm{H}, \mathrm{Me}, \mathrm{Et}, \mathrm{nBu}, \mathrm{Ph}$

Scheme 64. Wang et al. (2012).

\subsection{Formation of the Thiazole Ring}

\subsubsection{Reactions in Water}

Nagaraju et al., obtained thiazoloquinolines via a one-pot four-component cascade procedure. The derivatives were synthesized in water-PEG 400 from $\alpha$-enolic dithioesters, cysteamine, aldehydes, and cyclic 1,3-diketones. Besides the high efficiency and atom economy as a domino process, this reaction is an environmentally benign transformation as the isolation and purification of compounds was achieved by simple filtration and water washing, avoiding conventional chromatographic separation (Scheme 65) [107]. 


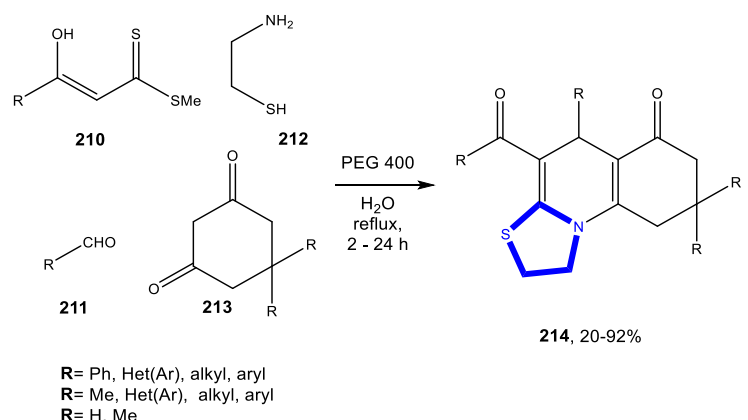

Scheme 65. Nagaraju et al. (2015).

Sengoden et al., disclosed an efficient process for the (3+2)-cycloaddition of aziridines from isothiocyanates, isoselenocyanates, and carbon disulfide with pyrrolidine as catalyst in water (Scheme 66) [108].
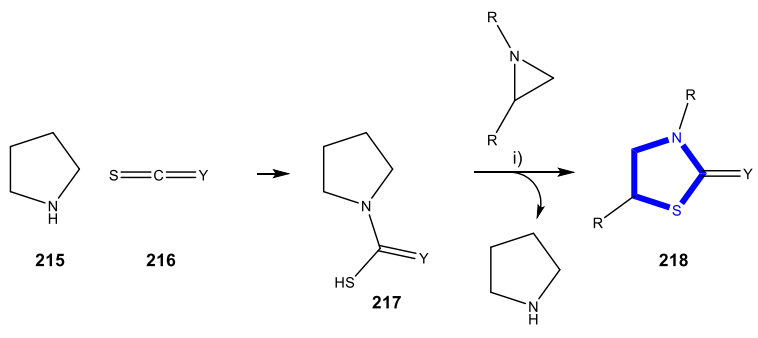

i) pyrrolidine, $\mathrm{H}_{2} \mathrm{O}, 50^{\circ} \mathrm{C}$

Scheme 66. Sengoden et al. (2014).

Aryanasab et al., published the synthesis of thiazolidine-2,4-diones through the reaction of aliphatic primary amines, carbon disulfide, and methyl 2-bromoacetate in aqueous medium. The authors related that when the reaction occurred with aliphatic primary amines the corresponding heterocyclic compounds were successfully obtained; the hindered primary amines such as 1-phenylethylenamine and cyclohexylamine underwent efficient addition with methyl 2-bromoacetate to give the dithiocarbamate acyclic intermediate in good yields, but only trace amounts of the pertinent heterocycle products were obtained. The experimental procedures for aliphatic amines (prepared by a one-pot three-component reaction) were different from those of aromatic amines (the dithiocarbamate salts were prepared with Et3N in diethyl ether before being used in following step) (Scheme 67) [109].
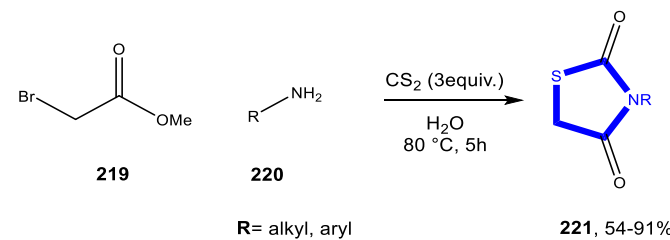

Scheme 67. Aryanasab et al. (2013).

Zhang et al., reported the synthesis of 2-aminobenzothiazoles in water by a 10-phenanthrolinecatalyzed tandem reaction using 2-iodoaniline and isothiocyanate. The strategy adopted led to construction of the desired product in the absence of transition metals and phase-transfer catalysts (Scheme 68) [110]. 


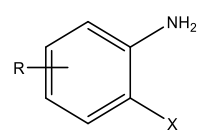

222

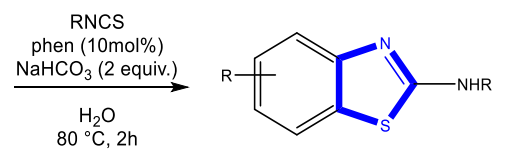

223, traces-99\%

$\mathbf{X}=\mathrm{Cl}, \mathrm{Br}, \mathrm{I}$

$\mathbf{R}=\mathrm{H}, \mathrm{Cl}, \mathrm{Me}, \mathrm{CF}_{3}, \mathrm{CO}_{2} \mathrm{Me}, \mathrm{NO}_{2}$

$\mathbf{R}=\mathrm{Ph}, \operatorname{Het}(\mathrm{Ar})$

Scheme 68. Zhang et al. (2012).

In 2011, Kumar's team also presented the preparation of thiazoles. The library was achieved from readily available $\alpha$-tosyloxy ketones with several thioamides using water as solvent in good yields (Scheme 69) [89].<smiles></smiles>

224

$\mathbf{R}=\mathrm{Me}, \mathrm{Ph}, \mathrm{Het}(\mathrm{Ar})$ $\mathbf{R}=\mathrm{H}, \mathrm{CO}_{2} \mathrm{Me}$

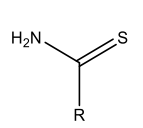

225

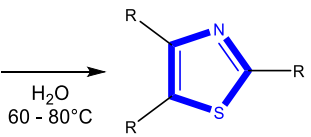

226, $50-93 \%$

Scheme 69. Kumar et al. (2011).

Pathak et al., successfully developed a water assisted tandem S-alkylation-cyclodeamination reaction of thioamides/haloamines. This approach involved the formation of an imidothiolinium species via S-alkylation; as the Imine nitrogen of imidothiolic ester is mildly basic, it was unable to hold the proton strongly in the presence of water and underwent reversible protonation. The free iminium nitrogen attacked the electrophilic carbon attached to the ammonium ion, leading to the formation of thiazoline. The presence of water also suppressed the dehydration of thioamide. Moreover, the use of a protonated aminohalide inhibited undesired side reactions (transamidation and self-condensation), leaving S-alkylation and subsequent cyclisation the only available reaction pathway (Scheme 70) [111].

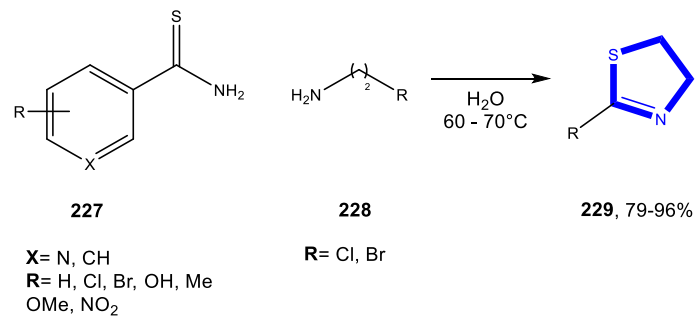

Scheme 70. Pathak et al. (2011).

Yavari et al., reported a one-pot procedure to achieve N-alkylthiazoline-2-thiones. The strategy adopted was a catalyst-free reaction system that started by the formation of an alkylammonium dithiocarbamate salt, followed by addition to 2-chloro-1,3-dicarbonyl compounds to generate the acyclic dithiocarbamate derivatives; then cyclization (and closure of the ring) and elimination of water in the presence of alkylammonium chloride led to the desired product. The various derivatives were prepared from primary amines, carbon disulfide, and 2-chloro-1,3-dicarbonyl compounds in water (Scheme 71) [112]. 


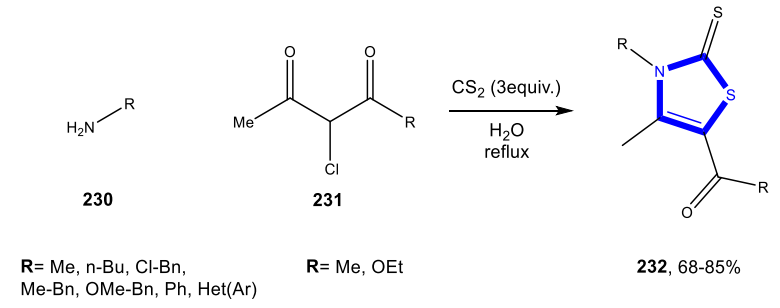

Scheme 71. Yavari et al. (2010).

In 2008, Tu et al., demonstrated a microwave-assisted multi-component approach for the preparation of thiazolidinones. In aqueous medium, a three-component reaction with various aromatic aldehydes, aniline, and mercaptoacetic acid afforded the desired products in excellent yields (Scheme 72) [113].

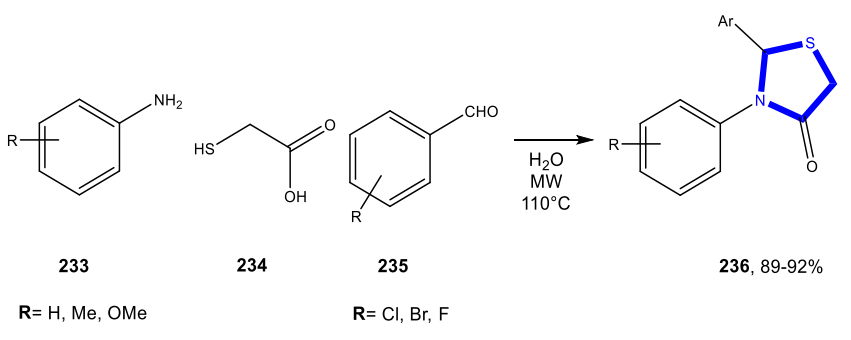

Scheme 72. Tu et al. (2009).

In 2009, Boeini and Najafabadi also accomplished the construction of the thiazole ring using 2-aminthiophenol and S-methylthioamidinium salt with HTAB as catalyst system (Scheme 73) [93].<smiles>Nc1ccccc1S</smiles>

237

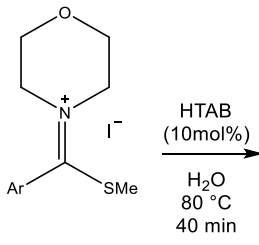

238

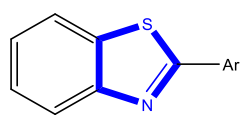

239, $69-91 \%$

$\mathbf{R}=\mathrm{Ph}, \operatorname{Het}(\mathrm{Ar})$

Scheme 73. Boeini and Najafabadi (2009).

Potewar et al., reported a direct method for the synthesis of 2-aminothiazoles under catalyst-free conditions and aqueous medium at room temperature. During evaluation of the scope and generality of the strategy, the team was able to verify that the phenacyl bromide with both an electron-rich and an electron-poor functionality underwent a condensation reaction with thioureas equally well to afford the corresponding 2-aminothiazoles in excellent isolated yields. Furthermore, $\alpha$-bromo-2-acetonaphthone smoothly reacted with thiourea and substituted thiourea, affording the corresponding products in excellent yields (Scheme 74) [114].<smiles>CCC(=O)c1ccccc1</smiles>

240<smiles>CC(N)=S</smiles>

241

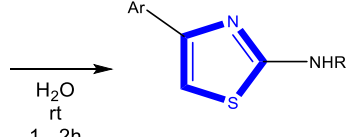

242, $89-97 \%$

$\mathbf{R}=\mathrm{H}, \mathrm{F}, \mathrm{NO}_{2}, \mathrm{OMe}, \mathrm{Ph} \quad \mathbf{R}=\mathrm{H}, \mathrm{Me}, \mathrm{Ph}$, Aryl

Scheme 74. Potewar et al. (2008). 
Chakraborti et al., generated benzothiazoles and benzothiazolines in excellent yields from various aldehydes and 2-aminothiophenol. The team applied a chemoselective protocol with no competitive thia-Michael addition, O-dealkylation/debenzoylation, reduction of the nitro or the unsaturated carbonyl groups, and substitution of the halogen atom or the nitro group (Scheme 75) [115].

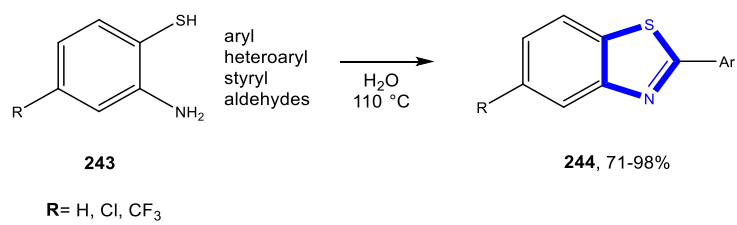

Scheme 75. Chakraborti et al. (2007).

\subsubsection{Reactions in PEG}

In 2016, Berteina-Raboin et al., managed to obtain substituted 2-aminobenzothiazole from isocyanides and 2-aminothiophenol as the starting materials in respectable yield. The results were achieved using iodine as a catalyst and hydrogen peroxide as an oxidant in PEG 400 (Scheme 76) [116].

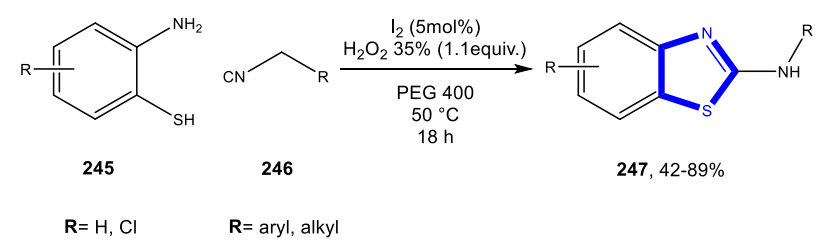

Scheme 76. Berteina-Raboin et al. (2016).

In 2015, Nagaraju et al., adopted a one-pot four-component cascade reaction to synthesize thiazoloquinoline derivatives from $\alpha$-enolic dithioesters, cysteamine, aldehydes, and cyclic 1,3-diketones. This result was achieved by first optimizing the sequential protocol that generated two rings by concomitant formation of $\mathrm{C}=\mathrm{C}, \mathrm{C}=\mathrm{N}$, and $\mathrm{C}-\mathrm{S}$ multiple bonds (Scheme 77) [107].

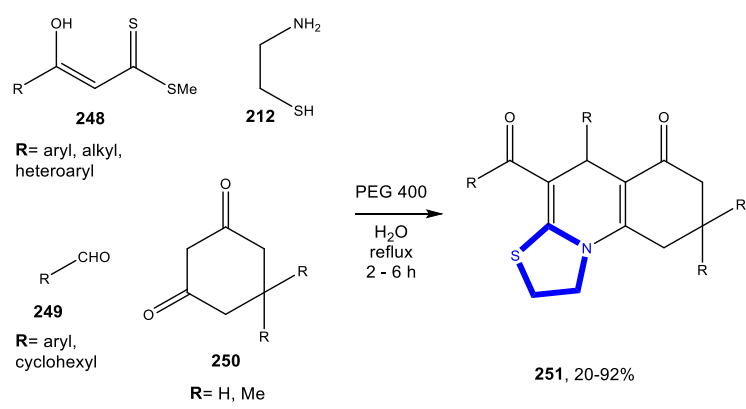

Scheme 77. Nagaraju et al. (2015).

Jin et al., successfully performed a condensation reaction of 2-aminothiophenol with aldehydes. This work developed an approach catalyzed by ceric ammonium nitrate in PEG to afford benzothiazoles in good yields in $5 \mathrm{~h}$ at room temperature. Additionally, the team was able to recover and reuse the catalyst system without any noticeable loss in activity (Scheme 78) [117].<smiles>Nc1ccccc1S</smiles>

237

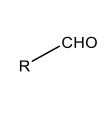

252

$R=P h, \operatorname{Het}(\mathrm{Ar})$

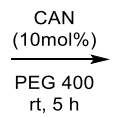

rt, $5 \mathrm{~h}$

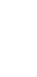

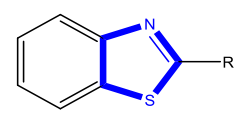

253, $64-97 \%$

Scheme 78. Jin et al. (2011). 
A year earlier (2010), Deligeorgiev et al., presented a synthetic strategy with similar starting reagents using p-toluenesulfonic acid as the catalyst system. In this case, they successfully monitored the reaction of 2,2'-diaminodiphenyldisulfides or 2-aminothiophenols and aldehydes in PEG 200/400 under microwave irradiation (Scheme 79) [118].

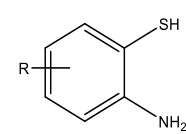

254

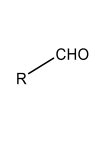

255

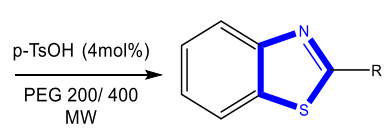

256, $58-97 \%$

$$
\mathbf{R}=\mathrm{H}, \mathrm{Cl}, \mathrm{OMe} \quad \mathbf{R}=\text { aryl, heteroaryl }
$$

Scheme 79. Deligeorgiev et al. (2010).

Zhu et al., published the synthesis of thiazoles through a catalyst-free protocol involving solvent reuse. This procedure, which produced the library in excellent yields, was based on the reaction of $\alpha$-haloketones with thioureas/thioamides at room temperature (Scheme 80) [119].<smiles>CC(=O)C(C)C(C)C</smiles>

257

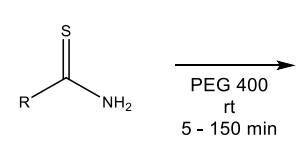

258

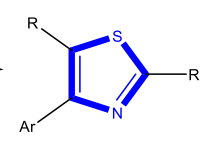

259, $84-98 \%$

$$
\begin{aligned}
& \mathbf{X}=\mathrm{Cl}, \mathrm{Br} \\
& \mathbf{R}=\mathrm{H}, \mathrm{Me}
\end{aligned} \quad \mathbf{R}=\mathrm{NH}_{2}, \mathrm{Me}, \mathrm{Ph}, \mathrm{NHPh}
$$

Scheme 80. Zhu et al. (2009).

\subsubsection{Reactions in Bio-Based Solvents}

Yu et al., succeeded in preparing 2-arylbenzothiazoles using proline-based ionic liquids as a catalyst prepared previously. The methodology proceeded in air and gave a high yield. The authors also reported the successful reuse of the catalytic system (Scheme 81) [120].

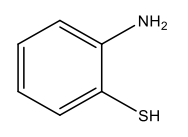

237

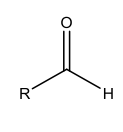

260

$\mathbf{R}=$ aryl

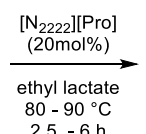
$80-90^{\circ} \mathrm{C}$
$25-6 \mathrm{~h}$

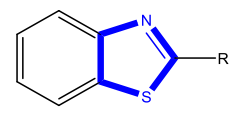

261, $55-92 \%$

Scheme 81. Yu et al. (2016).

\subsection{Formation of the Thiadiazole Ring}

Reactions in Water

Halimehjani et al., studied the scope and limitations of the preparation of substituted 2,5-diamino-1,3,4-thiadiazoles via the reaction of dithiocarbamates prepared with aromatic amines and hydrazine sulfate in water. This strategy involved key steps: a pyridine-water mixture gave a mild basic medium in which the hydrazine sulfate was converted to hydrazine; then cyclization via the nucleophilic attack of sulfur on the thiocarbonyl group produced the anion, which after absorbing a proton from water and aromatization followed by elimination of $\mathrm{H}_{2} \mathrm{~S}$, resulted in the desired final product (Scheme 82) [121]. 


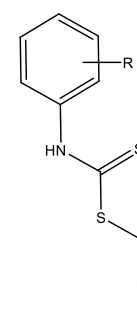

262
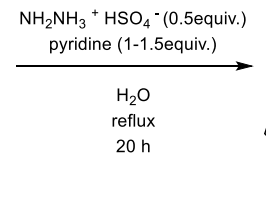

$\mathrm{R}=\mathrm{H}, \mathrm{Cl}, \mathrm{Br}, \mathrm{Me}, \mathrm{OMe}$
$\mathrm{R}=\mathrm{Ph}, \mathrm{Me}, \mathrm{CH}_{2} \mathrm{CN}, \mathrm{Ph}, \mathrm{CH}=\mathrm{CH}_{2}$

Scheme 82. Halimehjani et al. (2012).

\subsection{Formation of the Isoxazole Ring}

\subsubsection{Reactions in Water}

Recently, Ahmadzadeh et al., carried out a practical strategy to obtain methyl-4-(hetero)arylmethylene isoxazole-5(4H)-ones. The construction of these compounds was achieved by one-pot multicomponent cyclocondensation of hydroxylamine hydrochloride, ethyl acetoacetate and benzaldehyde derivatives in water under ultrasound irradiation. The process applied was catalyzed by SnII-Mont K10, which was prepared previously by ion exchange between $\mathrm{SnCl}_{2}$ and montmorillonite $\mathrm{K} 10$ (Scheme 83) [122] .

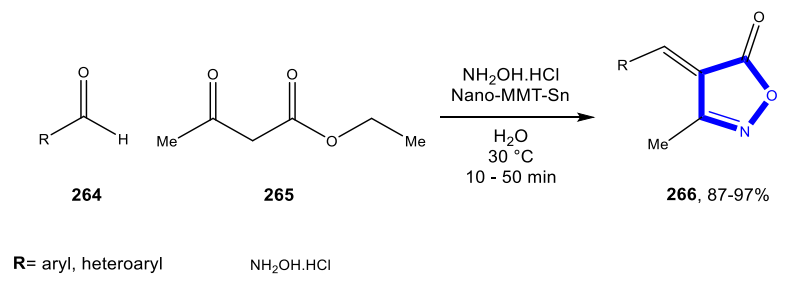

Scheme 83. Ahmadzadeh et al. (2018).

Using a one-pot Aza-Diels-Alder reaction, Dommaraju et al., succeeded in synthesising spiro(isoxazolo[5,4-b]pyridine-5,5-pyrimidine) using L-proline as catalyst in aqueous medium. The final products were prepared from 3-amino crotanonitrile, hydroxylamine hydrochloride, aromatic aldehydes, and barbituric acids in high yields (Scheme 84) [123].

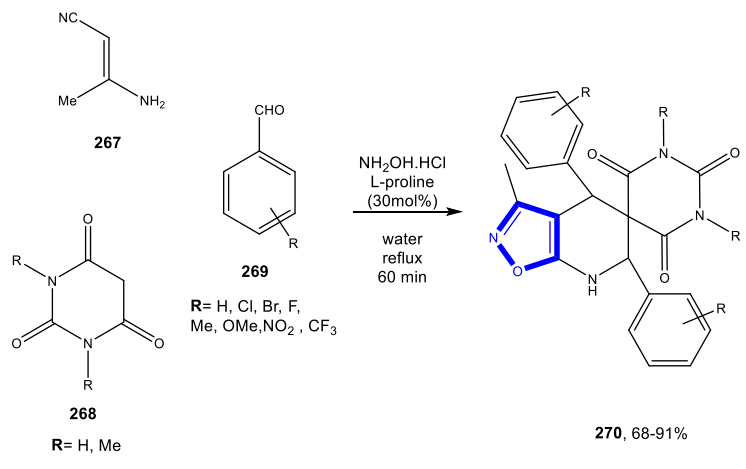

Scheme 84. Dommaraju et al. (2018).

Kiyani and Ghorbani investigated the synthesis of isoxazole derivatives using potassium hydrogen phthalate as catalyst and demonstrated a synthetic route to obtain 3,4-disubstituted isoxazol-5(4H)-ones in aqueous conditions at room temperature. A library of functionalized isoxazoles was synthesized from the reaction of hydroxylamine hydrochloride, aryl aldehydes and $\beta$-ketoesters (Scheme 85) [124]. 
<smiles>CC(=O)CC(=O)O</smiles>

271

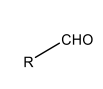

272
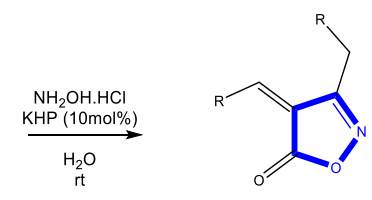

$273,88-97 \%$

Scheme 85. Kiyani and Ghorbani (2015).

Chary et al., worked on the preparation of isoxazoles and isoxazolines. These reactions were conducted with a 1,3-dipolar cycloaddition in aqueous polyethylene glycol. The series were efficiently synthesized from benzoylnitromethane/ethyl 2-nitroacetate and terminal alkynes or alkenes without the use of any base, catalyst, dehydrating agent, or hazardous solvent (Scheme 86) [125].

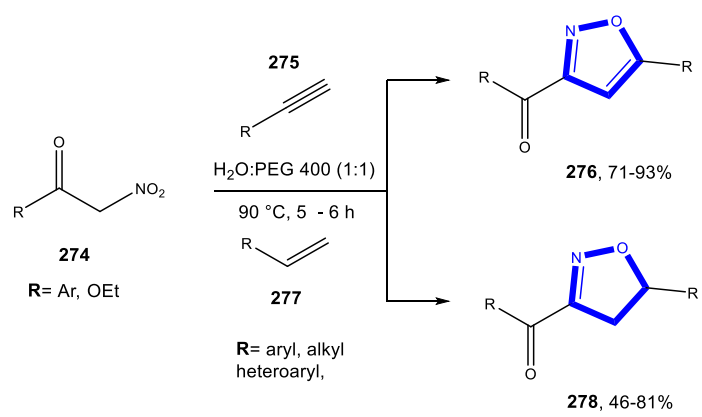

Scheme 86. Chary et al. (2014).

Trogu et al., successfully developed an acid-base-catalyzed condensation reaction to access the isoxazole series from nitroacetic esters and dipolarophiles. The team assumed that the reaction most likely involved reversible addition to a dipolarophile which was followed by acid-catalyzed irreversible dehydration of the cycloadduct (Scheme 87) [126].

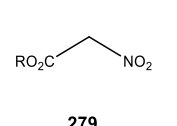

279

$\mathbf{R}=\mathrm{Me}, \mathrm{Et}$

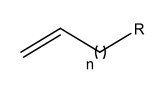

280

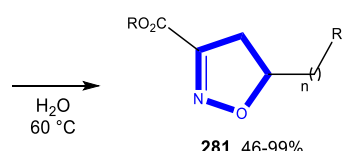

281, $46-99 \%$

$n=1-10$

$\mathrm{R}=\mathrm{H}, \mathrm{Br}, \mathrm{CN}, \mathrm{NO}_{2}, \mathrm{NH}_{3}$

$\mathrm{OH}, \mathrm{CHO}, \mathrm{COMe}, \mathrm{OEt}_{\text {, }} \mathrm{CH}$

Scheme 87. Trogu et al. (2012).

In 2010, Savant et al., also described the generation of trisubstituted isoxazoles via condensation of various R-acylketene dithioacetals with hydroxylamine hydrochloride followed by oxidation of sulfide to sulfone using water as solvent (Scheme 88) [74]. 


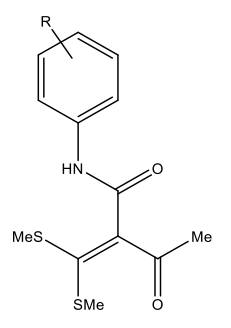

282

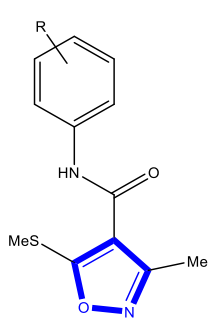

283, $87-98 \%$

$\mathbf{R}=\mathrm{Cl}, \mathrm{F}, \mathrm{Me}, \mathrm{Et}, \mathrm{OMe} \mathrm{NO}_{2}$

Scheme 88. Savant et al. (2010).

Tan et al., demonstrated a protocol for the synthesis of tetrahydronaphthalenes fused with an oxazolidine by a tandem approach. The route reported allowed for the formation of the desired product through tandem Michael/nitrone formation/intramolecular [3+2] nitrone-olefin cycloaddition in aqueous media (Scheme 89) [127].<smiles>O=C(O)/C=C/c1ccccc1/C=C/O</smiles>

284

$R=E t, B n$

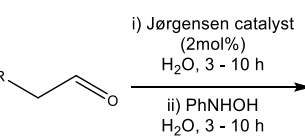

285

$R=M e, E t, i P r, n P r$, $\mathrm{Bn}, \mathrm{BnO}\left(\mathrm{CH}_{2}\right)_{2}$,

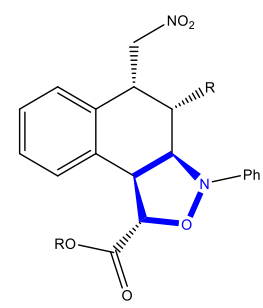

$286,48-83 \%$

Scheme 89. Tan et al. (2010).

\subsubsection{Reactions in PEG}

In 2013, Lavania et al., designed a route to synthesize 2-isoxazoline containing an anthracene moiety. The protocol involved the condensation of substituted chalcones with hydroxylamine hydrochloride in good yields (Scheme 90) [77].

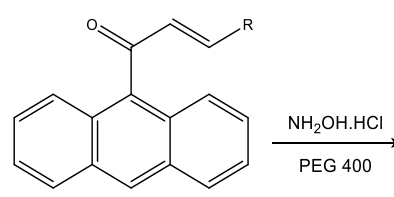

287

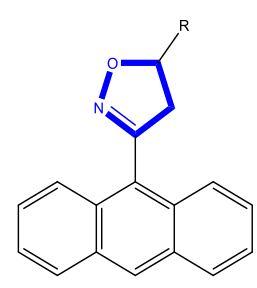

$288,81-85 \%$

$\mathrm{R}=\mathrm{Cl}, \mathrm{Br}, \mathrm{OMe}, \mathrm{NO}_{2}$

Scheme 90. Lavania et al. (2013).

\subsubsection{Reactions in Bio-Based Solvents}

Vaidya et al., adopted a reaction catalyzed by cerium chloride heptahydrate in ethyl lactate as bio-based solvent to achieve isoxazolone derivatives. The methodology was carried out at room temperature; the catalyst and solvent were reused (Scheme 91) [128]. 


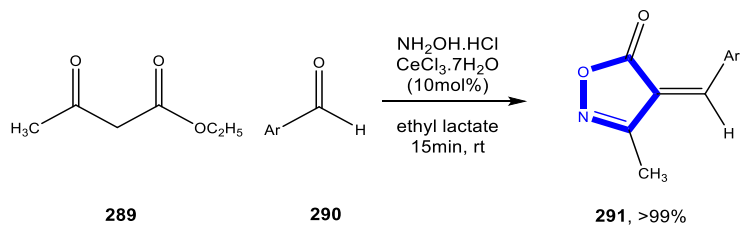

Scheme 91. Vaidya et al. (2016).

\subsection{Formation of the Oxazole Ring}

\subsubsection{Reactions in Water}

Boeini and Najafabadi, in the work reported in 2009, related the synthesis of benzoxazoles. The derivatives were obtained by reaction of the corresponding thioamidinium salts and 2-aminophenol (Scheme 92) [93]

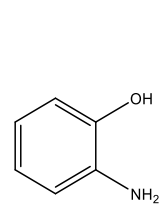

292

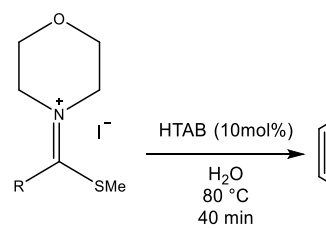

172

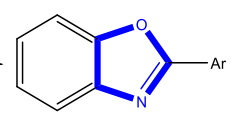

$293,62-88 \%$

$\mathbf{R}=\mathrm{Ph}, \operatorname{Het}(\mathrm{Ar})$

Scheme 92. Boeini and Najafabadi (2009).

Wallace et al., described a regioselective conversion of an aziridine to an oxazolidinone using only an iodide salt and $\mathrm{CO}_{2}$ in water. The group started with the known assumption, namely the fact that aziridines undergo ring opening in water using PBu3 as the nucleophile. Thus, they developed the synthesis strategy using a halide salt as the nucleophile and water as the solvent (Scheme 93) [129].

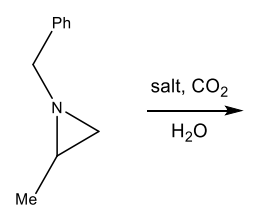

294

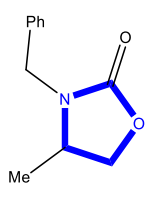

Salt: isomer $\mathbf{a} /$ isomer $\mathbf{b}$ il: 295a, 88\%/295b, $12 \%$ Nal: 296a, $80 \% / 296 b, 20 \%$ Csl: 297 a, $86 \% / 297 b, 14 \%$

Scheme 93. Wallace et al. (2005).

\subsubsection{Reactions in Bio-Based Solvents}

Balijapalli et al., applied lactic acid as solvent to investigate its utility in the synthesis of oxazolonaphthoimidazo[1,2-a]pyridines. The synthetic strategy adopted was highly compatible with various functionalities. The reactions using derivatives containing electron donating and withdrawing analogues were achieved in good yields (Scheme 94) [130]. 


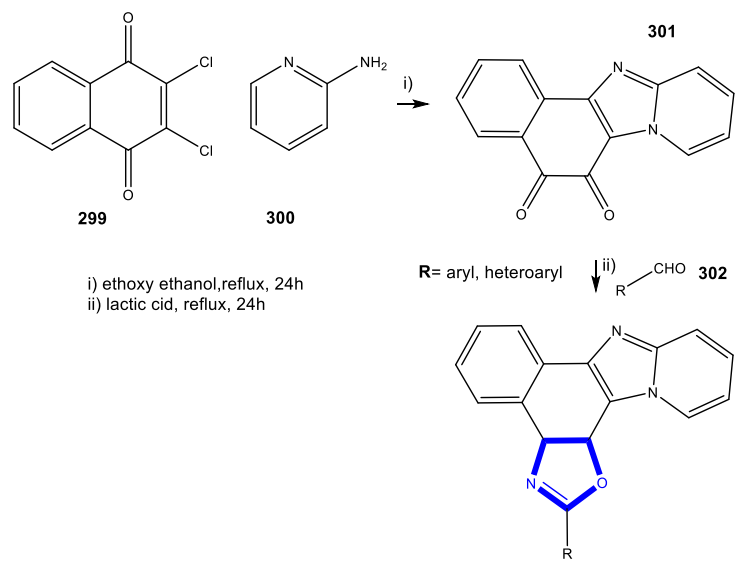

303, $81-98 \%$

Scheme 94. Balijapalli et al. (2016).

\section{Six-Membered Aromatic Nitrogen Heterocycles}

\subsection{Formation of the Pyridine Ring}

\subsubsection{Reactions in Water}

Naeimi and Didar developed a method to generate pyrido[2,3- $d: 6,5-d]$ dipyrimidines in high yields by reaction of aldehyde, 2-thiobarbituric acid and ammonium acetate. This approach was performed under water using a magnetically recyclable nanocatalyst $\left(\mathrm{CuFe}_{2} \mathrm{O}_{4}\right)$ (Scheme 95) [131].

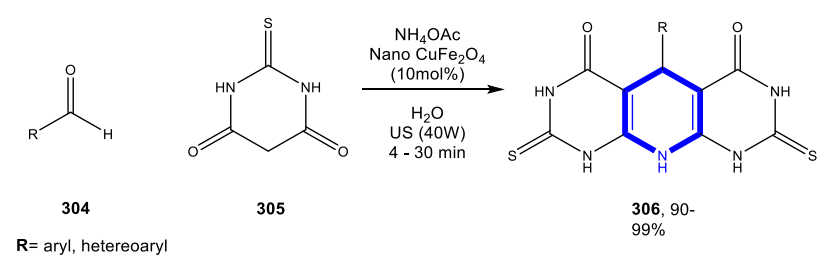

Scheme 95. Naeimi and Didar (2017).

As previously described, in 2017, Sagir et al., achieved a one-pot four-component reaction catalyzed by iodine in water. This reaction from hydrazine, ethylacetoacetate, 6 -amino-1-methyluracil, and isatin or aldehyde and iodine as catalyst also resulted in the formation of a pyridine ring (Scheme 96) [62].

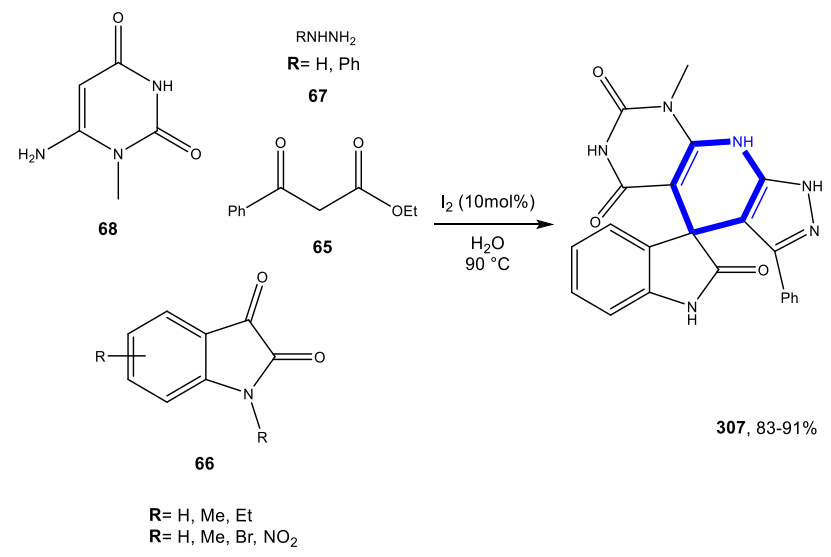

Scheme 96. Sagir et al. (2017).

Lezana et al., obtained tetrahydropyridines via an intramolecular imino-Diels-Alder reaction in water. The derivatives were synthesized under microwave irradiation and with no catalyst between 
the 2-amino pyrrole and 2-aminopyrazole to construct chiraltetracyclic dihydrochromeno-pyrrolo- and dihydrochromenopyrazolo-tetrahydropyridines (Scheme 97) [132].

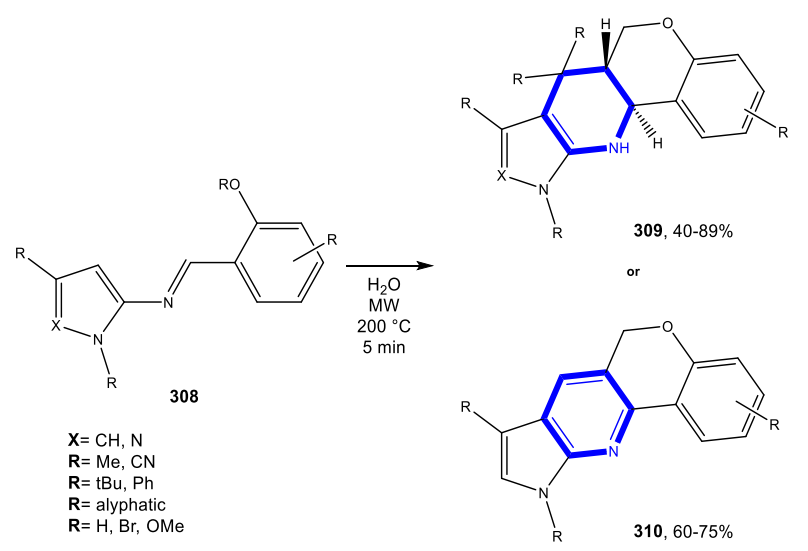

Scheme 97. Lezana et al. (2016).

Abdelmoniem et al., described a convenient procedure for the synthesis of spiro cyclic derivatives that included the formation of a pyridine ring. The process was catalyzed by $p$-toluenesulfonic acid in aqueous medium (Scheme 98) [133].

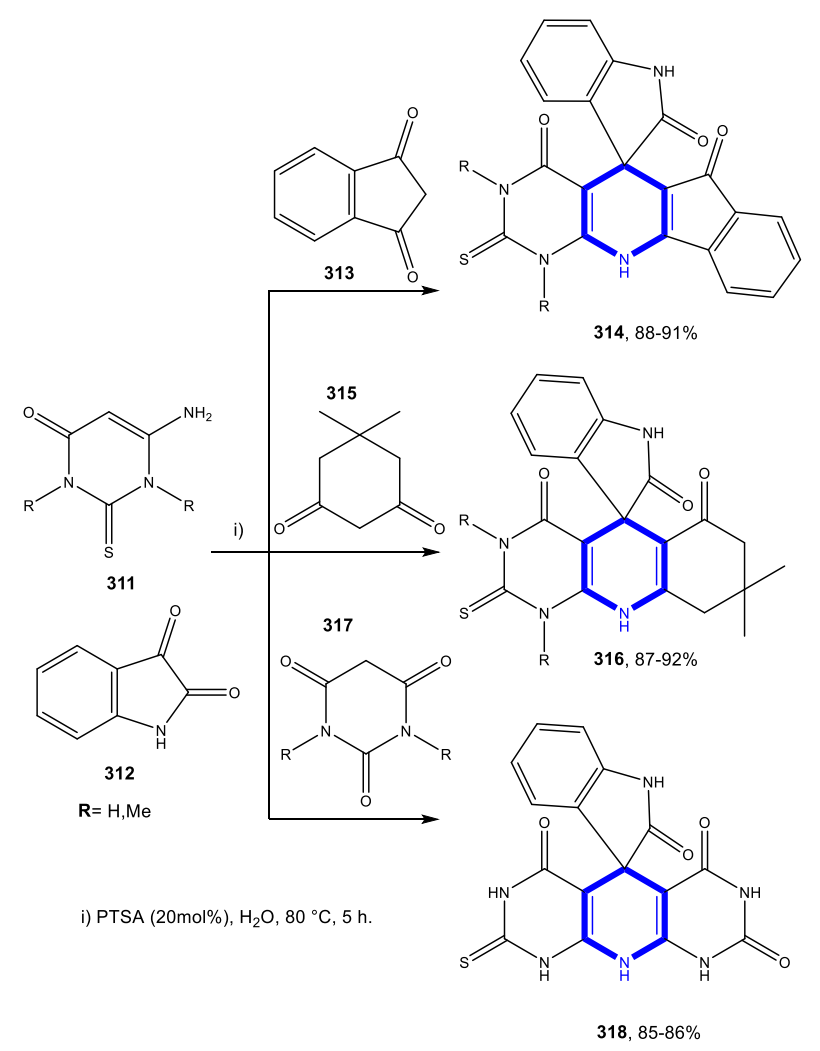

Scheme 98. Abdelmoniem et al. (2016).

Yaragorla et al., designed a methodology to access the construction of dihydropyridine and acridine scaffolds. After optimization, they monitored a one-pot multicomponent reaction with $\mathrm{Ca}(\mathrm{OTf})_{2}$ as catalyst using water as solvent (Scheme 99) [134]. 


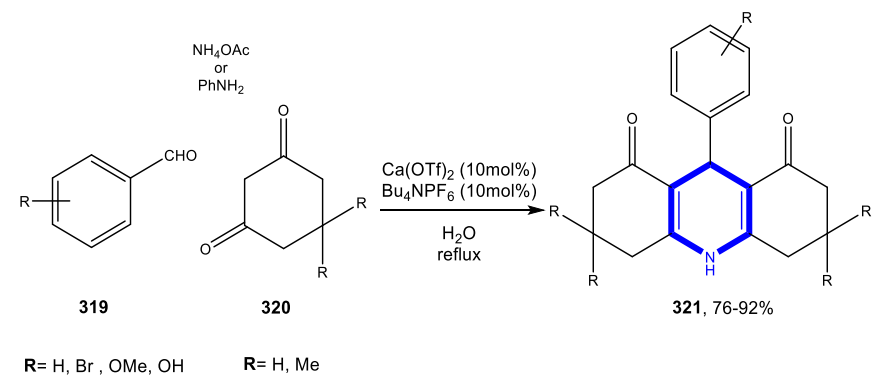

Scheme 99. Yaragorla et al. (2015).

By adopting a series of cascade cyclization reactions initiated by aza- or oxa-michael addition in water, Zhao et al., were able to synthesize Michael adduct 324 from nitroolefin and 2-aminobenzaldehyde as Michael donor. When nitroolefin was replaced by $\alpha, \beta$-unsaturated aldehyde as Michael acceptor, the result was compound 324 (Scheme 100) [135].

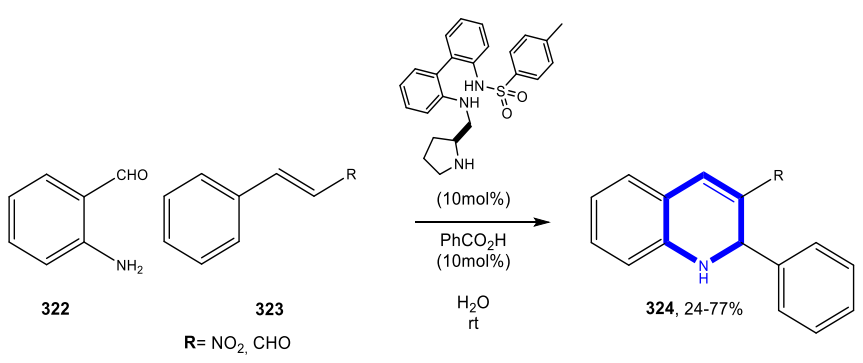

Scheme 100. Zhao et al. (2014).

Mosslemin et al., employed a one-pot, three-component approach for the preparation of 5-aryl-( $1 H, 3 H, 5 H, 10 H)$-pyrimido[4,5-b]quinoline-2,4-diones. The synthesis of several derivatives in high yields was achieved from anilines, aldehydes, and barbituric acids using 1,4-diaza-bicyclo [2.2.2]octane as catalyst system in water (Scheme 101) [136].

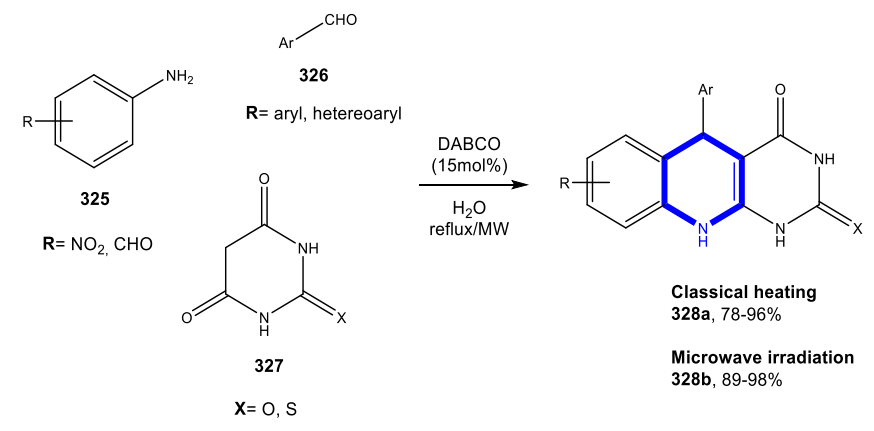

Scheme 101. Mosslemin et al. (2014).

As previously mentioned, Chanu et al., published the synthesis of imidazo[1,2-a]pyridines and pyrido[1,2-a]pyrimidines. In this study, it was also possible to observe the construction of the pyridine ring (Scheme 102) [84]. 


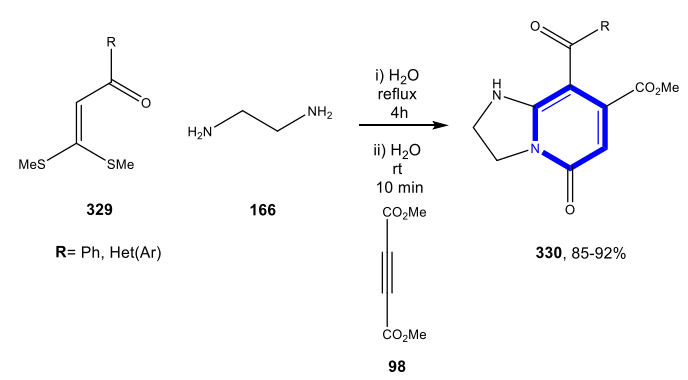

Scheme 102. Chanu et al. (2014).

Siddiqui et al., prepared fused pyridines through electron-rich amino heterocycles and Knoevenagel products derived from aldehyde and malononitrile in water with thiamine hydrochloride as a reusable catalyst. This protocol was successfully achieved from an addition on an activated olefinic bond formed in situ by Knoevenagel condensation between an aromatic aldehyde and an active methylene compound. The Michael product on subsequent cyclo-condensation yielded fused pyridine in high yield (Scheme 103) [137].

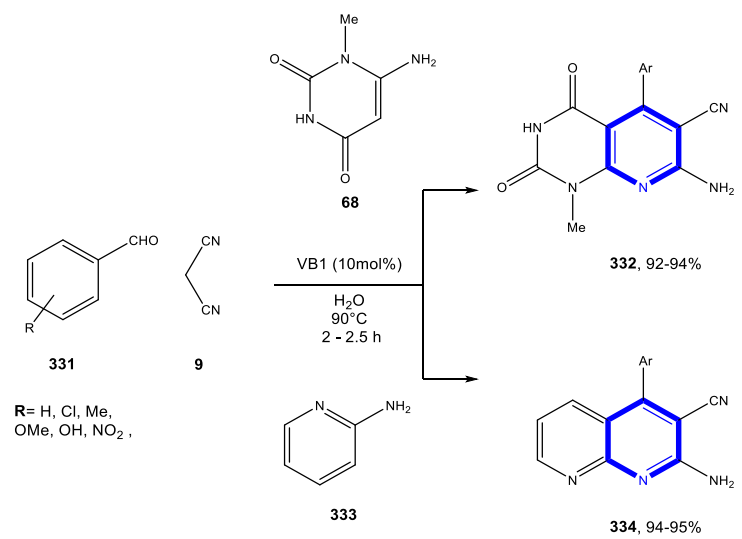

Scheme 103. Siddiqui et al. (2013).

Nasseri et al., succeeded in achieving the rapid synthesis of quinoline derivatives in high yields by $\mathrm{PEG}-\mathrm{SO}_{3} \mathrm{H}$ catalyzed reaction of $o$-aminoaryl ketones with various carbonyls in water (Scheme 104) [138].
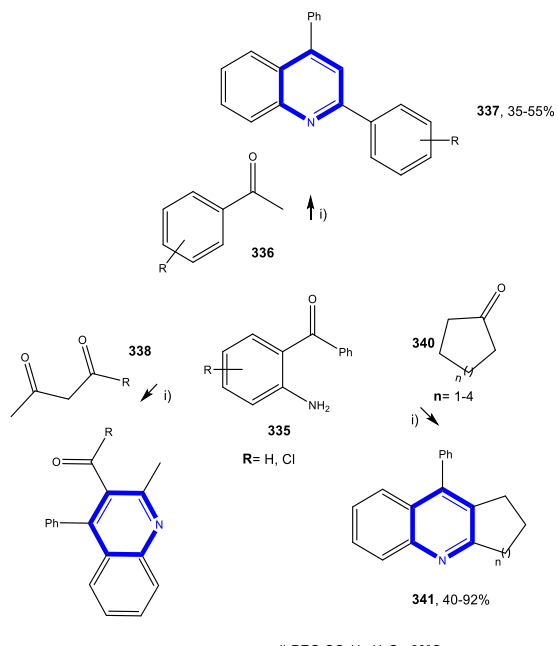

339, $75-95 \%$

i) PEG-SO $\mathrm{H}_{3}, \mathrm{H}_{2} \mathrm{O}, 60^{\circ} \mathrm{C}$

Scheme 104. Nasseri et al. (2013). 
Makone and Niwadange investigated the synthesis of 1,4-dihydropyridines in aqueous media. The various derivatives were prepared from the condensation of aldehyde, $\beta$-dicarbonyl compounds, and liquid ammonia in good yields (Scheme 105) [139].

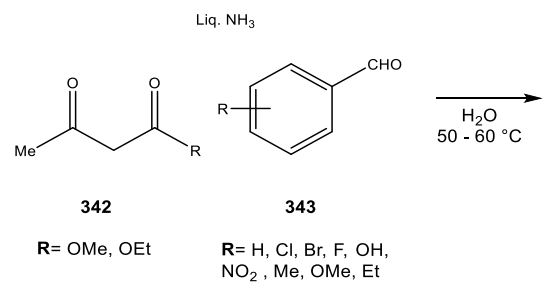<smiles>CC(=O)C1=C(C)NC(C)=C(C(C)=O)C1c1ccccc1</smiles>

344, $94-98 \%$

Scheme 105. Makone and Niwadange (2012).

Khurana et al., demonstrated a three-component condensation of aldehydes, 1,3-dicarbonyl compounds and electron-rich amino heterocycles catalyzed by indium trichloride in water under reflux. This protocol afforded several skeletons containing the pyridine ring in good yields [140]. Scheme 106 shows an example of constructing one of the pyridine-containing compounds reported by Khurana et al.

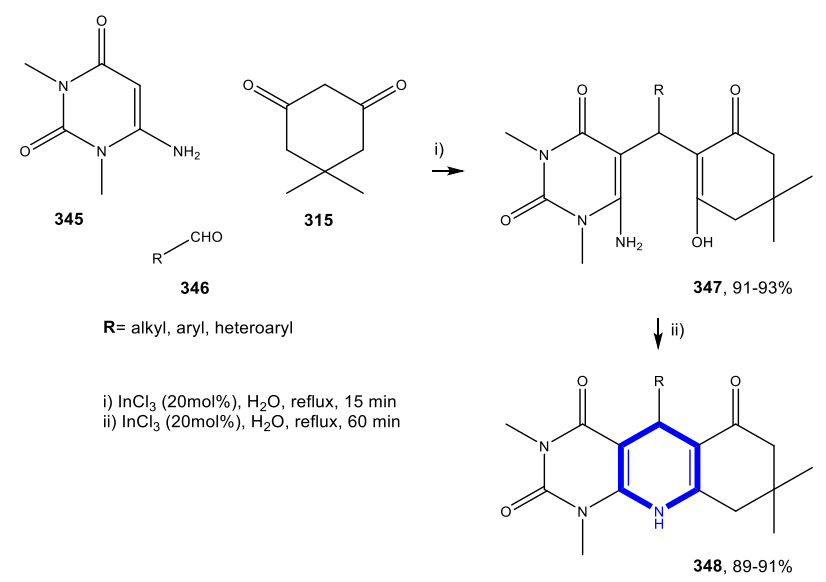

Scheme 106. Khurana et al. (2012).

Kumar et al., on the preparation of polyhydroquinolines. These reactions catalyzed by Thiourea dioxide in water were conducted via Hantzsch multicomponent coupling. The library was synthesized efficiently from aldehyde, dimedone, acetoacetate, and ammonium acetate (Scheme 107) [141].

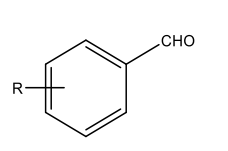

349

$\mathbf{R}=\mathrm{H}, \mathrm{Cl}, \mathrm{Me}, \mathrm{OMe}, \mathrm{NO}_{2}$<smiles>[R]OC(=O)CC(C)=O</smiles>

351<smiles>CC1(C)CC(=O)CC(=O)C1</smiles>

350

$\mathbf{R}=\mathrm{H}, \mathrm{Me}$

$\mathrm{NH}_{4}\left(\mathrm{OCOCH}_{3}\right)$<smiles>C=NC1(C)CC(=O)C2=C(C1)NC(C)C(C(=O)OC)C2c1ccccc1</smiles>

$352,85-94 \%$

$R=M e, E t$

Scheme 107. Kumar et al. (2012). 
Rahmati and Khalesi successfully developed a catalyst-free one-pot, three-component condensation reaction to access pyrido[2,3- $d]$ pyrimidines and pyrazolo[3,4- $b]$ pyridines series in water. Several derivatives were obtained from aldehydes, benzoyl acetonitriles and 6-amino-1, 3-dimethylpyrimidine-2,4(1H,3H)-dione or 3-methyl-1-phenyl-1H-pyrazol-5-amine (Scheme 108) [142].

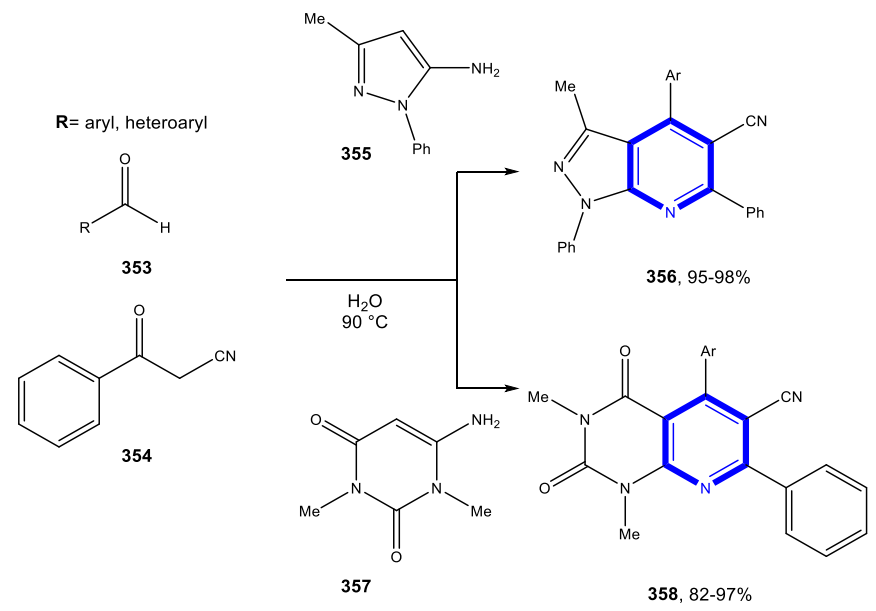

Scheme 108. Rahmati and Khalesi (2012).

Shen et al., reported a synthesis of quinolines from 2-aminobenzaldehyde with various ketones or malononitrile in water without using any catalyst by Friedländer reaction (Scheme 109) [143].<smiles>Nc1ccccc1O</smiles>

359<smiles>[R]CC([R])=O</smiles>

360

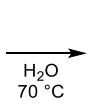

$70^{\circ} \mathrm{C}$

$\mathbf{R}=$ aryl, heteroaryl<smiles></smiles>

$361,53-99 \%$

Scheme 109. Shen et al. (2012).

$\mathrm{Xu}$ et al., described a generation of substituted pyridines via [2+2+2] cycloaddition of diynes with nitriles in aqueous medium. This ruthenium-catalyzed approach gave efficient access to highly functionalized pyridines (Scheme 110) [144].

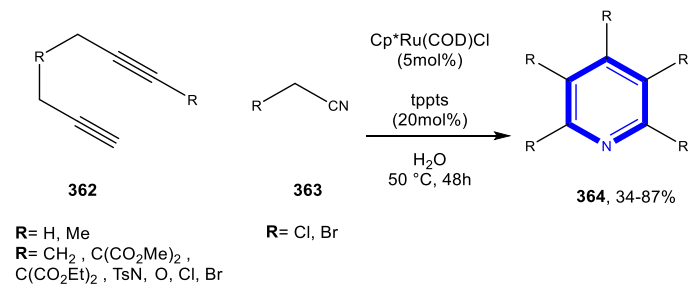

Scheme 110. Xu et al. (2012).

Mukhopadhyay et al., demonstrated the protocol for the synthesis of [1,6]-naphthyridines by a one-pot, catalyst-free, pseudo-five-component approach. In water methyl ketones reacted with amines and malononitrile to afford the corresponding 1,2-dihydro[1,6]naphthyridines in good yields. The reported protocol allows the formation of two pyridine rings in a one-pot reaction through the synthetic route without starting from any nitrogen-containing heterocycle moiety (Scheme 111) [145]. 


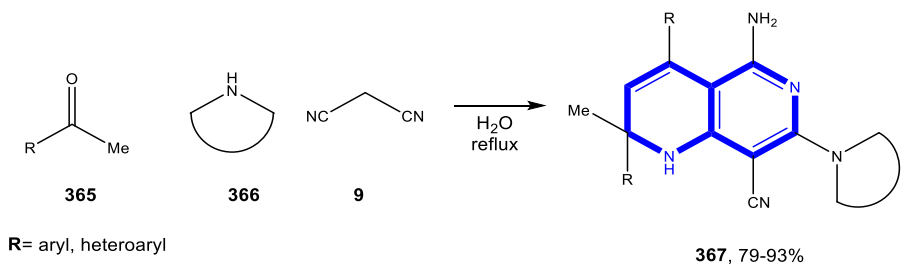

Scheme 111. Mukhopadhyay et al. (2011).

Paul et al., designed sequential ring closure methodologies to synthesize bisquinoline derivatives. The process involved a double Friedlander reaction in water between 2-[(2-oxo-2-arylethyl) sulfanyl]-1-aryl-1-ethanones/2-[(2-oxo-2-arylethyl)disulfanyl]-1-aryl-1-ethanones and 2-aminobenzophenone with p-toluenesulfonic acid as catalyst (Scheme 112) [146].
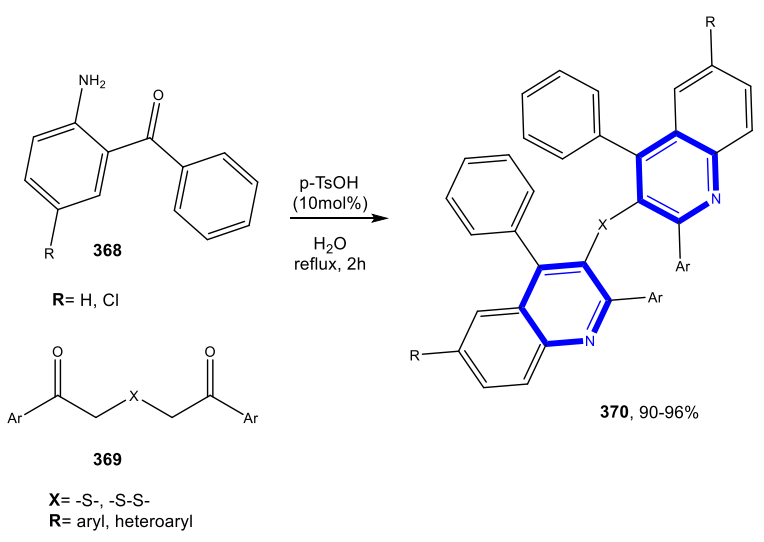

Scheme 112. Paul et al. (2011).

Das et al., adopted a three-component reaction in water to achieve quinolone derivatives. A key step in the synthesis was the reaction system between nitroarenes, aldehydes, and phenylacetylene in the presence of indium in dilute $\mathrm{HCl}$. This conversion involved reduction of the nitroarenes to anilines followed by coupling of the anilines, aldehydes, and phenylacetylene, concluding with cyclization of the resulting species, and dehydrogenation of the cyclic intermediates (Scheme 113) [147].

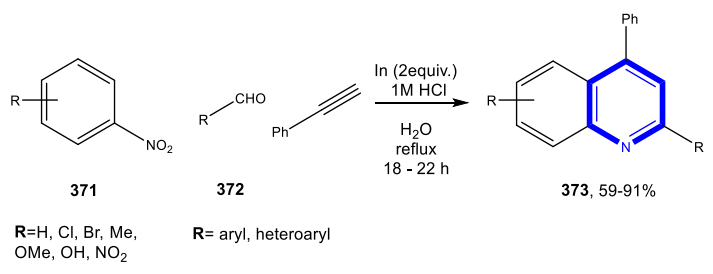

Scheme 113. Das et al. (2011).

Madhav et al., studied the synthesis of quinoline-2,3-dicarboxylates using water as solvent in neutral conditions. The optimized conditions were found with $\beta$-cyclodextrin as catalyst at low temperature for a short time (Scheme 114) [148]. 
<smiles>NC(=O)c1cc(Br)c(Br)cc1N</smiles>

374

$\mathrm{R}=\mathrm{H}, \mathrm{Me}, \mathrm{Ph}, \mathrm{Cl}-\mathrm{Ph}$ $\mathbf{R}=\mathrm{H}, \mathrm{Br}, \mathrm{OMe}, \mathrm{O}-\mathrm{CH}_{2}-\mathrm{O}$
$\mathbf{R}=\mathrm{H}, \mathrm{Cl}, \mathrm{OMe}, \mathrm{O}-\mathrm{CH}_{2}-\mathrm{O}$<smiles>O=C(O)C#CC(=O)O</smiles>

23

$R=\mathrm{Me}, \mathrm{Et}$

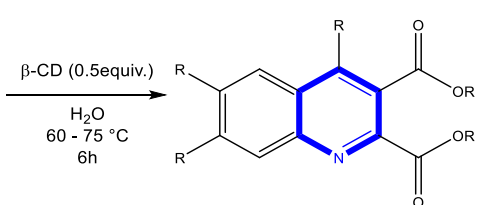

$375,78-94 \%$

Scheme 114. Madhav et al. (2010).

Wu et al., synthesized Benzo[h]pyrazolo[3,4- $b$ ]quinolines from 3-methyl-1-phenyl-1H-pyrazol5-amine, aldehydes and 2-hydroxynaphthalene-1,4-dione in water. This one-pot condensation strategy was catalyzed by diammonium hydrogen phosphate (Scheme 115) [149].

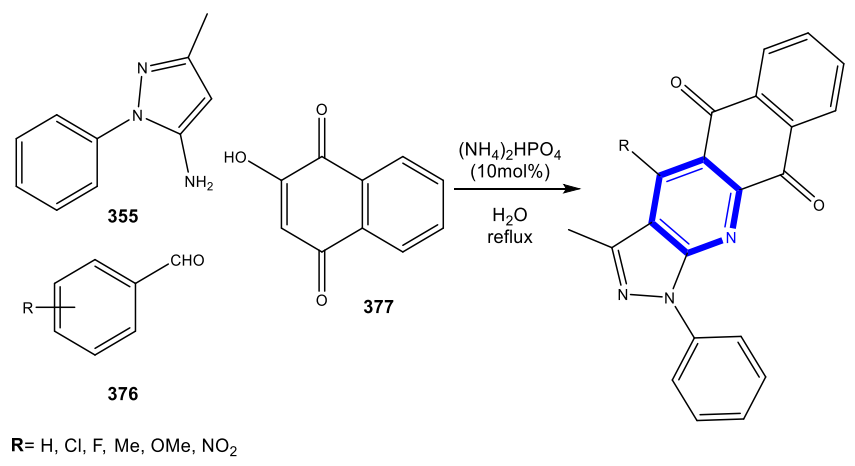

$378,85-93 \%$

Scheme 115. Wu et al. (2010).

Akbari et al., adopted a one-pot Friedlander reaction for a domino approach to quinoline synthesis in aqueous medium. The series were accomplished from 2 -aminoaryl ketones and $\beta$-ketoesters/ketones using the catalytic system of $\mathrm{SO}_{3} \mathrm{H}$-functionalized ionic liquid. With this strategy, it was possible to recover and reuse the catalytic system (Scheme 116) [150].<smiles>Nc1ccc(Br)cc1C(=O)O</smiles>

379

$\mathrm{R}=\mathrm{H}, \mathrm{Cl}$ $\mathbf{R}=\mathrm{Me}, \mathrm{Ph}$

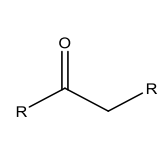

380

$\mathbf{R}=$ aryl, heteroaryl

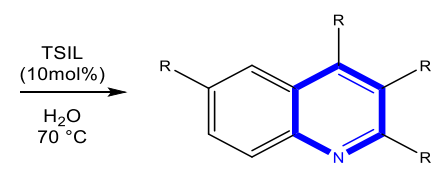

$381,85-98 \%$

Scheme 116. Akbari et al. (2010).

Shi and Yao synthesized furopyridine derivatives by three-component reaction of an aldehyde, with tetronic acid and 6-amino-1,3-dimethyl-pyrimidine-2,4-dione in aqueous media without using a catalyst. The team suggested that the reaction proceeded via three key steps: condensation, addition, and cyclization (Scheme 117) [151]. 


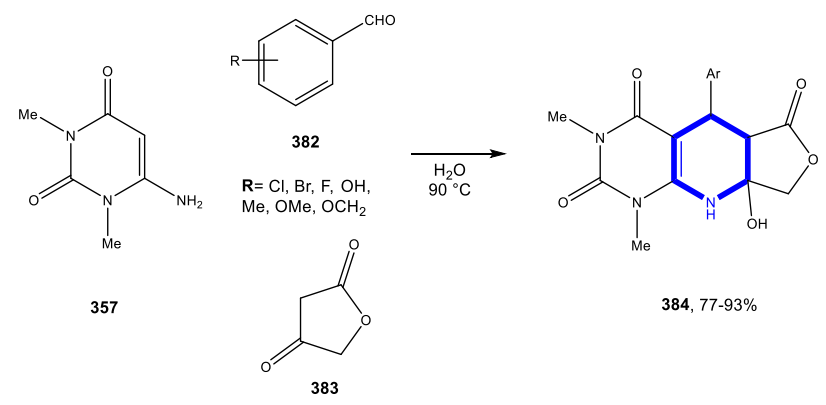

Scheme 117. Shi and Yao (2009).

Shi et al., attained furo[3,4-e]pyrazolo[3,4-b]pyridines via microwave irradiation without any catalyst. The group successfully performed a three-component reaction using aldehydes, 3-methyl1-phenyl-1H-pyrazol-5-amine and tetronic acid in water (Scheme 118) [152].

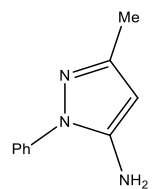

355

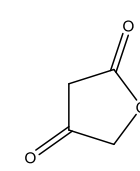

383

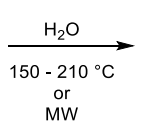

MW

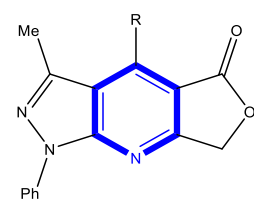

Classical heating $385 a, 68-77 \%$

Microwave irradiation 385b, $94-98 \%$

$\mathbf{R}=$ aryl, heteroaryl

Scheme 118. Shi et al. (2008).

In the same year, Shi et al., described the reaction of aromatic aldehydes, 6-aminoquinoline and either tetronic acid or 1,3-indanedione in water using similar conditions for the preparation of furo[3,4-b][4,7]phenanthroline and indeno[2,1-b][4,7]phenanthroline derivatives (Scheme 119) [153].

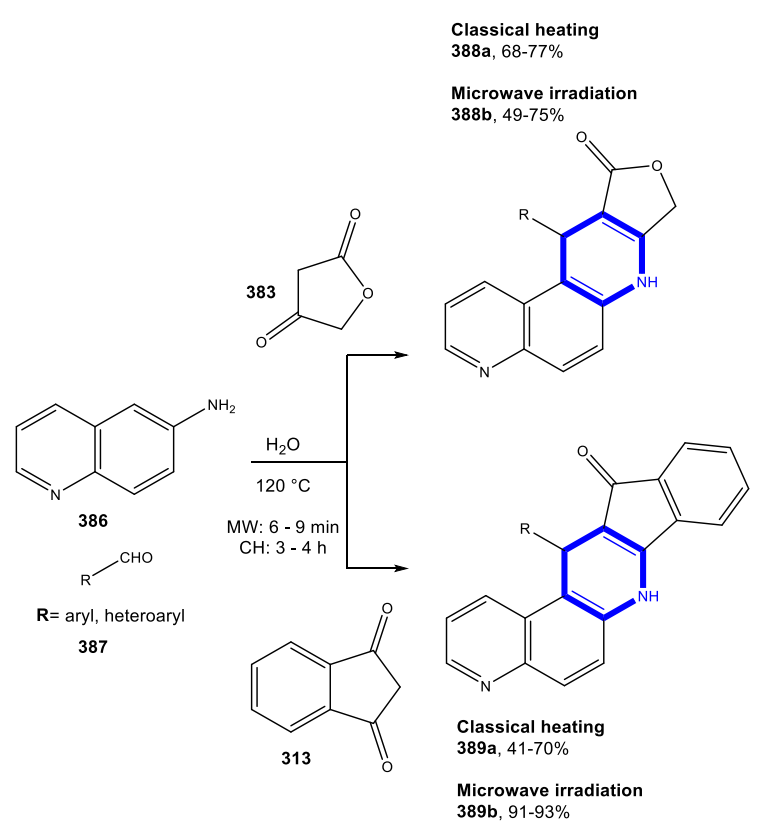

Scheme 119. Shi et al. (2008).

In 2008, Shi et al., also presented the synthesis of pyrazolo $\left[4^{\prime}, 3^{\prime}: 5,6\right]$ pyrido[2,3- $\left.d\right]$ pyrimidine derivatives. The protocol was assisted by p-toluene sulfonic acid in water under microwave heating (Scheme 120) [154]. 


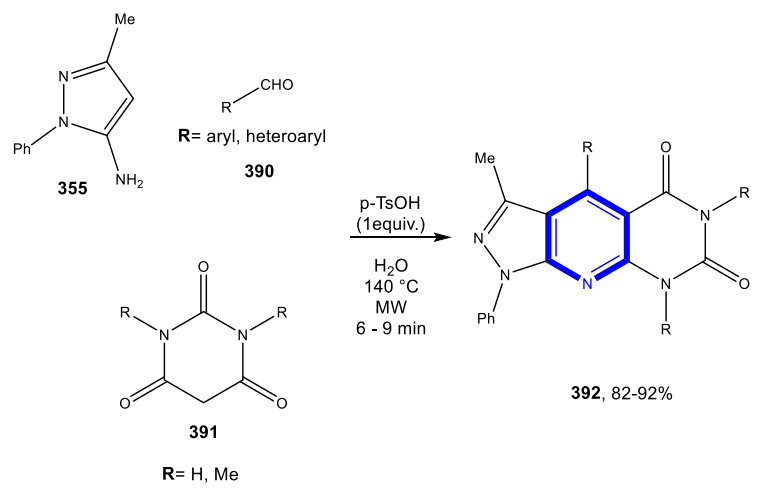

Scheme 120. Shi et al. (2008).

Additionally, the same team, Shi et al., reported a multi-component catalyst-free reaction of aldehyde, 3-methyl-1-phenyl-1H-pyrazol-5-amine and 1,3-indanedione in water under microwave irradiation to successfully achieve a library of indeno[2,1-e]pyrazolo[5,4-b]pyridines (Scheme 121) [155].

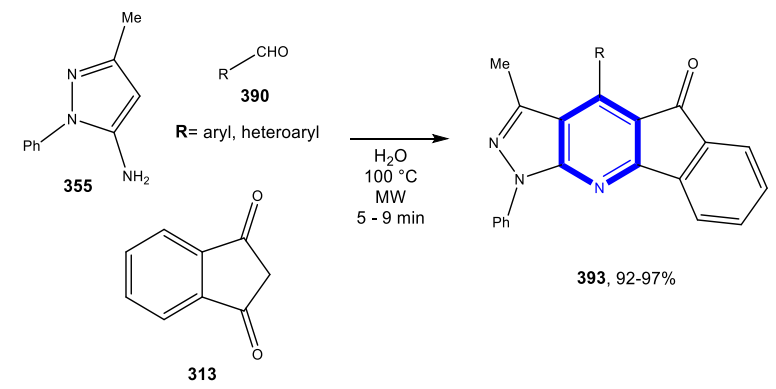

Scheme 121. Shi et al. (2008).

Kumar and Maurya prepared polyhydroquinolines using an unsymmetric Hantzsch catalyzed method. The library was obtained at room temperature from aldehydes, dimedones, acetoacetate ester or acetyl acetone, and ammonium acetate in good yields (Scheme 122) [156].

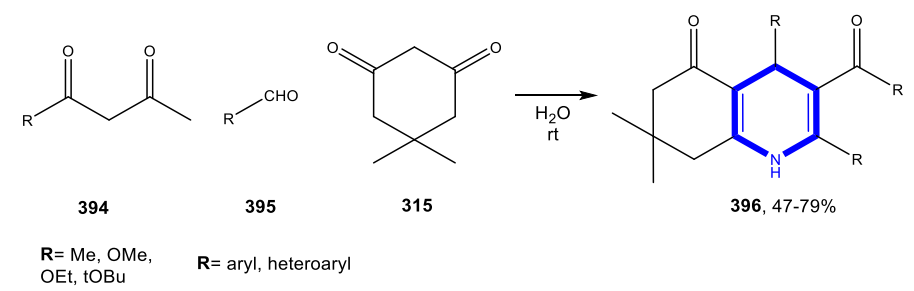

Scheme 122. Kumar and Maurya (2007).

As described above, in 2006, Barnard et al., achieved N-heterocyclizations with water as the solvent. The team was also able to prepare azacycloalkane in good yields (Scheme 123) [52].

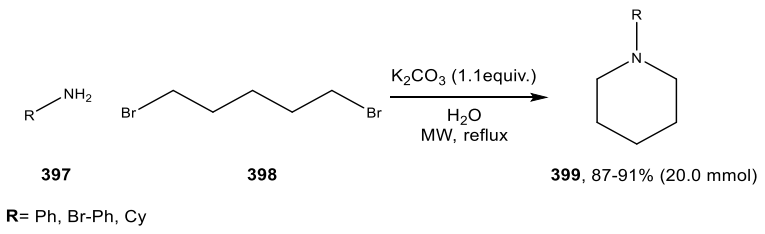

Scheme 123. Barnard et al. (2006). 
Wang et al., studied the Friedlander reaction of 2-aminoarylketone or 2-aminoarylaldehyde with carbonyl compounds in the presence of hydrochloric acid using water as the solvent. The methodology proved to be a highly efficient synthesis of quinolines (Scheme 124) [157].

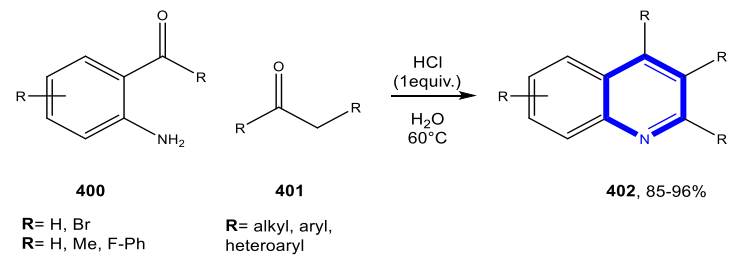

Scheme 124. Wang et al. (2006).

Tu et al., published a three-component approach to synthesize poly-substituted indeno[1,2-b] quinolines. The method involved reactions between aldehydes, 1,3-indanedione, enaminones and $\mathrm{p}$-toluene sulfonic acid ( $\mathrm{p}-\mathrm{TsOH})$ as catalyst. The reactions were performed at high-temperature, using water under microwave irradiation (Scheme 125) [158].

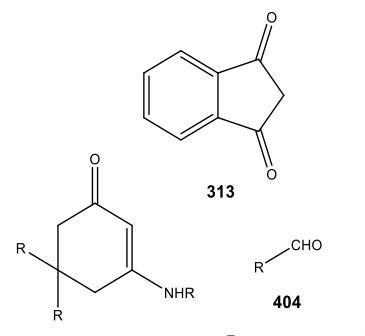

403

$\mathrm{R}=\mathrm{H}, \mathrm{Me}$

$\mathrm{R}=\mathrm{H}, \mathrm{Me}, \mathrm{Ph}, \mathrm{Me}-\mathrm{Ph}$,

$\mathbf{R}=$ aryl, heteroary

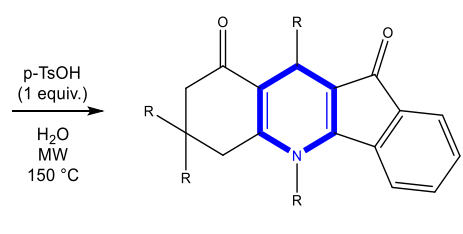

$405,86-94 \%$

Scheme 125. Tu et al. (2006).

Loncaric et al., attained dihydro-4-pyridones in high yields using AgOTf as catalyst. The reaction protocol was carried out by Aza-Diels-Alder reactions of Danishefsky's diene with imines in water. Additionally, the team accomplished silver triflate-catalyzed three-component reactions starting from aldehydes, amines, and Danishefsky's diene (Scheme 126) [159].

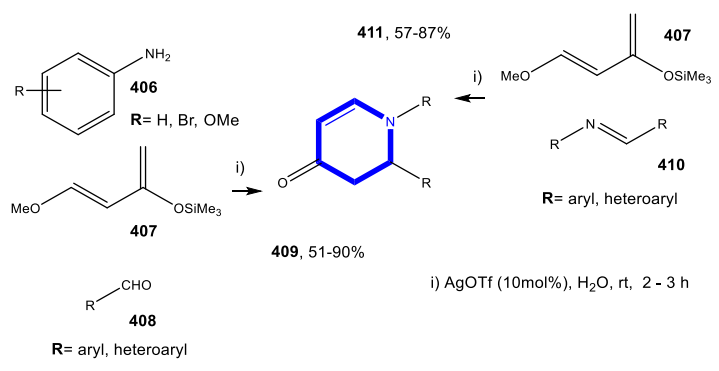

Scheme 126. Loncaric et al. (2003).

\subsubsection{Reactions in PEG}

Zhang et al., monitored a one-pot tandem aldol condensation/aza-addition reaction. Several pyrrolo[3,2-c] pyridinone products were successfully synthesized by heating 2-methyl-3-carbamoylpyrroles and aldehydes using PEG as solvent to afford 2,3,6,7-tetrahydro- $1 H$-pyrrolo[3,2-c]pyridin-4(5H)-ones in high yields (Scheme 127) [160]. 


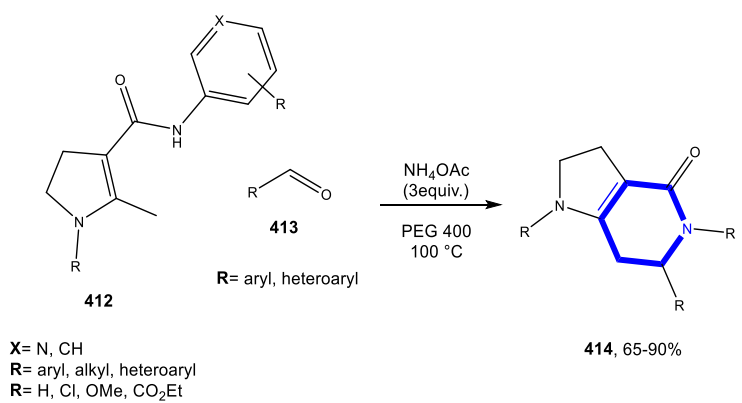

Scheme 127. Zhang et al. (2017).

Maryamabadi et al., prepared spiro-dihydropyridines by one-pot multi-component reaction of isatin or acenaphthoquinone derivatives with malononitrile and $N, N, 0$-substituted-2-nitroethene-1, 1-diamines in PEG 400 under catalyst-free conditions (Scheme 128) [161].

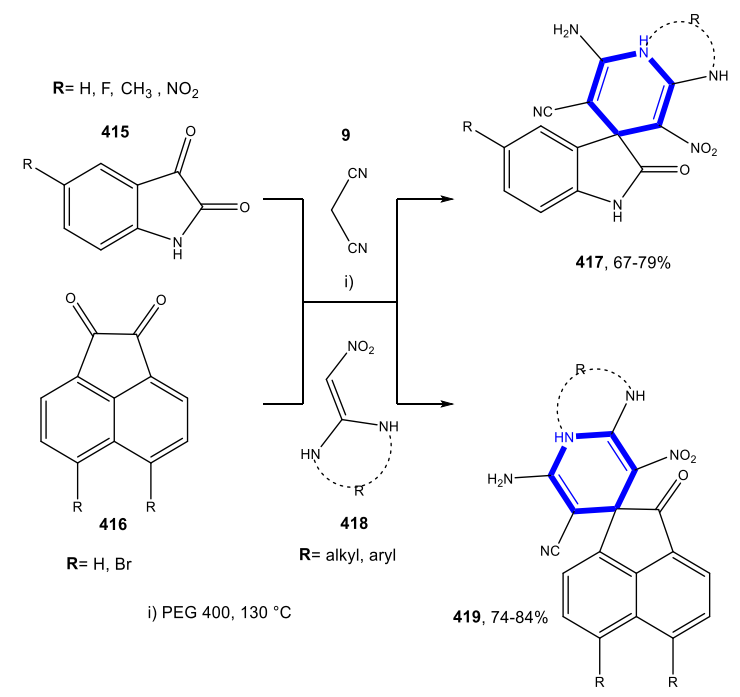

Scheme 128. Maryamabadi et al. (2016).

Using the strategy mentioned by us earlier, Nagaraju et al., also generated the construction of the pyridine ring on synthesis of thiazoloquinolines (Scheme 129) [107].

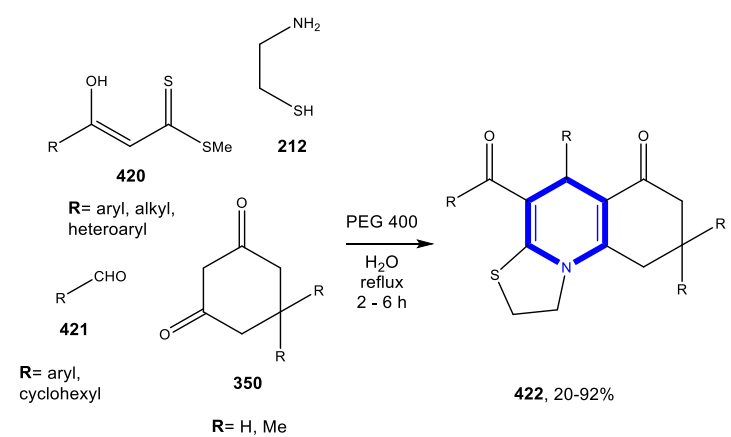

Scheme 129. Nagaraju et al. (2015).

Pal et al., described a synthesis of functionalized dihydropyridines via multicomponent reactions, at room temperature under catalyst free conditions in good yields. This methodology involved the reaction between different aromatic aldehydes, anilines, malononitrile derivatives, and dimethyl acetylenedicarboxylate (Scheme 130) [162]. 

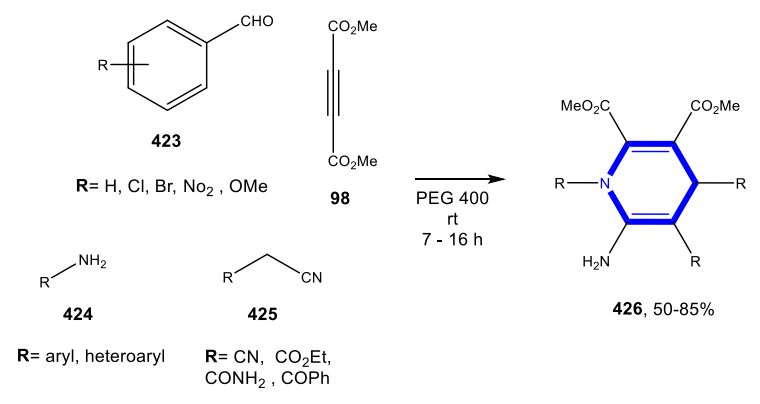

Scheme 130. Pal et al. (2013).

Paidepala et al., reported the successful construction of several polyhydroquinolines by performing a four-component coupling of aldehydes, dimedone, ethylacetoacetate, and ammonium acetate using polyethylene glycol as solvent at room temperature for a short time (Scheme 131) [163].

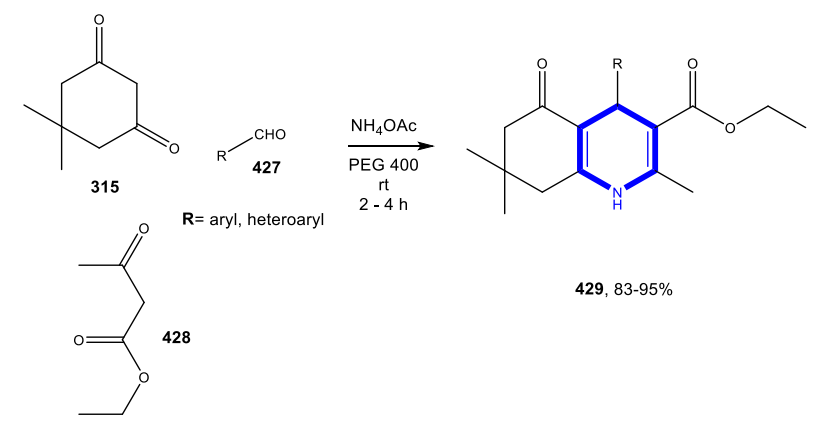

Scheme 131. Paidepala et al. (2014).

Wu et al., obtained various substituted quinolines by performing an indirect Friedländer reaction between the corresponding aminoalcohols and ketones using PEG 400 as reaction medium in the presence of a base, without any transition-metal catalyst (Scheme 132) [164].

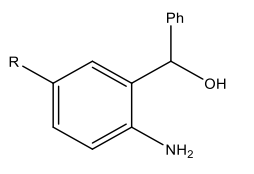

430

$\mathbf{R}=\mathrm{H}, \mathrm{Cl}$

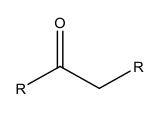

431

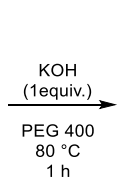

$1 \mathrm{~h}$

$\mathbf{R}=\mathrm{H}, \mathrm{Me}, \mathrm{Ph}$

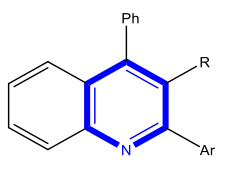

432, $81-92 \%$

Scheme 132. Wu et al. (2012).

Karnakar et al., generated pyrazolo[3,4-b]quinolines in good yields through a one-pot three-component protocol. After optimizing the experimental conditions, 3,4,5-trimethoxy benzaldehyde, 5,5-dimethyl-1,3-cyclohexanedione, and 5-amino-3-methyl-1-phenyl-pyrazole were reacted in the presence of recyclable polyethylene glycol PEG 400, resulting in the formation of the desired pyrazolo[3,4-b] quinoline derivatives (Scheme 133) [165]. 


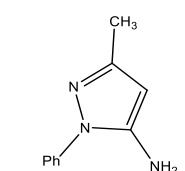

355

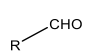

433<smiles>CC1(C)CC(=O)CC(=O)C1</smiles>

350

$\mathbf{R}=\mathrm{H}, \mathrm{Me}$

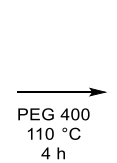

$4 \mathrm{~h}$

434, $75-92 \%$<smiles>Cc1c2c(nc3c1C(C)N=C3O)CC(C)(C)CC2=O</smiles>

Scheme 133. Karnakar et al. (2012).

Nalage et al., attained 4, 6-disubstituted 3-cyano-2-pyridones using PEG as solvent via a one-pot four-component approach. The series of compounds were synthesized from a catalyst-free reaction of ketones, aldehydes, ethyl cyanoacetate, and ammonium acetate (Scheme 134) [166].

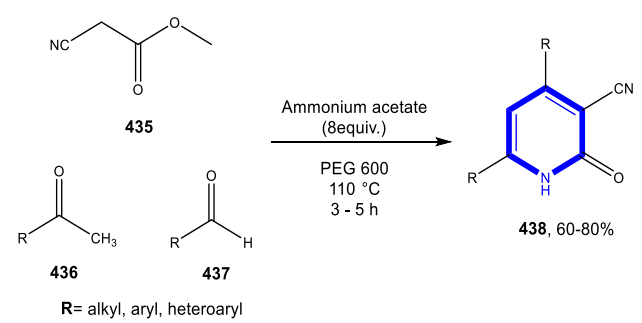

Scheme 134. Nalage et al. (2010).

Manvar et al., developed a three-component coupling between aldehyde, 1,3-diketone or ketoester and ammonia for the preparation of 1,4-dihydropyridines without using any catalyst. The protocol was performed at high temperature using microwave irradiation for 1 to 5 minutes (Scheme 135) [167].

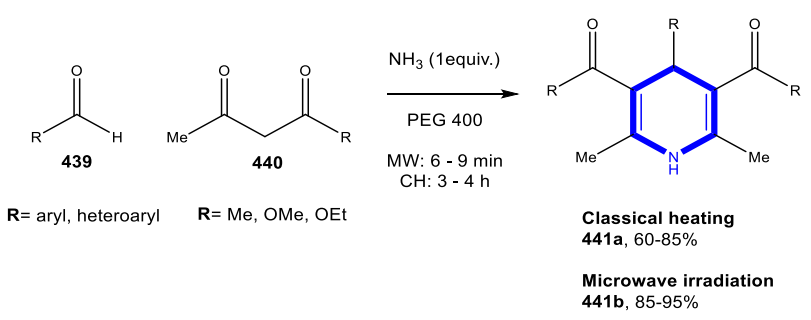

Scheme 135. Manvar et al. (2007).

Smith et al., studied the scope and limitations of a synthetic route to achieve amino-functionalised 2,4,6-triarylpyridines. The preparation of triaryl pyridine derivatives was obtained in good yields from p-aminoacetophenone and aryl aldehydes by treatment with ammonium acetate (Scheme 136) [168].

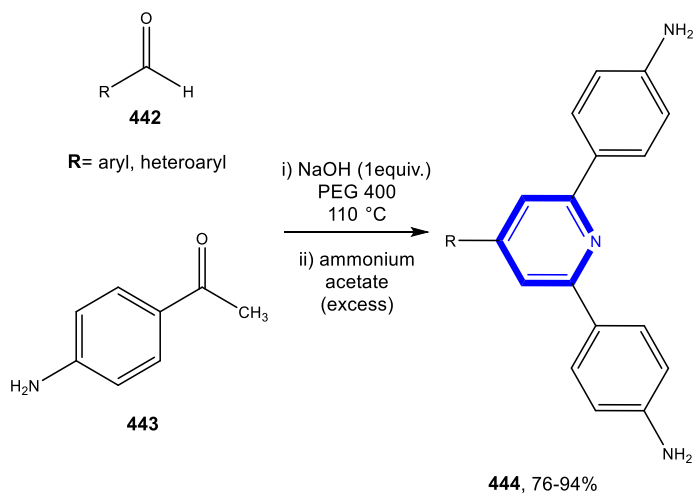

Scheme 136. Smith et al. (2007). 


\subsubsection{Reactions in Bio-Based Solvents}

In the article presented in 2012 by Yang et al., among the set of reactions that occurred in lactic acid, pyridine ring formation was contemplated. The construction of these compounds was achieved without the use of any catalyst through Friedländer annulation between 2-aminoacetophenone and 1,3-dicarbonyl compounds (Scheme 137) [58].

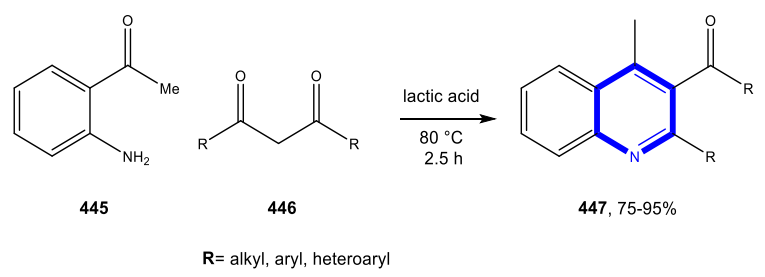

Scheme 137. Yang et al. (2012).

Paul and Das managed to obtain hydropyridyl derivatives using ethyl-L-lactate as solvent. The results were achieved from a one-pot three-component coupling of 4-aminocoumarin, aromatic aldehyde, and indane-1,3-dione or dimedone catalyzed by ( \pm )lactic acid (Scheme 138) [169].

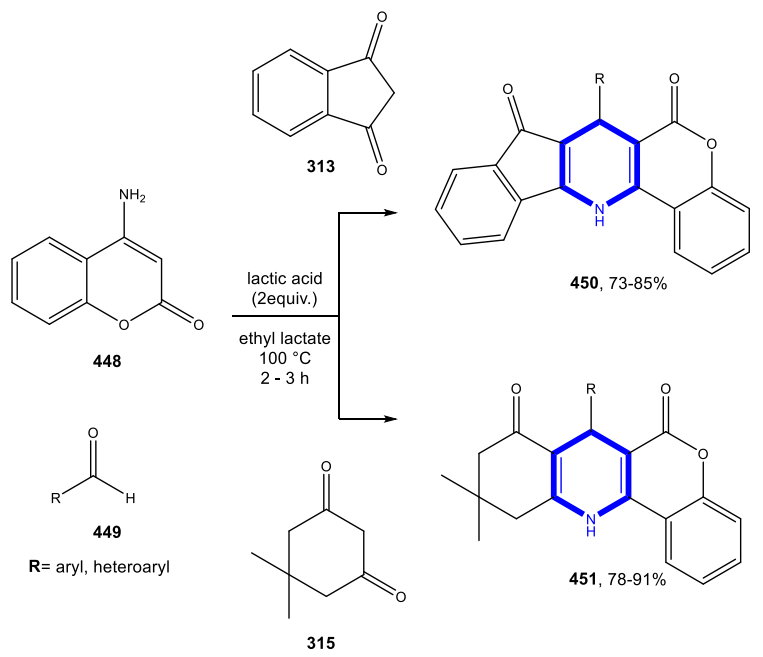

Scheme 138. Paul and Das (2012).

\subsection{Formation of the Pyridazine Ring}

Reactions in Water

Rimaz and Khalafy reported the synthesis of a series of alkyl 6-aryl-3-methylpyridazine -4-carboxylates in water. The reaction protocol involved a condensation reaction of $\beta$-ketoesters with arylglyoxals in the presence of hydrazine hydrate at room temperature (Scheme 139) [170].

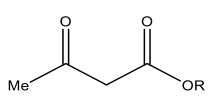

452

$\mathrm{R}=\mathrm{Me}, \mathrm{Et}, \mathrm{tBu}$

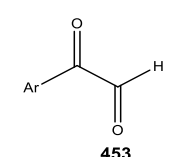

$\mathbf{R}=$ alkyl, aryl, heteroaryl

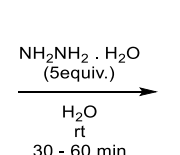

$30-60 \mathrm{~min}$

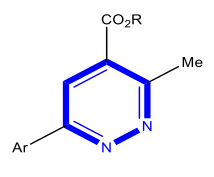

$454,70-97 \%$

Scheme 139. Rimaz and Khalafy (2010).

Earlier, the same authors, Rimaz et al., employed a one-pot three-component approach to prepare pyridazinones. The various 4 -cyano-3 $(2 H)$-pyridazinones were obtained by reaction of 
alkyl 2-cyanoacetates with aryl glyoxals in the presence of hydrazine hydrate in aqueous medium (Scheme 140) [171].

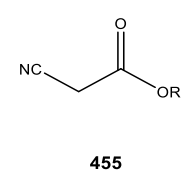

$R=M e, E t, n B u$<smiles>CC(=O)C(=O)OCC(=O)O</smiles>

456<smiles>Cc1cc(Cl)c(=O)[nH]n1</smiles>

457, $70-96 \%$

Scheme 140. Rimaz et al. (2010).

\subsection{Formation of the Pyrimidine Ring}

\subsubsection{Reactions in Water}

Yan et al., described the synthesis of alkyl 4-oxo-4H-pyrido[1,2-a]pyrimidine-2-carboxylate derivatives in water, using a catalyst-free approach with 2-aminopyridines and dialkyl ethylenedicarboxylates (Scheme 141) [172].

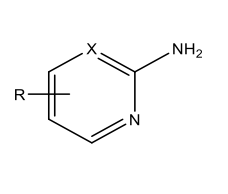

458

$\mathbf{X}=\mathrm{CH}, \mathrm{N}$

$\mathbf{R =} \mathrm{H}, \mathrm{Cl}, \mathrm{Br}, \mathrm{F}$

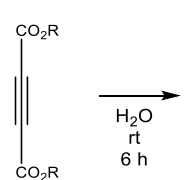

23

$\mathbf{R}=\mathrm{Me}, \mathrm{Et}$

Scheme 141. Yan et al. (2014).

Siddiqui demonstrated a catalyzed Biginelli reaction to access 3,4-dihydropyrimidin-2 (1H)-ones. The reaction involved a Lewis acid catalyst in water, bis[(L)prolinato- $N, O] Z n$ and stirred with methylene compounds, urea, and various aldehydes. The catalyst was recyclable up to five cycles (Scheme 142) [173].

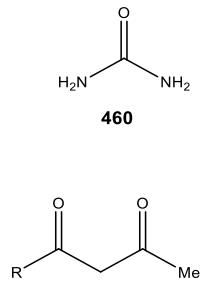

461

$\mathbf{R}=\mathrm{Me}, \mathrm{OEt}$

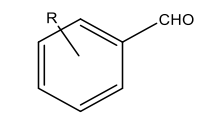

462

$\mathbf{R}=\mathrm{H}, \mathrm{Cl}, \mathrm{OH}, \mathrm{NO}_{2}$

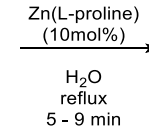

$5-9 \min$

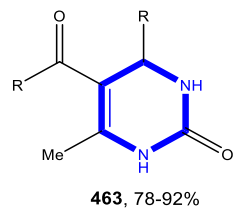

463, $78-92 \%$

Scheme 142. Siddiqui (2013).

Mukhopadhyay and Datta investigated an approach catalyzed by boric acid and glycerol in aqueous medium. The various substituted pyrimidinones were achieved from aromatic aldehydes, cyclopentanone and ureas (or thiourea). The team observed that aromatic aldehydes with electron-donating groups required a longer reaction time to produce the substituted pyrimidinones; aldehydes with stronger electron-withdrawing groups provided the products in greater yields compared to ortho-substituted ones; and thiourea required more time for completion of the reaction than urea (Scheme 143) [174]. 


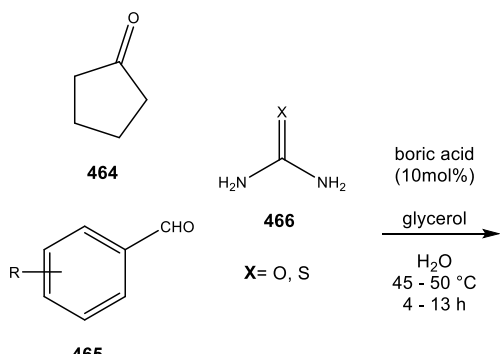

$\mathrm{R}=\mathrm{H}, \mathrm{Cl}, \mathrm{Br}, \mathrm{Me}, \mathrm{OMe}$, $\mathrm{CN}, \mathrm{NO}_{2}$

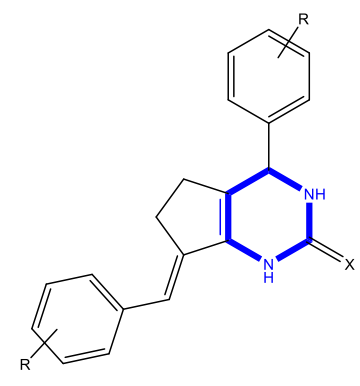

$467,62-86 \%$

Scheme 143. Mukhopadhyay and Datta (2013).

Ramesh et al., acquired a library of 2-phenyl-2,3-dihydroquinazolin-4(1H)-ones via a cyclodextrin catalyzed strategy in high yields. The synthetic route studied was based on the reaction between aldehydes and anthranilamides in water (Scheme 144) [175].<smiles>NC(=O)c1ccccc1N</smiles>

468

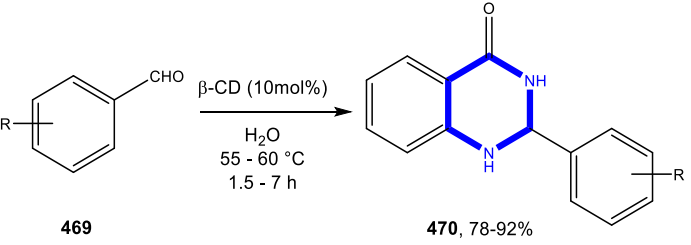

$\mathrm{R}=\mathrm{H}, \mathrm{Br}, \mathrm{F}, \mathrm{Me}, \mathrm{OMe}$ $\mathrm{NO}_{2}$, O-allyloxy

Scheme 144. Ramesh et al. (2012).

Li et al., carried out the preparation of 2-alkylthio-4-amino-5-cyano-6-aryl(alkyl)pyrimidines in water through three-component, one-pot synthesis. The methodology applied was the reaction of aldehydes with malononitrile and S-alkylisothiouronium salts at room temperature (Scheme 145) [176].

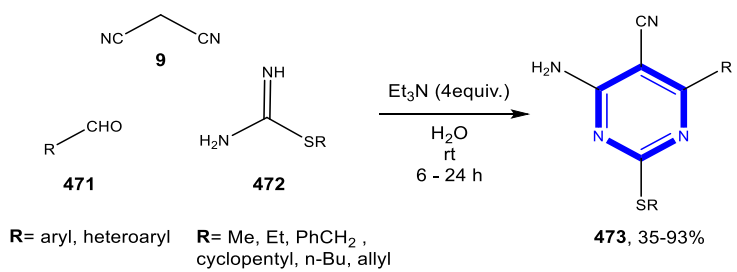

Scheme 145. Li et al. (2012).

Das et al., disclosed an efficient approach for the synthesis of tetrahydropyrimidines. The construction of these compounds was achieved using the same procedure as that described previously-except for the ratio applied to the starting material: in this case, the molar ratios of these substrates were 2:1:4 (Scheme 146) [51].

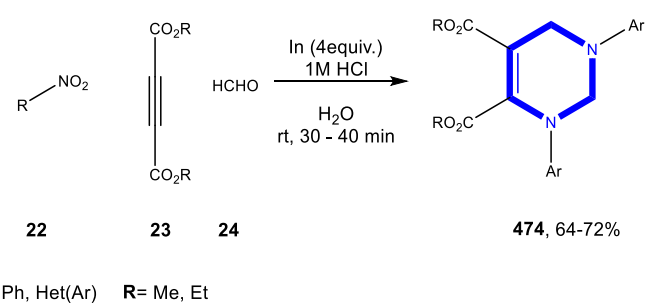

Scheme 146. Das et al. (2010). 
Zhang et al., were able to prepare quinazolinone derivatives via iron-catalyzed $\mathrm{C}-\mathrm{N}$ coupling using water as solvent. The reaction proceeded successfully from substituted 2-halobenzoic acids and amidines under microwave irradiation (Scheme 147) [177].

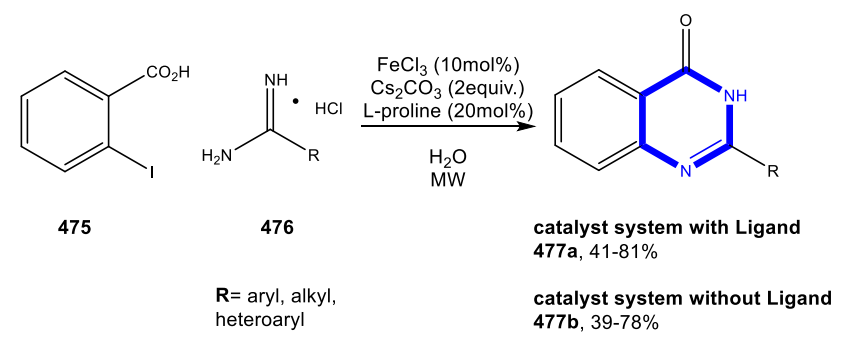

Scheme 147. Zhang et al. (2009).

$\mathrm{Xu}$ et al., managed a route to the construction of 3,4-Dihydropyrimidin-2(1H)-ones by Biginelli reaction. This procedure embraced a micellar system according to the Biginelli reaction using ketoester, urea, and an appropriate aromatic aldehyde in the presence of $\mathrm{CuCl}_{2} \cdot \mathrm{H}_{2} \mathrm{O}$ as catalyst. The reactions were successfully carried out in water without any organic solvent and gave high yields (Scheme 148) [178].

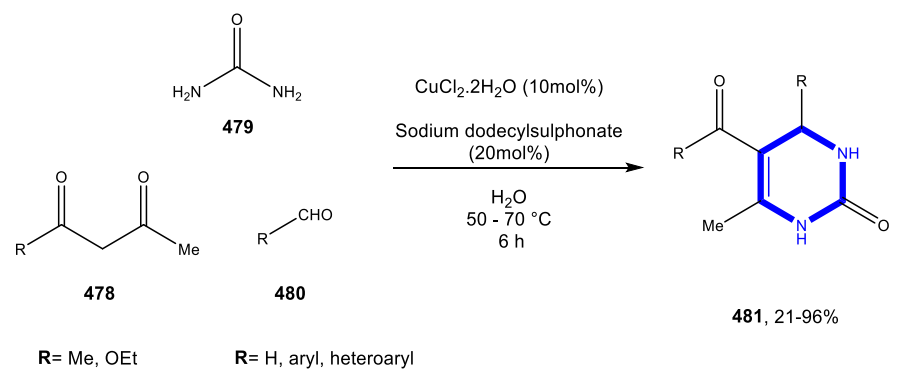

Scheme 148. Xu et al. (2008).

\subsubsection{Reactions in PEG}

Hese et al., implemented a one-pot three-component approach for the synthesis of pyrido[1,2-a]pyrimidine-3-carbonitrile derivatives. The construction of these compounds was achieved from the corresponding 2-aminopyridines, substituted aldehydes, malononitrile, and using bleaching earth clay as catalyst (Scheme 149) [179].

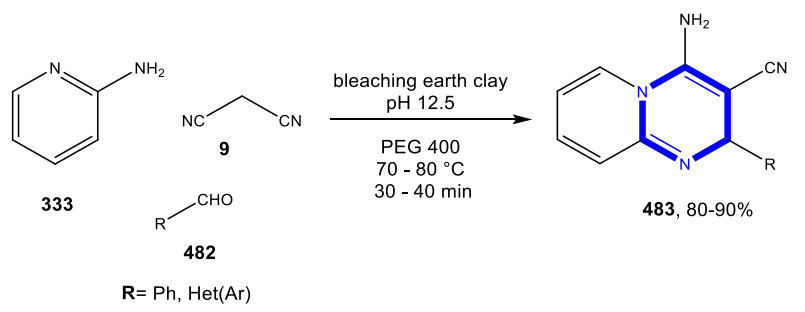

Scheme 149. Hese et al. (2015).

Konda succeeded in obtaining pyrazolo[1,5-a]pyrimidines in PEG as reaction medium from 4 -(4'-chloro-phenylazo)-5-aminopyrazole with $\alpha, \beta$-unsaturated carbonyl compounds. The advantages of this protocol are the simplicity of operation, the high yields of products, and the recyclability of the solvent (Scheme 150) [180]. 


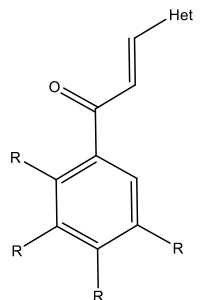

484

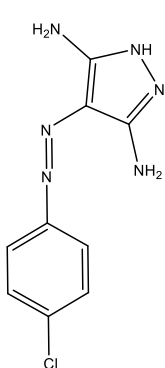

485

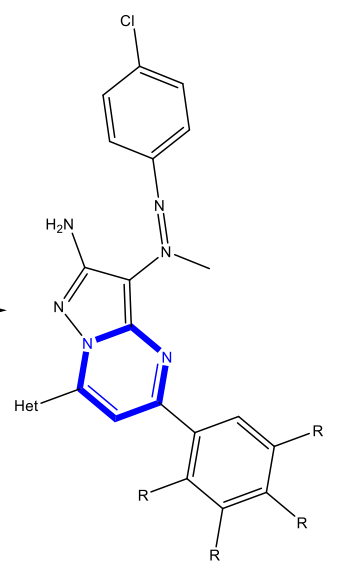

486, $86-92 \%$

$\mathbf{R}=\mathrm{H}, \mathrm{Cl}, \mathrm{Br}, \mathrm{OH}, \mathrm{I}, \mathrm{Me}$

Scheme 150. Konda (2014).

Using a tandem reaction mediated by PEG 600, Reddy et al., developed an approach to the synthesis of 2-methyl-3H-quinazoline-4-one by a thermal condensation of anthranilamide with acetic anhydride for a short time (Scheme 151) [181].

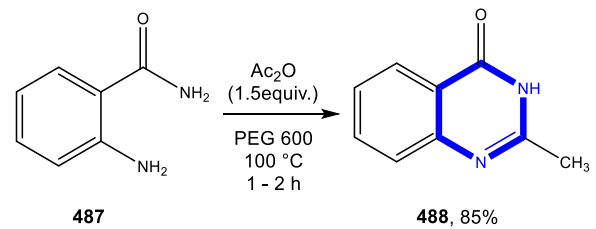

Scheme 151. Reddy et al. (2013).

Maddila et al., monitored the catalyst-free condensation reaction of aromatic aldehydes, ethyl propionate and guanidine hydrochloride in PEG to access successfully a series of 2-amino6-(substitutedphenyl)-5-methylpyrimidin-4-ol compounds (Scheme 152) [182].

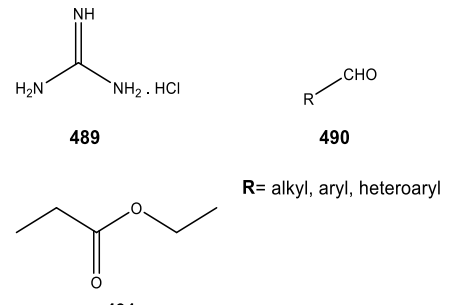

491

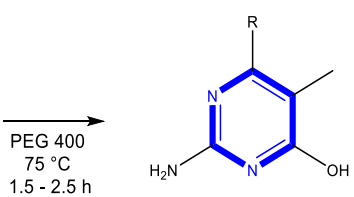

492, $85-92 \%$

Scheme 152. Maddila et al. (2012).

Mahnaz and Nikpour reported a one-pot synthesis of 2,4 $(1 H, 3 H)$-quinazolinediones by cyclization reaction of anthranilic acid derivatives with potassium cyanate and acetic acid in PEG. These results were achieved using short reaction times and without any catalyst (Scheme 153) [183]. 
<smiles>[2H]c1nc(N)c(C(=O)O)cc1Br</smiles>

493

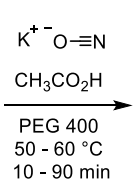

$10-90 \mathrm{~min}$<smiles>[2H]c1cc2c(=O)[nH]c(=O)[nH]c2nc1Br</smiles>

$494,78-95 \%$

$\mathbf{X}=\mathrm{CH}, \mathrm{CMe}, \mathrm{N}$ $\mathbf{R}=\mathrm{H}, \mathrm{Cl}, \mathrm{Br}, \mathrm{OH}$, $\mathrm{OMe}, \mathrm{CO}_{2} \mathrm{H}$

Scheme 153. Mahnaz and Nikpour (2012).

Kidwai et al., successfully adopted a one-pot process catalyzed by Amberlyst-15®in PEG 400 to accomplish a library of benzothiazolo-[2,3-b]-quinazolinones. For that, the team monitored and optimized a condensation of 2-aminobenzothiazole, cyclic $\beta$-diketones and various aldehydes. (Scheme 154) [184].

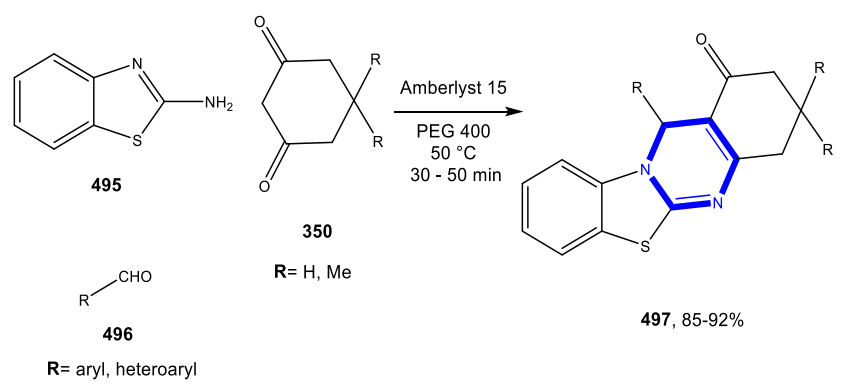

Scheme 154. Kidwai et al. (2012).

Through a one-pot catalyst-free reaction Nikpour et al., achieved the synthesis of 2-mercapto$4(3 H)$-quinazolinones in good yields using direct cyclo-condensation of anthranilic acid derivatives with thiourea in PEG (Scheme 155) [185].

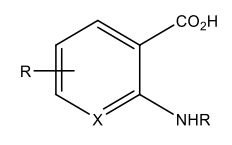

498

$\mathbf{X}=\mathrm{CH}, \mathrm{N}$

$\mathbf{R}=\mathrm{H}, \mathrm{Cl}, \mathrm{Br}, \mathrm{Me}$<smiles>NC(=S)S</smiles>

499 PEG 400
$140-150^{\circ} \mathrm{C}$ $140-6.5 \mathrm{~h}$
$4-150$

(2.6.5

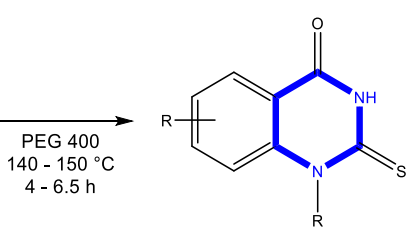

500, $30-80 \%$

Scheme 155. Nikpour et al. (2009).

Wang et al., employed a tandem Michael addition and intramolecular cyclization to prepare $5 H, 6 H-[1,3,4]$ thiadiazolo[1,2-a]pyrimidine-7-ones. The synthesis of several derivatives was achieved in the presence of $\mathrm{K}_{2} \mathrm{CO}_{3}$ as the catalyst on a reaction system between 2-amino-5-aryloxymethyl-1, 3,4-thiadiazoles and methyl acrylate (Scheme 156) [186]. 


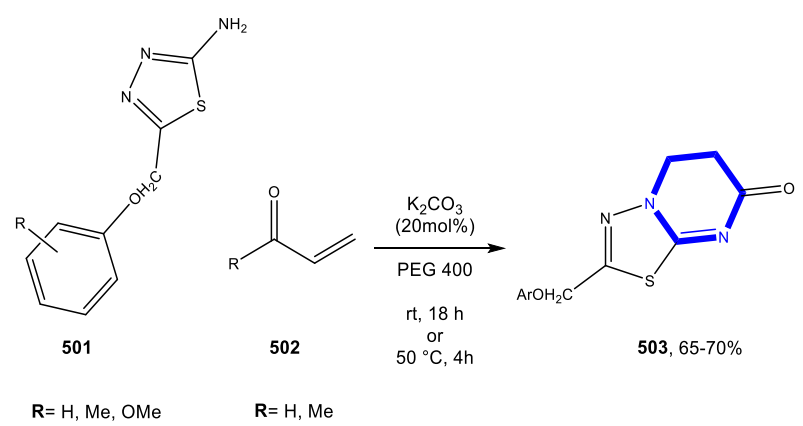

Scheme 156. Wang et al. (2007).

\subsubsection{Reactions in Bio-Based Solvents}

Khandelwal et al., published the preparation of spiroquinazolines using gluconic acid aqueous solution as bio-based catalytic solvent system. This procedure was based on the three-component reaction of isatoic anhydride, aromatic amines, and substituted isatins (Scheme 157) [187].

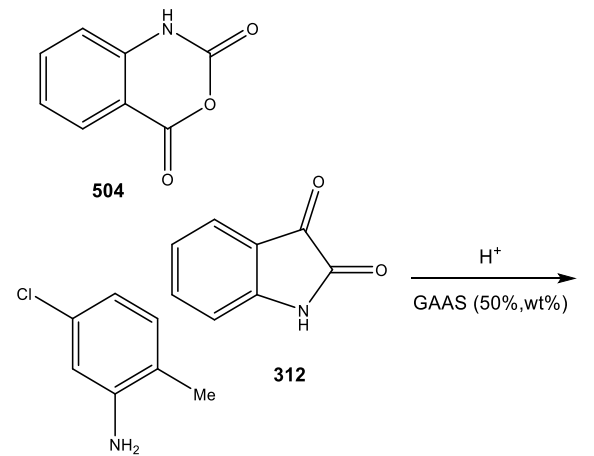

505

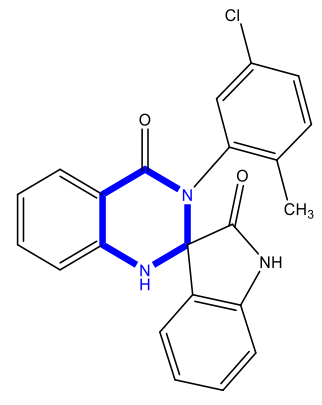

506

Scheme 157. Khandelwal et al. (2015).

The same group adopted a similar strategy to obtain 2,3-dihydroquinazolin-4(1H)-one derivatives. In a one-pot procedure and using three components (isatoic anhydride, anilines and aromatic aldehydes) the desired products were successfully achieved (Scheme 158) [188]

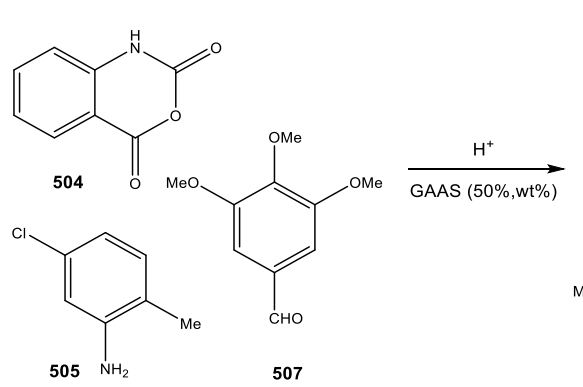

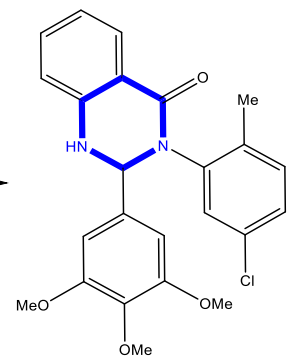

508

Scheme 158. Khandelwal et al. (2015).

The group of $\mathrm{Xu}$ adopted the Biginelli reaction for the preparation of dihydropyrimidinthione derivatives using ethyl lactate as solvent. A short and efficient route to obtain the library from aldehydes, thioureas, 1,3-dicarbonyl, and trimethylsilyl chloride as catalyst was achieved (Scheme 159) [189]. 


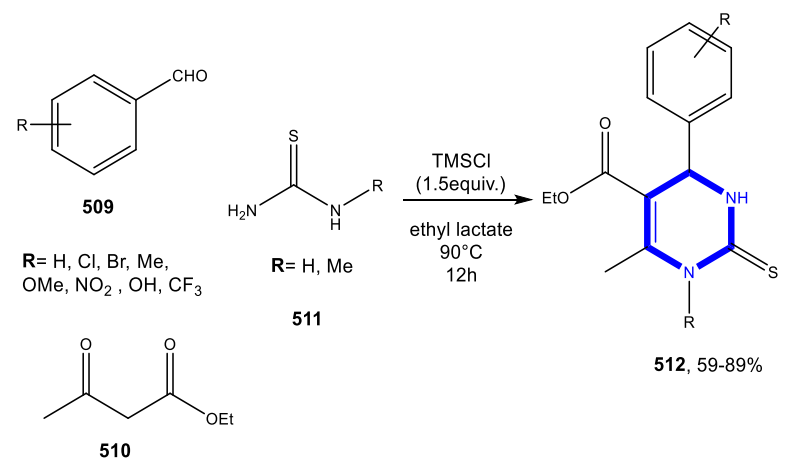

Scheme 159. Xu et al. (2014).

\subsection{Formation of the Pyrazine Ring}

\subsubsection{Reactions in Water}

Rashidi et al., performed the synthesis of quinoxalines using acidic supported ionic liquid $\left([\mathrm{PPy}] \mathrm{HSO}_{4} @ \mathrm{nSiO}_{2}\right)$ as catalyst, which was previously prepared. Optimization of the conditions was achieved and the final products resulted from 1-(2-aminophenyl)pyrrole with acetophenone derivatives in aqueous medium (Scheme 160) [190].

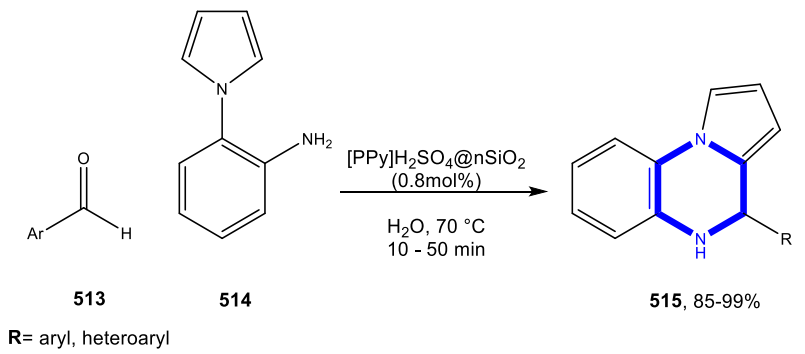

Scheme 160. Rashidi et al. (2018).

Liu et al., successfully employed a $\mathrm{B}_{2}(\mathrm{OH})_{4}$-mediated one-pot reaction for the preparation of tetrahydroquinoxalines. An approach was designed to obtain the library via the reaction between 2-amino(nitro)anilines and 1,2-dicarbonyl using water as solvent and hydrogen donor under metal-free conditions (Scheme 161) [191].

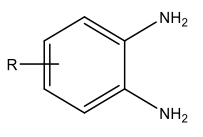

516

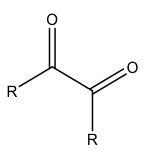

517

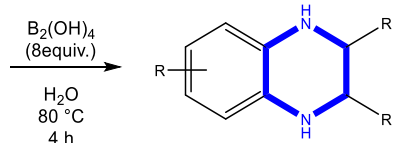

518, $62-85 \%$

$\mathbf{R}=\mathrm{H}, \mathrm{Cl}, \mathrm{Br}, \mathrm{F}$

$\mathbf{R}=\mathrm{H}, \mathrm{Me}, \mathrm{Et}, \mathrm{Ph}$

Scheme 161. Liu et al. (2017).

Afshin et al., adopted a one-pot four-component condensation between 2-hydroxynaphthalene-1, 4-dione, benzene-1,2-diamines, aromatic aldehyde and pyridinium ylide, to synthesize trans-1, 2-dihydrobenzo[ $a]$ furo[2,3-c]phenazines in good yields. The reaction catalyzed by theophylline was performed in water (Scheme 162) [192]. 


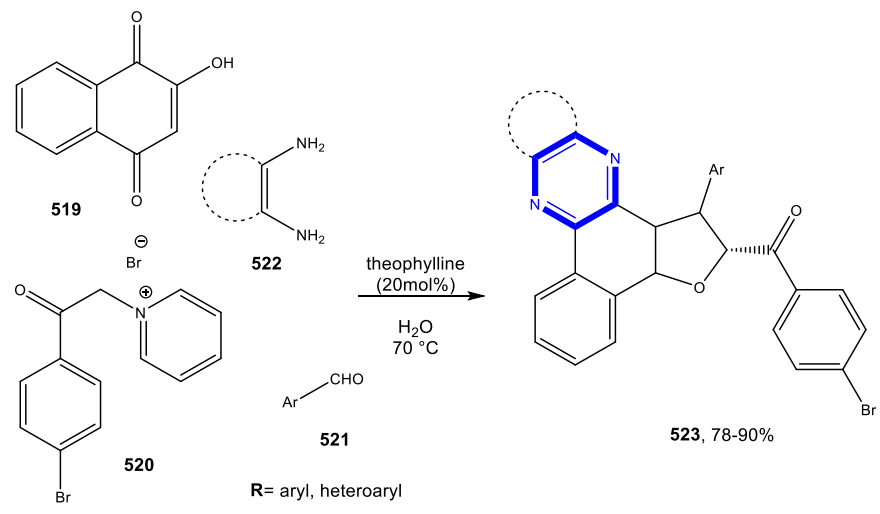

Scheme 162. Afshin et al. (2016).

Bardajee et al., attained 2,3-disubstituted quinoxaline and pyridopyrazine derivatives using an SBA-15-supported palladium catalyst containing $\mathrm{N}-\mathrm{O}$ chelating Schiff-base ligand. The series of derivatives containing the pyrazine ring were synthesized through cyclo-condensation of various 1,2-diamines and 1,2-diketones using a nanocatalyst complex in aqueous solution and water as solvent (Scheme 163) [193].

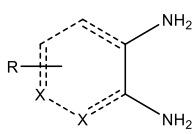

524

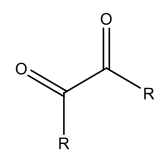

525

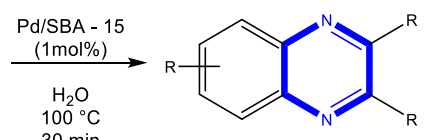

526, $94-99 \%$

$\mathbf{X}=\mathrm{CH}, \mathrm{N}$ $\mathrm{R}=\mathrm{H}, \mathrm{Me}, \mathrm{NO}_{2}$

$\mathbf{R}=$ aryl, heteroaryl

Scheme 163. Bardajee et al. (2013).

Alinezhad et al., generated quinoxaline derivatives in high yields from o-phenylenediamine and 1,2-diketone through a 2-Methylpyridinium trifluoromethanesulfonate ([2-MPyH]OTf) catalyzed reaction. The catalytic complex system was prepared previously and was reusable (Scheme 164) [194].

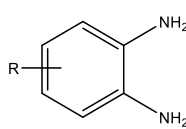

527<smiles>[R]C(=O)C([R])=O</smiles>

528<smiles></smiles>

529, $95-98 \%$

$\mathbf{R}=\mathrm{H}, \mathrm{Me}, \mathrm{NO}_{2} \quad \mathbf{R}=\mathrm{H}$, Aryl, Alkyl

Scheme 164. Alinezhad et al. (2013).

In 2013 Bardajee reported another strategy to achieve quinoxaline and pyrazine derivatives using water as solvent. In this case the reaction was catalyzed by Zirconium(IV) oxide chloride. Various pyridopyrazine and 2,3-disubstituted quinoxaline derivatives were readily prepared in high yields under green conditions by cyclo-condensation of the desired 1,2-diamine and 1,2-diketone (Scheme 165) [195]. 
<smiles>Nc1cccnc1N</smiles>

530<smiles>O=C(O)C(=O)O</smiles>

531

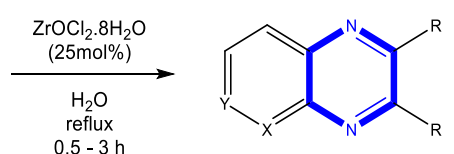

532, $85-98 \%$

$\mathbf{X}=\mathrm{CH}, \mathrm{N} \quad \mathbf{R}=$ aryl, aliphatic

Scheme 165. Bardajee (2013).

In a report published in 2012, Rustagi et al., demonstrated the versatility of the optimized methodology catalyzed by AgI applied to the formation of the pyrazine ring [88]. This work arose following the continuation of the study of these procedures by this team (Scheme 166) [90].

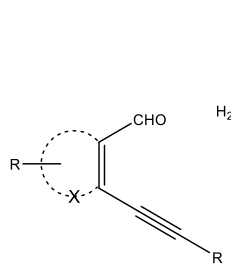

533

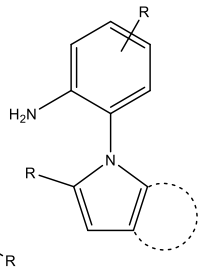

534

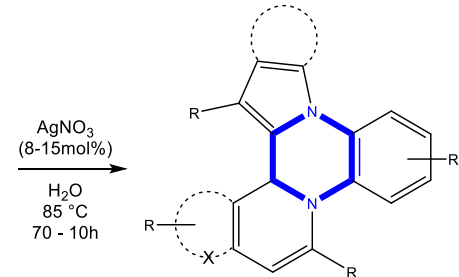

$535,45-91 \%$

$X=N, C H$ $\mathbf{R}=\mathrm{Ph}, \operatorname{Het}(\mathrm{Ar})$
aliphatic

$R=H, M e$

Scheme 166. Rustagi et al. (2011-2012).

Feng et al., performed a gold-catalyzed tandem reaction to access fused polycyclic indole derivatives. Synthesis of the final products was achieved from substituted 2-(1H-indol-1-yl) alkylamines and alkynoic acids in water under microwave irradiation by formation of one new $\mathrm{C}-\mathrm{C}$ bond and two new C-N bonds in a single operation (Scheme 167) [196].

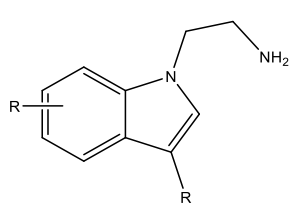

536

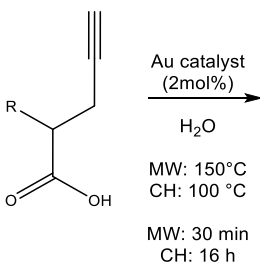

537

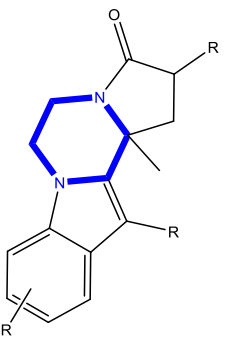

$538,62-93 \%$

$\mathbf{R}=\mathrm{H}, \mathrm{Cl}, \mathrm{Br}, \mathrm{FMe}, \quad \mathbf{R}=\mathrm{H}, \mathrm{Me}, \mathrm{Hex}$ $\mathrm{CN}, \mathrm{NO}_{2}$, Et, $\mathrm{OM}$ $\mathrm{R}=\mathrm{H}, \mathrm{Me}, \mathrm{CN}$

Scheme 167. Feng et al. (2012).

Zhang and collaborators disclosed a synthetic approach to obtain quinoxaline using water as solvent without any catalyst. The construction of benzoxazine was achieved using 539 as starting material (Scheme 168) [197]. 


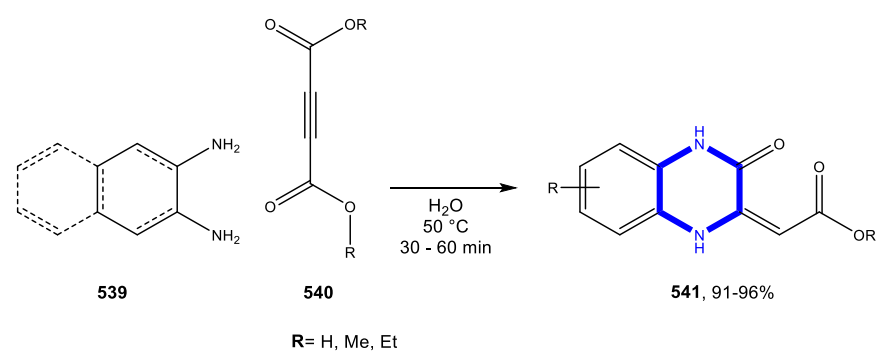

Scheme 168. Zhang et al. (2008).

Srinivas et al., accomplished the synthesis of quinoxaline derivatives in Water by reacting various 1,2-dicarbonyls and 1,2-diamines. All substrates produced the corresponding desired products in good yields using a reusable polyaniline catalyst or polyaniline and sodium laurylsulfate in the reaction system (Scheme 169) [198].<smiles>NC(=O)C(=O)O</smiles>

$\mathbf{R}=\mathrm{H}$, aryl, heteroaryl

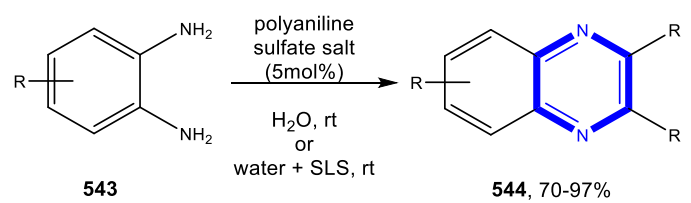

Scheme 169. Srinivas et al. (2008).

\subsubsection{Reactions in PEG}

Khurana et al., explored a one-pot two-step domino protocol for the preparation of benzo[a]-phenazine. The team monitored the reaction of 2-hydroxynaphthalene-1,4-dione, ortho-phenylenediamines, aromatic aldehydes and cyclic 1,3-dicarbonyl compounds with p-TSA as in PEG 400 (Scheme 170) [199].<smiles>Nc1cc(I)c(I)cc1N</smiles>

545
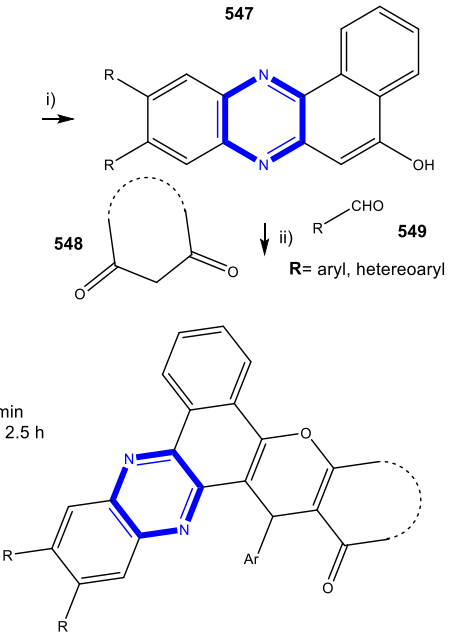

$550,82-92 \%$

Scheme 170. Khurana et al. (2012).

Huang et al., reported the preparation of pyrazines in the presence of silica sulfuric acid with good yields. The team was able to synthesize quinoxaline and pyrazine derivatives applying the condensation of 1,2-diamines with $\alpha$-hydroxyketones (Scheme 171) [200]. 


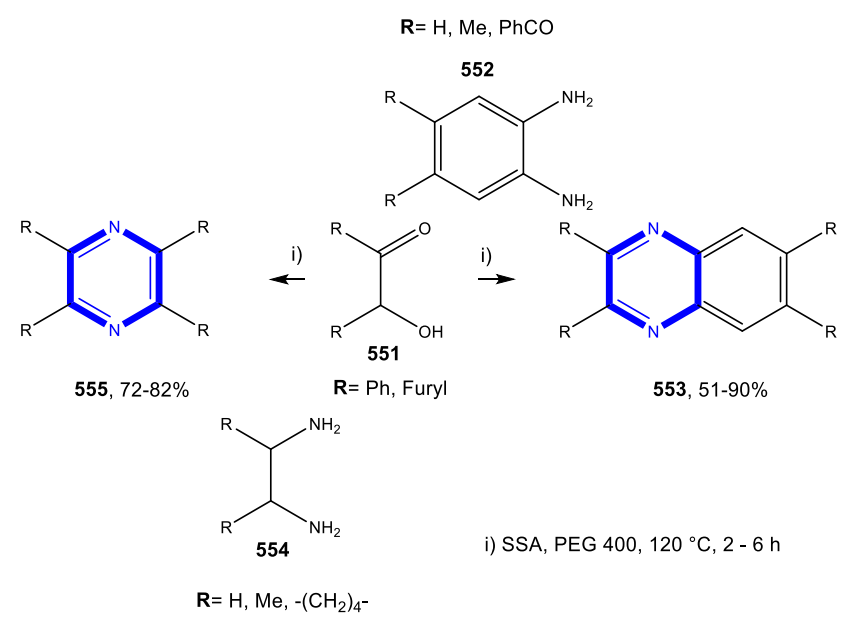

Scheme 171. Huang et al. (2011).

In 2010, Nagarapu et al., employed a protocol for the synthesis of quinoxaline derivatives from various orthophenylenediamines with ketones under catalyst-free conditions using PEG as recyclable medium (Scheme 172) [201].

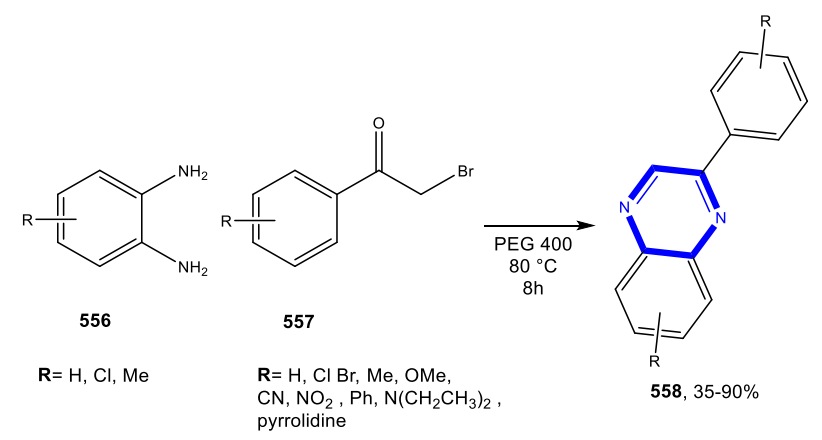

Scheme 172. Nagarapu et al. (2010).

\subsection{Formation of the Oxazine Ring}

\subsubsection{Reactions in Water}

Allahbakhsh and Hassanabadi developed a method for the formation of oxazine derivatives. The 4-aryl-7-methyl-3,4-dihydropyrano[3,4-e][1,3]oxazine-2,5-dione were synthesized through an acyclocondensation reaction between 4-hydroxy-6-methyl-2H-pyran-2-one, aromatic aldehydes and methyl carbamate using p-toluene sulfonic acid in aqueous media (Scheme 173) [202].

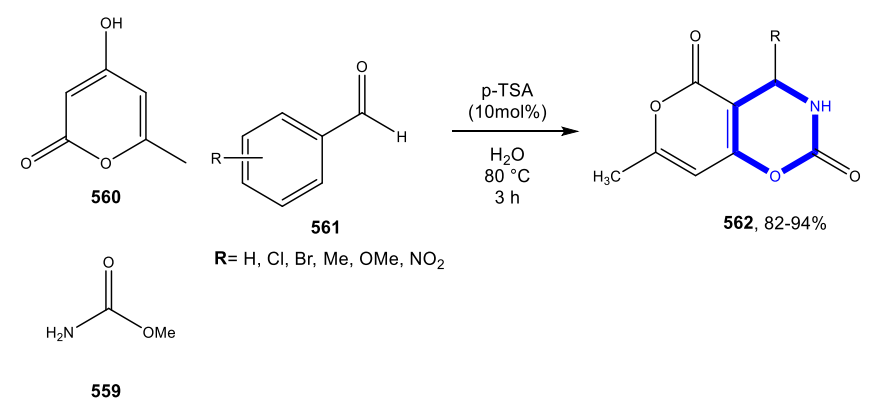

Scheme 173. Allahbakhsh and Hassanabadi (2016).

Faramarz et al., generated oxazine derivatives within 10 hours using a one-pot three-component approach. The reaction of benzoyl cyanide and activated acetylenic compounds was stirred in 
water at room temperature in the presence of $\mathrm{N}$-nucleophiles such as isoquinoline, quinoline, or N-methylimidazole (Scheme 174) [203].

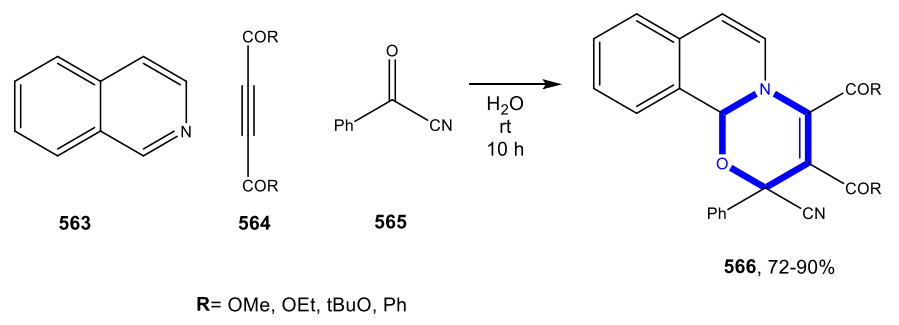

Scheme 174. Faramarz et al. (2013).

Paira et al., in a one-pot sequence using the ion exchange resin Amberlite IRA 402(OH) were able to synthesize fused tricyclic oxaza quinolinium salts. The authors demonstrated the plausible pathway of the reaction: it was presumed that the reaction was initiated by amberlite resin converting the hydroxyquinoline to the quinoxide ion and thus promoting it towards the organic layer (dibromoalkane) by acting as phase-transfer catalyst. Then, the resin bound quinoxide ion reacted with dibromoalkane to furnish the desired quinolinium through $O, N$-dialkylation. The methodology was also applied to obtain compounds 569 (Scheme 175) [204].

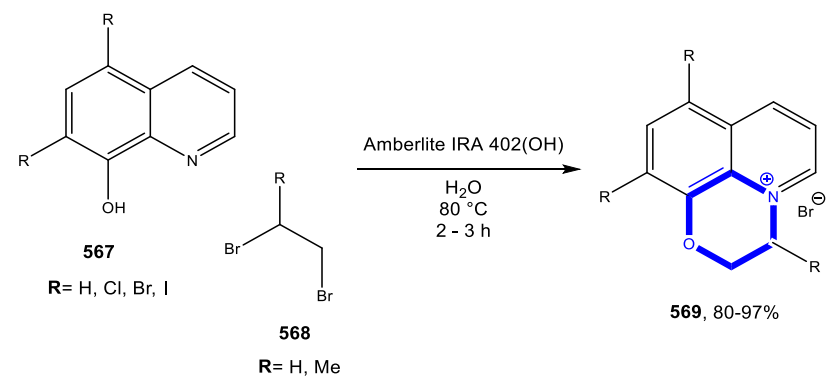

Scheme 175. Paira et al. (2010).

In 2008, Zhang et al., carried out a protocol for the synthesis of benzo-fused $\mathrm{N}, \mathrm{O}$-heterocycles in water without using any catalyst. The construction of benzoxazine was achieved using 2-aminophenol as starting material (Scheme 176) [197].

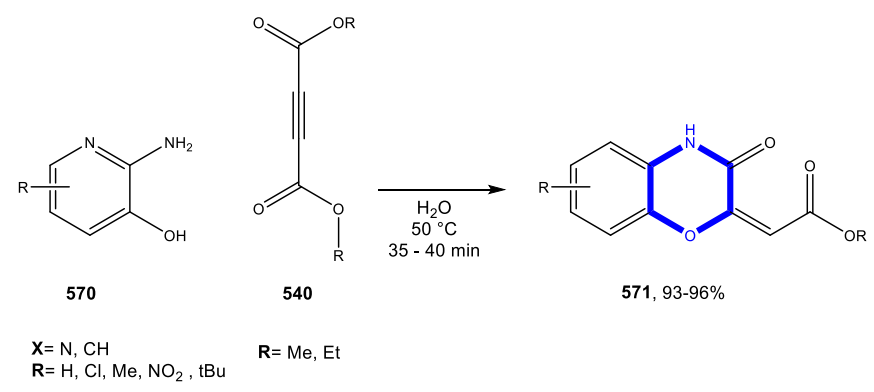

Scheme 176. Zhang et al. (2008).

\subsubsection{Reactions in PEG}

Shinde et al., achieved the synthesis of 1,3-oxazine derivatives in PEG medium. They reported access to the library by reaction between aromatic amines naphthol as well as naphthol and formaldehyde solution (Scheme 177) [205]. 


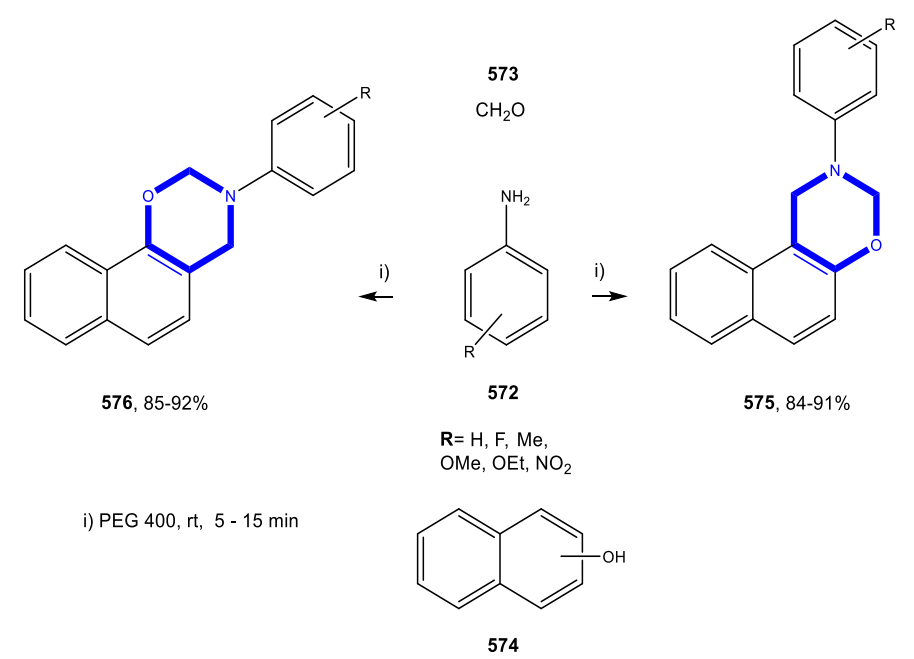

Scheme 177. Shinde et al. (2011).

\subsection{Formation of the Triazine and Thiadiazine Rings}

\section{Reactions in PEG}

Sridhar et al., monitored the reaction of isatin, and semicarbazide/thiosemicarbazide in PEG 400 under catalyst-free conditions. The team developed a tandem approach to obtain $5,9 b$-dihydro- $1 H$ $[1,2,4]$ triazino[5,6- $b$ ] indole-3-ols/thiols at 70-75 ${ }^{\circ} \mathrm{C}$ in 6-9 $\mathrm{h}$ in good yields (Scheme 178) [206].

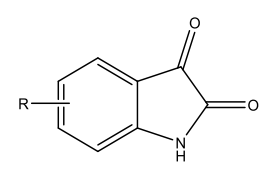

575
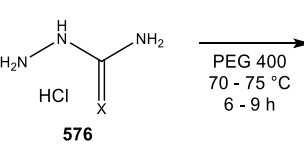
$70-75^{\circ} \mathrm{C}$

(20)<smiles>[R]c1ccc2c(c1)C1NN=C(N)N=C1N2</smiles>

$\mathrm{R}=\mathrm{H}, \mathrm{Cl}, \mathrm{Br}, \mathrm{F}, \mathrm{Me}, \mathrm{OMe}, \mathrm{NO}_{2}$
$\mathbf{X}=\mathrm{O}, \mathrm{S}$

Scheme 178. Sridhar et al. (2014).

As mentioned earlier in this review, in 2014, Reddy et al., reported the synthesis of triazolo-1,2, 4-benzothiadiazine-1,1-dioxides via a copper-catalyzed tandem cyclisation of ynamides in PEG 400. This approach also afforded the construction of the thiadiazine ring (Scheme 179) [102].

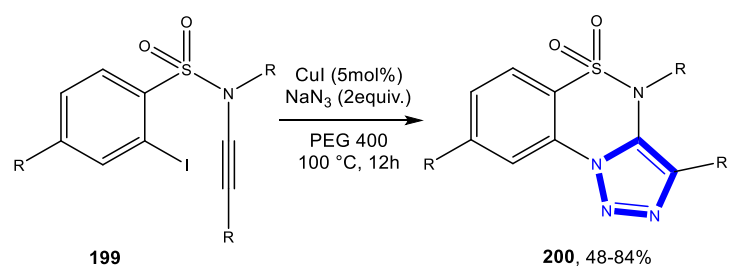

$\mathrm{R}=\mathrm{tBu}, \mathrm{Me}, \mathrm{OMe}, \mathrm{Ph}$ $\mathbf{R}=\operatorname{Het}(\mathrm{Ar})$

Scheme 179. Reddy et al. (2014). 


\section{Seven-Membered Aromatic Nitrogen Heterocycles}

\subsection{Formation of the Azepine Ring}

\subsubsection{Reactions in Water}

Prasad et al., employed a domino approach for the synthesis of azepines in water. They reported access to 2-benzazepine derivatives from the reaction of 4-chloro-3-formyl coumarin with benzyl amines under catalyst-free conditions in excellent yields (Scheme 180) [207].

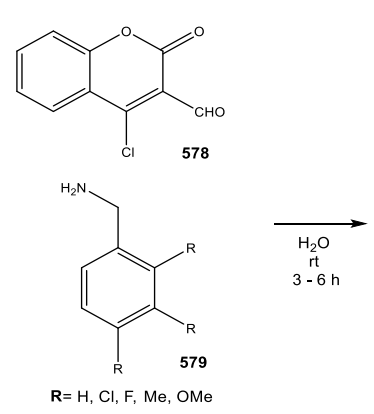

Scheme 180. Prasad et al. (2010).

\subsubsection{Reactions in PEG}

Mallepalli et al., developed a one-pot synthesis of N-substituted azepines without the use of any catalyst system. This protocol was conducted smoothly in PEG, and the desired products were obtained from the three-component condensation of 2,5-dimethoxyfuran with actylenedicarboxylate, and amines (Scheme 181) [208].

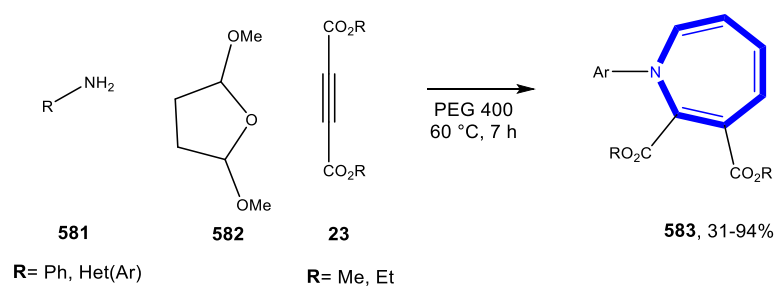

Scheme 181. Mallepalli et al. (2011).

\subsection{Formation of the Diazepine Ring}

Reactions in Water

The group of Alinezhad accomplished the synthesis of diazepines in aqueous medium using 2-methylpyridinium trifluoromethanesulfonate as catalyst. The 1,5-benzodiazepine were produced in good yields by reacting o-phenylenediamine with ketone. The methodology presented relevant advantages, such as short reaction time and reusable catalyst system (Scheme 182) [194].

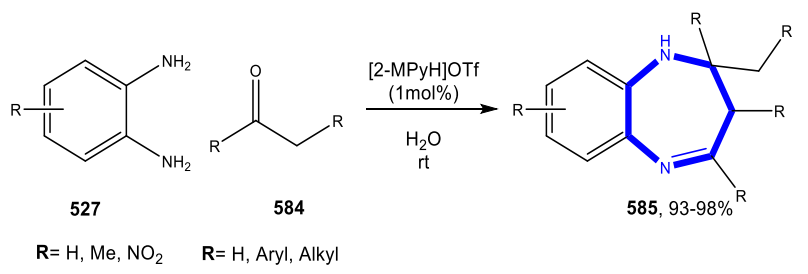

Scheme 182. Alinezhad et al. (2013). 
The Shaabani team carried out a one-pot pseudo-five-component synthesis of 4,5,6,7-tetrahydro1H-1,4-diazepine-5-carboxamide derivatives. The derivatives were successfully achieved from 2,3-diaminomaleonitrile, a cyclic or acyclic ketone, an isocyanide, and water in the presence of a catalytic amount of $p$-toluenesulfonic acid in aqueous medium at room temperature in high yields (Scheme 183) [209].

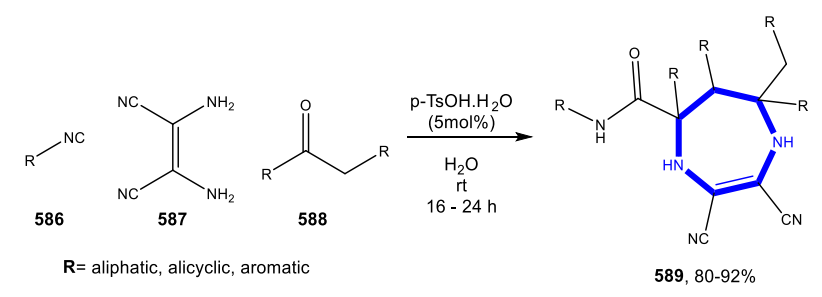

Scheme 183. Shaabani et al. (2008).

\subsection{Formation of the Thiazepine Ring}

\subsubsection{Reactions in Water}

Dandia et al., attempted and achieved a three-component reaction of aldehydes, 5-amino-3-methylpyrazole, and $\alpha$-mercaptocarboxylic acids in water under sonication to obtain pyrazolo[3,4-e][1,4]thiazepines. The authors noted that the formation of benzothiazepines instead of thiazolidinones was surprising. The chemoselectivity can be explained by the nucleophilic addition reaction of 5-amino-3-methylpyrazole on the carbonyl carbon atom of aldehyde to afford the Baylis-Hillman product; which subsequently reacted with $\alpha$-mercaptoacetic acid to give a substituted pyrazolo[3,4-e][1,4]thiazepine (Scheme 184) [210].
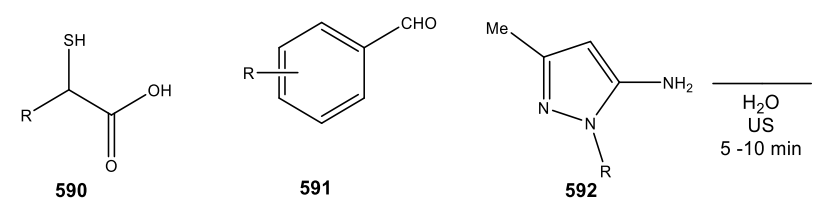

$$
\mathbf{R}=\mathrm{H}, \mathrm{Me}
$$

$\mathbf{R}=\mathrm{Cl}, \mathrm{Br}, \mathrm{F}, \mathrm{Me}, \mathrm{OMe}$,

$\mathbf{R}=\mathrm{H}, \mathrm{Ph}$

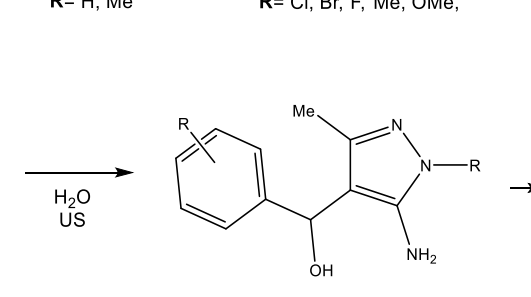

593

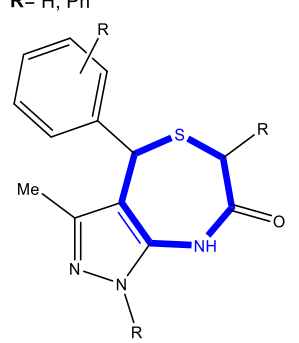

594, $83-93 \%$

Scheme 184. Dandia et al. (2015).

Yan et al., reported the synthesis of thiazepines using tetrabutylammonium tribromide as catalyst. Various derivatives were prepared via a one-pot condensation reaction of 2-aminothiophenol with 1,3-diaryl-2-propenones in water (Scheme 185) [211]. 
<smiles>Nc1ccccc1S</smiles>

237<smiles>O=C(/C=C/c1ccccc1)c1ccccc1</smiles>

595

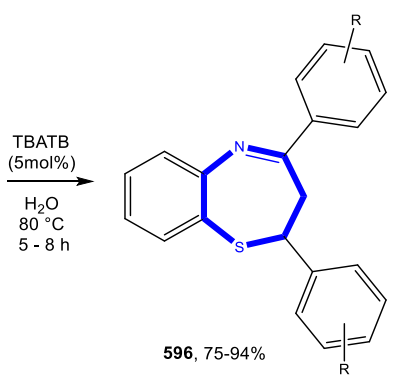

$$
\begin{aligned}
& \mathbf{R}=\mathrm{H}, \mathrm{Cl}, \mathrm{OMe}, \mathrm{OH}, \mathrm{NO}_{2} \\
& \mathrm{OCH}_{2} \mathrm{CH}=\mathrm{CH}_{2}
\end{aligned}
$$$$
\mathrm{R}=\mathrm{Het}(\mathrm{Ar})
$$

Scheme 185. Yan et al. (2012).

In $2008 \mathrm{Tu}$ et al., also obtained benzo[ $e][1,4]$ thiazepin-2- $(1 H, 3 H, 5 H)$-ones by performing a microwave-assisted multi-component reaction in aqueous media. The construction was prepared from aromatic aldehyde, aniline and mercaptoacetic acid (Scheme 186) [113].

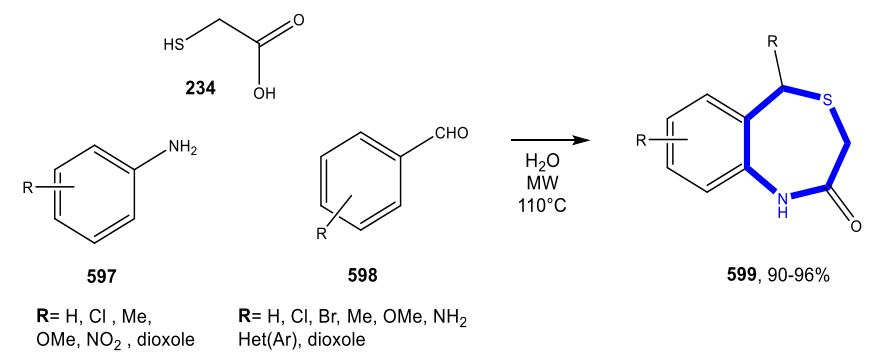

Scheme 186. Tu et al. (2009).

\subsubsection{Reactions in PEG}

Lingampalle et al., synthesized 1,5-benzothiazepines employing a one-pot protocol by condensing 2-propen-1-ones with 2-aminothiopheol in polyethylene glycol PEG 400 as solvent and catalyst. Additionally, in this case, the team was able to reuse the PEG 400 (Scheme 187) [212].

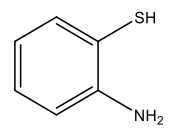

237

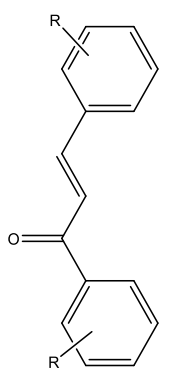

600

$\mathbf{R}=\mathrm{H}, \mathrm{F}, \mathrm{Me}, \mathrm{OMe}$

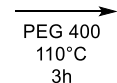

$3 \mathrm{~h}$

$\mathbf{6 0 1 , 6 1 - 7 8 \%}$

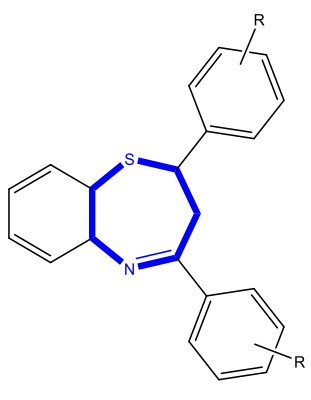

Scheme 187. Lingampalle et al. (2014).

\section{Conclusions}

In this review, we listed the reactions reporting with green methodologies for the synthesis of 5,6 or 7-membered nitrogen or poly-nitrogen heterocyclic compounds. These molecules often have interesting biological activities and are structures often generated in medicinal chemistry. We hope that gathering information will enable the scientific community to implement syntheses that respect our environment a little better in order to reduce our impact as organic chemists on the state of the planet.

Author Contributions: Conceptualization and methodology, J.F.C. and S.B.-R.; investigation, J.F.C.; data curation, J.F.C. and S.B.-R.; writing-original draft preparation, J.F.C.; writing-review and editing, S.B.-R.; supervision, 
project administration and funding acquisition, S.B.-R. All authors have read and agreed to the published version of the manuscript.

Conflicts of Interest: The authors declare no conflict of interest.

\section{References}

1. Candeias, N.R.; Branco, L.C.; Gois, P.M.P.; Afonso, C.A.M.; Trindade, A.F. More Sustainable Approaches for the Synthesis of N-Based Heterocycles. Chem. Rev. 2009, 109, 2703-2802. [CrossRef] [PubMed]

2. Varma, R.S. Greener and Sustainable Trends in Synthesis of Organics and Nanomaterials. ACS Sustain. Chem. Eng. 2016, 4, 5866-5878. [CrossRef]

3. Gupta, P.; Mahajan, A. Green chemistry approaches as sustainable alternatives to conventional strategies in the pharmaceutical industry. RSC Adv. 2015, 5, 26686-26705. [CrossRef]

4. Varma, R.S. Journey on greener pathways: From the use of alternate energy inputs and benign reaction media to sustainable applications of nano-catalysts in synthesis and environmental remediation. Green Chem. 2014, 16, 2027-2041. [CrossRef]

5. Deligeorgiev, T.; Gadjev, N.; Vasilev, A.; Kaloyanova, S.; Vaquero, J.J.; Alvarez-Builla, J. Green Chemistry in Organic Synthesis. Mini-Rev. Org. Chem. 2010, 7, 44-53.

6. Hülsey, M.J.; Yang, H.; Yan, N. Sustainable Routes for the Synthesis of Renewable Heteroatom-Containing Chemicals. ACS Sustain. Chem. Eng. 2018, 65, 5694-5707. [CrossRef]

7. Kaur, N.; Jangid, N.K.; Sharma, V. Metal-and nonmetal-catalyzed synthesis of five-membered S,N-heterocycles. J. Sulfur Chem. 2018, 39, 193-236. [CrossRef]

8. Bhaskaruni, S.V.H.S.; Maddila, S.; Gangu, K.K.; Jonnalagadda, S.B. A review on multi-component green synthesis of N-containing heterocycles using mixed oxides as heterogeneous catalysts. Arab. J. Chem. 2017. In press. [CrossRef]

9. Batista, V.F.; Pinto, D.C.G.A.; Silva, A.M.S. Synthesis of Quinolines: A Green Perspective. ACS Sustain. Chem. Eng. 2016, 4, 4064-4078. [CrossRef]

10. Frecentese, F.; Saccone, I.; Caliendo, G.; Corvino, A.; Fiorino, F.; Magli, E.; Perissutti, E.; Severino, B.; Santagada, V. Microwave Assisted Organic Synthesis of Heterocycles in Aqueous Media: Recent Advances in Medicinal Chemistry. Med. Chem. 2016, 12, 720-732. [CrossRef]

11. Prashant, K.N.; Kumar, K.R. Green Synthesis of Benzimidazole Derivatives: An Overview of Bulk Drug Synthesis. Int. J. Pharmtech. Res. 2015, 8, 60-68.

12. Kaur, N. A Review on the Synthesis of Six-Membered N,N-Heterocycles by Microwave Irradiation. Synth. Commun. 2015, 45, 1145-1182. [CrossRef]

13. Chakrabarty, M.; Mukherji, A. Eco-Friendly Synthesis of Condensed Nitrogen Heterocycles: A Brief Experience from Our Group. J. Indian Chem. Soc. 2013, 90, 1681-1694. [CrossRef]

14. Ivantsova, M.N.; Tokareva, M.I.; Mironov, M.A. Multicomponent interphase synthesis of heterocyclic compounds (review). Chem. Heterocycl. Comp. 2012, 48, 584-600. [CrossRef]

15. Sharma, S.; Gangal, S.; Rauf, A. Green chemistry approach to the sustainable advancement to the synthesis of heterocyclic chemistry. Rasayan J. Chem. 2008, 1, 693-717.

16. Bryson, T.A.; Gibson, J.M.; Stewart, J.J.; Voegtle, H.; Tiwari, A.; Dawson, J.H.; Marley, W.; Harmon, B. Synthesis of quinolines, pyridine ligands and biological probes in green media. Green Chem. 2003, 5, 177-180. [CrossRef]

17. Taylor, R.D.; MacCoss, M.; Lawson, A.D.G. Rings in Drugs. J. Med. Chem. 2014, 57, 5845-5859. [CrossRef] [PubMed]

18. Vitaku, E.; Smith, D.T.; Njardarson, J.T. Analysis of the Structural Diversity, Substitution Patterns, and Frequency of Nitrogen Heterocycles among U.S. FDA Approved Pharmaceuticals. J. Med. Chem. 2014, 57, 10257-10274. [CrossRef]

19. Gu, Y. Multicomponent reactions in unconventional solvents: State of the art. Green Chem. 2012, 14, $2091-2128$. [CrossRef]

20. Ranu, B.C.; Chattopadhyay, K. Eco-Friendly Synthesis of Fine Chemicals, Chap 5; Ballini, R., Ed.; The Royal Society of Chemistry: Cambridge, UK, 2009; pp. 186-219.

21. Rahmati, A.; Pashmforoush, N. Synthesis of various heterocyclic compounds via multi-component reactions in water. J. Iran. Chem. Soc. 2015, 12, 993-1036. [CrossRef] 
22. Gawande, M.B.; Bonifácio, V.D.B.; Luque, R.; Branco, P.S.; Varma, R.S. Benign by design: Catalyst-free in-water, on-water green chemical methodologies in organic synthesis. Chem. Soc. Rev. 2013, 42, 5522-5551. [CrossRef] [PubMed]

23. Panda, S.S.; Jain, S.C. "In Water" Syntheses of Heterocyclic Compounds. Mini Rev. Org. Chem. 2011, 8, 455-464. [CrossRef]

24. Pires, M.J.D.; Purificação, S.I.; Santos, A.S.; Marques, M.M.B. The Role of PEG on Pd-and Cu-Catalyzed Cross-Coupling Reactions. Synthesis 2017, 49, 2337-2350. [CrossRef]

25. Colacino, E.; Martinez, J.; Lamaty, F.; Patrikeeva, L.S.; Khemchyan, L.L.; Ananikov, V.P.; Beletskaya, I.P. PEG as an alternative reaction medium in metal-mediated transformations. Coord. Chem. Rev. 2012, 256, $2893-2920$. [CrossRef]

26. Vafaeezadeh, M.; Hashemi, M.M. Polyethylene glycol (PEG) as a green solvent for carbon-carbon bond formation reactions. J. Mol. Liq. 2015, 207, 73-79. [CrossRef]

27. Byrne, F.; Jin, S.; Sherwood, J.; McElroy, C.R.; Farmer, T.J.; Clark, J.H.; Hunt, A.J. Bio-Based Solvents, 1st ed.; Chap 3; Jérôme, F., Luque, R., Eds.; John Wiley \& Sons Ltd: Hoboken, NJ, USA, 2017; pp. 49-82.

28. Paul, S.; Pradhan, K.; Das, A.R. Ethyl Lactate as a Green Solvent: A Promising Bio-compatible Media for Organic Synthesis. Curr. Green Chem. 2016, 3, 111-118. [CrossRef]

29. Hulsbosch, J.; De Vos, D.E.; Binnemans, K.; Ameloot, R. Bio-based ionic liquids: Solvents for a green processing industry? ACS Sustain. Chem. Eng. 2016, 4, 2917-2931. [CrossRef]

30. Pereira, C.S.M.; Silva, V.M.T.M.; Rodrigues, A.E. Ethyl lactate as a solvent: Properties, applications and production processes-a review. Green Chem. 2011, 13, 2658-2671. [CrossRef]

31. Manabe, K.; Iimura, S.; Sun, X.M.; Kobayashi, S. Dehydration Reactions in Water. Brønsted Acid-Surfactant-Combined Catalyst for Ester, Ether, Thioether, and Dithioacetal Formation in Water. J. Am. Chem. Soc. 2002, 124, 11971-11978. [CrossRef]

32. Tsukinoki, T.; Nagashima, S.; Mitoma, Y.; Tashiro, M. Organic reaction in water. Part 4. New synthesis of vicinal diamines using zinc powder-promoted carbon-carbon bond Formation. Green Chem. 2000, 2, 117-119. [CrossRef]

33. Bigi, F.; Conforti, M.L.; Maggi, R.; Piccinno, A.; Sartori, G. Clean synthesis in water: Uncatalysed preparation of ylidenemalononitriles. Green Chem. 2000, 2, 101-103. [CrossRef]

34. Tundo, P.; Anastas, P.; Black, D.S.; Breen, J.; Collins, T.; Memoli, S.; Miyamoto, J.; Polyakoff, M.; Tumas, W. Synthetic pathways and processes in green chemistry. Introductory overview. Pure Appl. Chem. 2000, 72, 1207-1228. [CrossRef]

35. Diels, O.; Alder, K. The Diels-Alder Diene Synthesis. Ann. Chem. 1931, 490, 243-247. [CrossRef]

36. Rideout, D.C.; Breslow, R. Hydrophobic Acceleration of Diels-Alder Reactions. J. Am. Chem. Soc. 1980, 102, 7816-7817. [CrossRef]

37. Breslow, R. Hydrophobic Effects on Simple Organic Reactions in Water. Acc. Chem. Res. 1991, $24,159-164$. [CrossRef]

38. Chen, J.; Spear, S.K.; Huddleston, J.G.; Rogers, R.D. Polyethylene glycol and solutions of polyethylene glycol as green reaction media. Green Chem. 2005, 7, 64-82. [CrossRef]

39. Zhu, Y.; Romain, C.; Williams, C.K. Sustainable polymers from renewable resources. Nature 2016, 540, $354-362$. [CrossRef]

40. Harris, J.M.; Zalipsky, S. Polyethylene Glycol: Chemistry and Biological Application; ACS Books: Washington, DC, USA, 1997.

41. Harris, J.M. Poly(ethylene Glycol) Chemistry; Biotechnological and Biomedical Applications Plenum Press: New York, NY, USA, 1992.

42. Knop, K.; Hoogenboom, R.; Fischer, D.; Schubert, U.S. Poly(ethylene glycol) in Drug Delivery: Pros and Cons as well as Potential Alternatives. Angew. Chem. Int. Ed. 2010, 49, 6288-6308. [CrossRef]

43. Clark, J.H.; Farmer, T.J.; Hunt, A.J.; Sherwood, J. Opportunities for Bio-Based Solvents Created as Petrochemical and Fuel Products Transition towards Renewable Resources. Int. J. Mol. Sci. 2015, 16, 17101-17159. [CrossRef]

44. Campos, J.F.; Scherrmann, M.-C.; Berteina-Raboin, S. Eucalyptol: A new solvent for the synthesis of heterocycles containing oxygen, sulfur and nitrogen. Green Chem. 2019, 21, 1531-1539. [CrossRef] 
45. Reddy, G.R.; Reddy, T.R.; Chary, R.G.; Joseph, S.C.; Mukherjee, S.; Pal, M. $\beta$-Cyclodextrin mediated MCR in water: Synthesis of dihydroisoindolo[2,1-a]quinazoline-5,11-dione derivatives under microwave irradiation. Tetrahedron Lett. 2013, 54, 6744-6746. [CrossRef]

46. Suresh, R.; Muthusubramanian, S.; Nagaraj, M.; Manickam, G. Indium trichloride catalyzed regioselective synthesis of substituted pyrroles in water. Tetrahedron Lett. 2013, 54, 1779-1784. [CrossRef]

47. Karamthulla, S.; Pal, S.; Khan, M.N.; Choudhury, L.H. Synthesis of novel spiro[indoline-3,79-pyrrolo [1,2-c]imidazole]-69-carbonitrile derivatives in water using a regioselective sequential three component reaction. RSC Adv. 2013, 3, 15576-15581. [CrossRef]

48. Keivanloo, A.; Bakherad, M.; Nasr-Isfahani, H.; Esmaily, S. Highly efficient synthesis of 5,6-disubstituted-5H-pyrrolo[2,3-b]pyrazine-2,3-dicarbonitriles through a one-pot palladium-catalyzed coupling reaction/cyclization in water. Tetrahedron Lett. 2012, 53, 3126-3130. [CrossRef]

49. Gogoi, S.; Dutta, M.; Gogoi, J.; Boruah, R.C. Microwave promoted synthesis of cycl[3.2.2]azines in water via a new three-component reaction. Tetrahedron Lett. 2011, 52, 813-816. [CrossRef]

50. Yu, L.; Jiang, X.; Wang, L.; Li, Z.; Wu, D.; Zhou, X. Catalytic Alkynylation Coupling Reactions by Copper(II) Complex in Water and Its Applications to Domino Synthesis of 2-Arylindoles. Eur. J. Org. Chem. 2010, 29, 5560-5562. [CrossRef]

51. Das, B.; Shinde, D.B.; Kanth, B.S.; Satyalakshmi, G. An Efficient Multicomponent Synthesis of Polysubstituted Pyrrolidines and Tetrahydropyrimidines Starting Directly from Nitro Compounds in Water. Synthesis 2010, 16, 2823-2827. [CrossRef]

52. Barnard, T.M.; Vanier, G.S.; Collins, M.J. Scale-Up of the Green Synthesis of Azacycloalkanes and Isoindolines under Microwave Irradiation. Org. Process Res. Dev. 2006, 10, 1233-1237. [CrossRef]

53. Demir, A.S.; Emrullahoglu, M. Zinc perchlorate catalyzed one-pot amination-annulation of a-cyanomethyl-b-ketoesters in water. Regioselective synthesis of 2-aminopyrrole-4-carboxylates. Tetrahedron 2006, 62, 1452-1458. [CrossRef]

54. Yedukondalu, M.; Sridhar, R.; Luther, B.J.; Rao, M.V.B. Synthesis of Tetrahydro Carbazoles And Tetrahydro- $\Gamma$-Carbolines Catalyzed By PEG-400 As Recyclable Reaction Medium. J. Appl. Chem. 2014, 3, 1295-1305.

55. Mishra, S.; Naskar, B.; Ghosh, R. CuCl catalyzed green and efficient one-pot synthesis of aminoindolizine frameworks via three-component reactions of aldehydes, secondary amines, and terminal alkynes in PEG. Tetrahedron Lett. 2012, 53, 5483-5487. [CrossRef]

56. Dandia, A.; Jain, A.K.; Laxkar, A.K. Ethyl lactate as a promising bio based green solvent for the synthesis of spirooxindole derivatives via 1,3 dipolar cycloaddtion reaction. Tetrahedron Lett. 2013, 54, 3929-3932. [CrossRef]

57. Wang, S.-F.; Guo, C.-L.; Cui, K.-K.; Zhu, Y.-T.; Ding, J.-X.; Zou, X.-Y.; Li, Y.-H. Lactic acid as an invaluable green solvent for ultrasound-assisted scalable synthesis of pyrrole derivatives. Ultrason. Sonochem. 2015, 26, 81-86. [CrossRef] [PubMed]

58. Yang, J.; Tana, J.-N.; Gu, Y. Lactic acid as an invaluable bio-based solvent for organic reactions. Green Chem. 2012, 14, 3304-3317. [CrossRef]

59. Li, B.-L.; Li, P.-H.; Fang, X.-N.; Li, C.-X.; Sun, J.-L.; Mo, L.-P.; Zhang, Z.-H. One-pot four-component synthesis of highly substituted pyrroles in gluconic acid aqueous solution. Tetrahedron 2013, 69, 7011-7018. [CrossRef]

60. Muthusamy, S.; Gangadurai, C. “On water” cascade synthesis of benzopyranopyrazoles and their macrocycles. Tetrahedron Lett. 2018, 59, 1501-1505. [CrossRef]

61. Eswararao, S.V.; Venkataramireddy, V.; Sreenivasareddy, M.; Pramod, K. Water mediated one- potsynthesis of 1h-pyrazolo[1,2-b]phthalazine-5,10-diones and 2h-indazolo[2,1-b]phthalazine-1,6,11(13h)-triones. Heterocycl. Lett. 2017, 7, 895-903.

62. Sagir, H.; Rai, P.; Rahila; Tiwari, S.; Siddiqui, I.R. Iodine/Water Mediated Parallel Synthesis of Bioactive Diversely Substituted Pyrazolo-Pyrido-Pyrimidines and Its Spiro Analogues: An Enviro-Economic Approach. J. Heterocycl. Chem. 2017, 54, 397-405. [CrossRef]

63. Maleki, B.; Nasiri, N.; Tayebee, R.; Khojastehnezhad, A.; Akhlaghi, H.A. Green Synthesis of Tetrahydrobenzo[b]pyrans, Pyrano [2, 3-c]pyrazoles and Spiro [indoline-3,4'-pyrano[2,3-c]pyrazoles Catalyzed by Nano-structured diphosphate in Water. RSC Adv. 2016, 6, 79128-79134. [CrossRef] 
64. Bakherad, M.; Keivanloo, A.; Gholizadeh, M.; Doosti, R.; Javanmardi, M. Using magnetized water as a solvent for a green, catalyst-free, and efficient protocol for the synthesis of pyrano[2,3-c]pyrazoles and pyrano[40,30:5,6]pyrazolo[2,3-d]pyrimidines. Res. Chem. Intermed. 2017, 43, 1013-1029. [CrossRef]

65. Marković, V.; Joksović, M.D. “On water” synthesis of N-unsubstituted pyrazoles:semicarbazide hydrochloride as an alternative to hydrazine for preparation of pyrazole-3-carboxylate derivatives and 3,5-disubstituted pyrazoles. Green Chem. 2015, 17, 842-847. [CrossRef]

66. Dam, B.; Saha, M.; Pal, A.K. Magnetically Recyclable Nano-FDP: A Novel, Efficient Nano-Organocatalyst for the One-Pot Multi-Component Synthesis of Pyran Derivatives in Water under Ultrasound Irradiation. Catal. Lett. 2015, 145, 1808-1816. [CrossRef]

67. Srivastava, M.; Rai, P.; Singhb, J.; Singh, J. Efficient iodine-catalyzed one pot synthesis of highly functionalised pyrazoles in water. New J. Chem. 2014, 38, 302-307. [CrossRef]

68. Khoraamabadi-zad, A.; Azadmanesh, M.; Karamian, R.; Asadbegyb, M.; Akbari, M. Triethanolamine as an inexpensive and efficient catalyst for the green synthesis of novel 1Hpyrazolo[1,2-a]pyridazine-5,8-diones under ultrasound irradiation in water and their antibacterial activity. RSC Adv. 2014, 4, 47721-47725. [CrossRef]

69. Heravi, M.M.; Mousavizadeh, F.; Ghobadi, N.; Tajbakhsh, M. A green and convenient protocol for the synthesis of novel pyrazolopyranopyrimidines via a one-pot, four-component reaction in water. Tetrahedron Lett. 2014, 55, 1226-1228. [CrossRef]

70. Sachdeva, H.; Saroj, R. ZnO Nanoparticles as an Efficient, Heterogeneous, Reusable, and Ecofriendly Catalyst for Four-Component One-Pot Green Synthesis of Pyranopyrazole Derivatives in Water. Sci. World J. 2013, 2013, 680671. [CrossRef]

71. Wu, M.; Feng, Q.; Wan, D.; Ma, J. CTACl as Catalyst for Four-Component, One-Pot Synthesis of Pyranopyrazole Derivatives in Aqueous Medium. Synth. Commun. 2013, 43, 1721-1726. [CrossRef]

72. Zonouz, A.M.; Eskandari, I.; Khavasi, H.R. A green and convenient approach for the synthesis of methyl 6-amino-5-cyano-4-aryl-2,4-dihydropyrano[2,3-c]pyrazole-3-carboxylates via a one-pot, multi-component reaction in water. Tetrahedron Lett. 2012, 53, 5519-5522. [CrossRef]

73. Madjea, B.R.; Bharada, J.V.; Ubalea, M.B.; Shingareb, M.S. Alum promoted synthesis of 2H-indazolo[2,1-b]phthalazinetrione derivatives in water. Orbital Electron. J. Chem. 2012, 4, 202-208. [CrossRef]

74. Savant, M.M.; Pansuriya, A.M.; Bhuva, C.V.; Kapuriya, N.; Patel, A.S.; Audichya, V.B.; Pipaliya, P.V.; Naliapara, Y.T. Water Mediated Construction of Trisubstituted Pyrazoles/Isoxazoles Library Using Ketene Dithioacetals. J. Comb. Chem. 2010, 12, 176-180. [CrossRef]

75. Mali, J.R.; Pratap, U.R.; Jawale, D.V.; Mane, R.A. Water-mediated one-pot synthetic route for pyrazolo[3,4-b]quinolones. Tetrahedron Lett. 2010, 51, 3980-3982. [CrossRef]

76. Karnakar, K.; Ramesh, K.; Reddy, K.H.V.; Kumar, B.S.P.A.; Nanubonula, J.B.; Nageswar, Y.V.D. A novel one pot four-component reaction for the efficient synthesis of spiro[indoline-3,40-pyrano[2,3-c]pyrazole]-30-carboxylate and trifluoromethylated spiro[indole-3,40-pyrano[2,3-c]pyrazole] derivatives using recyclable PEG-400. New J. Chem. 2015, 39, 8978-8983. [CrossRef]

77. Lavania, A.; Dasary, K.; Yadav, M.; Anand, A.V.K. Eco-friendly Synthesis and characterization of some (2-pyrazoline) and (2-isoxazoline) containing anthracene moiety by using PEG(400) as a Catalyst. J. Appl. Chem. 2013, 2, 1341-1346.

78. Kidwai, M.; Chauhan, R.; Jahan, A. Efficient CAN catalyzed synthesis of 1H-indazolo[1,2-b] phthalazine-1,6,11-triones: An eco-friendly protocol. Chin. Sci. Bull. 2012, 57, 2273-2279. [CrossRef]

79. Bhat, P.; Shridhar, G.; Ladage, S.; Ravishankar, L. An eco-friendly synthesis of 2-pyrazoline derivatives catalyzed by $\mathrm{CeCl}_{3} \cdot 7 \mathrm{H}_{2} \mathrm{O}$. J. Chem. Sci. 2017, 129, 1441-1448. [CrossRef]

80. Dheer, D.; Rawal, R.K.; Singh, V.; Sangwan, P.L.; Das, P.; Shankar, R. b-CD/CuI catalyzed regioselective synthesis of iodo substituted 1,2,3-triazoles, imidazo[1,2-a]-pyridines and benzoimidazo[2,1-b]thiazoles in water and their functionalization. Tetrahedron 2017, 73, 4295-4306. [CrossRef]

81. Bhagat, S.B.; Telvekar, V.N. NBS mediated protocol for the synthesis of N-bridged fused heterocycles in water. Tetrahedron Lett. 2017, 58, 3662-3666. [CrossRef]

82. Wagare, D.S.; Farooqui, M.; Keche, T.D.; Durrani, A. Efficient and green microwave-assisted one-pot synthesis of azaindolizines in PEG-400 and water. Synth. Commun. 2016, 46, 1741-1746. [CrossRef] 
83. Nikoofar, K.; Haghighi, M.; Lashanizadegan, M.; Ahmadvand, Z. ZnO nanorods: Efficient and reusable catalysts for the synthesis ofsubstituted imidazoles in water. J. Taibah Univ. Sci. 2015, 9, 570-578. [CrossRef]

84. Chanu, L.G.; Singh, T.P.; Jang, Y.J.; Yoon, Y.-J.; Singh, O.M.; Lee, S.-G. Synthesis of Imidazo[1,2-a]pyridines and Pyrido[1,2-a]pyrimidines in Water and their SNAr Cyclizations. Bull. Korean Chem. Soc. 2014, 35, 994-1000. [CrossRef]

85. Siddiqui, I.R.; Rai, P.; Rahila; Srivastava, A.; Shamim, S. Synthesis of imidazo[1,2-a]pyridine in the presence of iodine-water catalytic system. Tetrahedron Lett. 2014, 55, 1159-1163. [CrossRef]

86. Peshkov, V.A.; Peshkov, A.A.; Pereshivko, O.P.; Hecke, K.V.; Zamigaylo, L.L.; Van der Eycken, E.V.; Gorobets, N.Y. Three-Component Reaction of a 2-Aminoazine, a 2-Oxoaldehyde, and a Cyclic 1,3-Dicarbonyl Compound for the Synthesis of Imidazo[1,2-a]azine Derivatives. ACS Comb. Sci. 2014, 16, 535-542. [CrossRef]

87. Bangade, V.M.; Reddy, B.C.; Thakur, P.B.; Babu, B.M.; Meshram, H.M. DABCO catalyzed highly regioselective synthesis of fused imidazo-heterocycles in aqueous medium. Tetrahedron Lett. 2013, 54, 4767-4771. [CrossRef]

88. Rustagi, V.; Tiwari, R.; Verma, A.K. AgI-Catalyzed Cascade Strategy: Regioselective Access to Diversely Substituted Fused Benzimidazo[2,1-a]isoquinolines, Naphthyridines, Thienopyridines, and Quinoxalines in Water. Eur. J. Org. Chem. 2012, 4590-4602. [CrossRef]

89. Kumar, D.; Kumar, N.M.; Patel, G.; Gupta, S.; Varma, R.S. A facile and eco-friendly synthesis of diarylthiazoles and diarylimidazoles in water. Tetrahedron Lett. 2011, 52, 1983-1986. [CrossRef]

90. Rustagi, V.; Aggarwal, T.; Verma, A.K. Highly efficient Ag(I)-catalyzed regioselective tandem synthesis of diversely substituted quinoxalines and benzimidazoles in water. Green Chem. 2011, 13, 1640-1643. [CrossRef]

91. Peng, J.; Ye, M.; Zong, C.; Hu, F.; Feng, L.; Wang, X.; Wang, Y.; Chen, C. Copper-Catalyzed Intramolecular C-N Bond Formation: A Straightforward Synthesis of Benzimidazole Derivatives in Water. J. Org. Chem. 2011, 76, 716-719. [CrossRef] [PubMed]

92. Chanu, L.G.; Singh, O.M.; Jang, S.H.; Lee, S.-G. Regioselective Synthesis of Heterocyclic Ketene N,N-, N,Oand N,S-acetals in Aqueous Medium. Bull. Korean Chem. Soc. 2010, 31, 859-862. [CrossRef]

93. Boeini, H.Z.; Najafabadi, K.H. Efficient One-Step Synthesis of Benzazoles in Aqueous Media. Eur. J. Org. Chem. 2009, 4926-4929. [CrossRef]

94. Barbero, N.; Carril, M.; SanMartin, R.; Dominguez, E. Copper-catalyzed intramolecular N-arylation of ureas in water: A novel entry to benzoimidazolones. Tetrahedron 2008, 64, 7283-7288. [CrossRef]

95. Mekala, R.S.; Balam, S.K.; Harinath, J.P.S.; Gajjal, R.R.; Cirandur, S.R. Polyethylene glycol (PEG-400): An efficient medium for the synthesis of 1,2-disubstituted benzimidazoles. Cogent Chem. 2015, 1, 1049932. [CrossRef]

96. Hiebel, M.-A.; Fall, Y.; Scherrmann, M.-C.; Berteina-Raboin, S. Straightforward Synthesis of Various 2,3-Diarylimidazo[1,2-a]pyridines in PEG400 Medium through One-Pot Condensation and C-H Arylation. Eur. J. Org. Chem. 2014, 4643-4650. [CrossRef]

97. Guchhait, S.K.; Madaan, C. An Efficient, Regioselective, Versatile Synthesis of N-Fused 2- and 3-Aminoimidazoles via Ugi-Type Multicomponent Reaction Mediated by Zirconium(IV) Chloride in Polyethylene Glycol-400. Synlett 2009, 4, 628-632. [CrossRef]

98. Hiroki, H.; Ogata, K.; Fukuzawa, S.-I. 12et-teEr thynylpyridine-Promoted Rapid Copper(I) Chloride Catalyzed Azide-Alkyne Cycloaddition Reaction in Water. Synlett 2013, 24, 843-846. [CrossRef]

99. Kshirsagar, S.S.; Mutha, M.M.; Shitre, M.R.; Baheti, K.G. Multicomponent stereo and regioselective reactions of beta lactams in water: Click reaction. OCAIJ 2013, 9, 229-235.

100. Kumar, I.; Mir, N.A.; Rode, C.V.; Wakhloo, B.P. Intramolecular Huisgen [3+2] cycloaddition in water: Synthesis of fused pyrrolidine-triazoles. Tetrahedron Asymmetry 2012, 23, 225-229. [CrossRef]

101. Kumar, B.S.P.A.; Reddy, K.H.V.; Madhav, B.; Ramesh, K.; Nageswar, Y.V.D. Magnetically separable $\mathrm{CuFe}_{2} \mathrm{O}_{4}$ nano particles catalyzed multicomponent synthesis of 1,4-disubstituted 1,2,3-triazoles in tap water using 'click chemistry'. Tetrahedron Lett. 2012, 53, 4595-4599. [CrossRef]

102. Reddy, A.S.; Reddy, M.N.; Swamy, K.C.K. A simple copper-catalysed tandem cyclisation of ynamides leading to triazolo-1,2,4-benzothiadiazine-1,1-dioxides in PEG-400 Medium. RSC Adv. 2014, 4, 28359-28367. [CrossRef]

103. Saiprathima, P.; Srinivas, K.; Sridhar, B.; Rao, M.M. “On water” one-pot synthesis of quaternary centered 3-hydroxy-3-(1H-tetrazol-5-yl)indolin-2-ones. RSC Adv. 2013, 3, 7708-7712. [CrossRef] 
104. Khalili, B.; Darabi, F.S.; Eftekhari-Sis, B.; Rimaz, M. Green chemistry: ZrOCl28H2O catalyzed regioselective synthesis of 5-amino-1-aryl-1H-tetrazoles from secondary arylcyanamides in water. Monatsh. Chem. 2013, 144, 1569-1572. [CrossRef]

105. Habibi, D.; Nasrollahzadeh, M.; Faraji, A.R.; Bayat, Y. Efficient synthesis of arylaminotetrazoles in water. Tetrahedron 2010, 66, 3866-3870. [CrossRef]

106. Wang, F.; Chen, C.; Deng, G.; Xi, C. Concise Approach to Benzisothiazol-3(2H)-one via Copper-Catalyzed Tandem Reaction of o-Bromobenzamide and Potassium Thiocyanate in Water. J. Org. Chem. 2012, 77, 4148-4151. [CrossRef] [PubMed]

107. Nagaraju, A.; Ramulu, B.J.; Shukla, G.; Srivastava, A.; Verma, G.K.; Raghuvanshib, K.; Singh, M.S. Catalyst-free one-pot four-component domino reactions in water-PEG-400: Highly efficient and convergent approach to thiazoloquinoline scaffolds. Green Chem. 2015, 17, 950-958. [CrossRef]

108. Sengoden, M.; Vijay, M.; Balakumara, E.; Punniyamurthy, T. Efficient Pyrrolidine Catalyzed Cycloaddition of Aziridines with Isothiocyanates, Isoselenocyanates and Carbon Disulfide "On Water". RSC Adv. 2014, 4, 54149-54157. [CrossRef]

109. Aryanasaba, F.; Shokrib, A.; Saidib, M.R. A simple approach to the synthesis of 3-substituted rhodanines and thiazolidine-2,4-diones. Sci. Iran. C 2013, 20, 1833-1838.

110. Zhang, W.; Yue, Y.; Yu, D.; Song, L.; Xu, Y.-Y.; Tian, Y.-J.; Guo, Y.-J. 1,10-Phenanthroline-Catalyzed Tandem Reaction of 2-Iodoanilines with Isothiocyanates in Water. Adv. Synth. Catal. 2012, 354, 2283-2287. [CrossRef]

111. Pathak, U.; Bhattacharyya, S.; Dhruwansh, V.; Pandey, L.K.; Tank, R.; Suryanarayana, M.V.S. Easy access to thiazolines and thiazines via tandem S-alkylation-cyclodeamination of thioamides/haloamines. Green Chem. 2011, 13, 1648-1651. [CrossRef]

112. Yavari, I.; Sirouspour, M.; Souri, S. A one-pot synthesis of N-alkylthiazoline-2-thiones from CS2, primary amines, and 2-chloro-1,3-dicarbonyl compounds in water. Monatsh. Chem. 2010, 141, 49-52. [CrossRef]

113. Tu, S.-J.; Cao, X.-D.; Hao, W.-J.; Zhang, X.-H.; Yan, S.; Wu, S.-S.; Han, Z.-G.; Shi, F. An efficient and chemoselective synthesis of benzo[e][1,4]thiazepin-2-(1H,3H,5H)-ones via a microwave-assisted multi-component reaction in water. Org. Biomol. Chem. 2009, 7, 557-563. [CrossRef]

114. Potewar, T.M.; Ingale, S.A.; Srinivasan, K.V. Catalyst-free efficient synthesis of 2-aminothiazoles in water at ambient temperature. Tetrahedron 2008, 64, 5019-5022. [CrossRef]

115. Chakraborti, A.K.; Rudrawar, S.; Jadhav, K.B.; Kaur, G.; Chankeshwara, S.V. “On water” organic synthesis: A highly efficient and clean synthesis of 2-aryl/heteroaryl/styryl benzothiazoles and 2-alkyl/aryl alkyl benzothiazolines. Green Chem. 2007, 9, 1335-1340. [CrossRef]

116. Dumonteil, G.; Hiebel, M.-A.; Scherrmann, M.-C.; Berteina-Raboin, S. Iodine-catalyzed formation of substituted 2-aminobenzothiazole derivatives in PEG400. RSC Adv. 2016, 6, 73517-73521. [CrossRef]

117. Jin, H.-L.; Cheng, T.-X.; Chen, J.-X. Cerium-catalyzed tandem synthesis of 2-substituted benzothiazoles in PEG. Appl. Organometal. Chem. 2011, 25, 238-240. [CrossRef]

118. Deligeorgiev, T.G.; Kaloyanova, S.; Vasilev, A.; Vaquero, J.J. Novel Green Procedure for the Synthesis of 2-Arylbenzothiazoles Under Microwave Irradiation in Peg 200 Or Peg 400. Phosphorus Sulfur Silicon Relat. Elem. 2010, 185, 2292-2302. [CrossRef]

119. Zhu, D.; Chen, J.; Xiao, H.; Liu, M.; Ding, J.; Wu, H. Efficient and Expeditious Synthesis of Di- and Trisubstituted Thiazoles in PEG Under Catalyst-Free Conditions. Synth. Commun. 2009, 39, 2895-2906. [CrossRef]

120. Yu, Z.-Y.; Fang, Q.-S.; Zhou, J.; Song, Z.-B. Reusable proline-based ionic liquid catalyst for the simple synthesis of 2-arylbenzothiazoles in a biomass medium. Res. Chem. Intermed. 2016, 42, 2035-2045. [CrossRef]

121. Halimehjani, A.Z.; Ashouri, A.; Marjani, K. Dithiocarbamates as an Efficient Intermediate for the Synthesis of Symmetrical Substituted 2,5-Diamino-1,3,4-thiadiazoles in Water. J. Heterocycl. Chem. 2012, 49, 939-942. [CrossRef]

122. Ahmadzadeh, M.; Zarnegar, Z.; Safari, J. Sonochemical synthesis of methyl-4-(hetero)arylmethylene isoxazole-5(4H)-ones using SnII-montmorillonite. Green Chem. Lett. Rev. 2018, 11, 78-85. [CrossRef]

123. Dommaraju, Y.; Borthakura, S.; Prajapati, D. L-Proline-Catalysed One-Pot aza-Diels-Alder Reaction in Water: Regioselective Synthesis of Spiro(isoxazolo[5,4-b]pyridine-5,5'-pyrimidine) Derivatives. Synlett 2018, 29, 1195-1198. [CrossRef] 
124. Kiyani, H.; Ghorbani, F. Efficient tandem synthesis of a variety of pyranannulated heterocycles, 3,4-disubstituted isoxazol-5(4H)-ones, and a,b-unsaturated nitriles catalyzed by potassium hydrogen phthalate in water. Res. Chem. Intermed. 2015, 41, 7847-7882. [CrossRef]

125. Chary, R.G.; Reddy, G.R.; Ganesh, Y.S.S.; Prasad, K.V.; Raghunadh, A.; Krishna, T.; Mukherjee, S.; Pal, M. Effect of Aqueous Polyethylene Glycol on 1,3-Dipolar Cycloaddition of Benzoylnitromethane/Ethyl 2-Nitroacetate with Dipolarophiles: Green Synthesis of Isoxazoles and Isoxazolines. Adv. Synth. Catal. 2014, 356, 160-164. [CrossRef]

126. Trogu, E.; Vinattieri, C.; De Sarlo, F.; Machetti, F. Acid-Base-Catalysed Condensation Reaction in Water: Isoxazolines and Isoxazoles from Nitroacetates and Dipolarophiles. Chem. Eur. J. 2012, 18, 2081-2093. [CrossRef] [PubMed]

127. Tan, B.; Zhu, D.; Zhang, L.; Chua, P.J.; Zeng, X.; Zhong, G. Water-More Than Just a Green Solvent: A Stereoselective One-Pot Access to All-Chiral Tetrahydronaphthalenes in Aqueous Media. Chem. Eur. J. 2010, 16, 3842-3848. [CrossRef] [PubMed]

128. Vaidya, S.P.; Shridhar, G.; Ladage, S.; Ravishankar, L. A Facile Synthesis of Isoxazolone Derivatives Catalyzed by Cerium Chloride Heptahydrate in Ethyl Lactate as a Solvent: A Green Methodology. Curr. Green Chem. 2016, 3, 160-167. [CrossRef]

129. Wallace, J.R.; Lieberman, D.L.; Hancock, M.T.; Pinhas, A.R. Conversion of an Aziridine to an Oxazolidinone Using a Salt and Carbon Dioxide in Water. J. Chem. Educ. 2005, 82, 1229-1230. [CrossRef]

130. Balijapalli, U.; Thiyagarajan, M.D.; Manickam, S.; Sathiyanarayanan, K.I. Synthesis of T-shaped Oxazolonaphthoimidazo[1,2-a]pyridines using Lactic Acid as Bio-based Green Solvent: An Insight into Photophysical Studies. ChemistrySelect 2016, 1, 2900-2908. [CrossRef]

131. Naeimi, H.; Didar, A. Efficient sonochemical green reaction of aldehyde, thiobarbituric acid and ammonium acetate using magnetically recyclable nanocatalyst in water. Ultrason Sonochem. 2017, 34, 889-895. [CrossRef]

132. Lezana, N.; Matus-Pérez, M.; Galdámez, A.; Lührb, S.; Vilches -Herrera, M. Highly stereoselective and catalyst-free synthesis of annulated tetrahydropyridines by intramolecular imino-Diels-Alder reaction under microwave irradiation in water. Green Chem. 2016, 18, 3712-3717. [CrossRef]

133. Abdelmoniem, A.M.; Hassaneen, H.M.E.; Abdelhamid, I.A. An Efficient One-pot Synthesis of Novel Spiro Cyclic 2-Oxindole Derivatives of Pyrimido[4,5-b]Quinoline, Pyrido[2,3-d:6,5-d']Dipyrimidine and Indeno[2' $\left.{ }^{\prime} 1^{\prime}: 5,6\right]$ Pyrido [2,3-d]Pyrimidine in Water. J. Heterocycl. Chem. 2016, 53, 2084-2090. [CrossRef]

134. Yaragorla, S.; Singh, G.; Pareek, A. Highly stereoselective and catalyst-free synthesis of annulated tetrahydropyridines by intramolecular imino-Diels-Alder reaction under microwave irradiation in water. Indian J. Chem. 2015, 54, 1321-1326.

135. Zhao, H.-W.; Yang, Z.; Yue, Y.-Y.; Li, H.-L.; Song, X.-Q.; Sheng, Z.-H.; Meng, W.; Guo, X.-Y. 1 Asymmetric Direct Michael Reactions of Cyclohexanone with Aromatic Nitroolefins in Water Catalyzed by Novel Axially Unfixed Biaryl-Based Bifunctional Organocatalysts. Synlett 2014, 25, 293-297. [CrossRef]

136. Mosslemin, M.H.; Zarenezhad, E.; Shams, N.; Rad, M.N.S.; Anaraki-Ardakani, H.; Fayazipoor, R. Green synthesis of 5-aryl-(1H,3H,5H,10H)-pyrimido[4,5-b]quinoline-2,4-diones catalysed by 1,4-diazabicyclo [2.2.2] octane in water. J. Chem. Res. 2014, 38, 169-171. [CrossRef]

137. Siddiqui, I.R.; Rai, P.; Rahila; Srivastava, A.; Srivastava, A.; Srivastava, A. Synthesis of fused pyridines in the presence of thiamine hydrochloride as an efficient and reusable catalyst in aqueous conditions. New J. Chem. 2013, 37, 3798-3804. [CrossRef]

138. Nasseri, M.A.; Alavi, S.A.; Zakerinasab, B. PEG-SO3H as a catalyst in aqueous media: A simple, proficient and green approach for the synthesis of quinoline derivatives. J. Chem. Sci. 2013, 125, 109-116. [CrossRef]

139. Makone, S.S.; Niwadange, S.N. An efficient and simple un-catalysed synthesis of 1,4-dihydropyridines in an aqueous media. Chem. Sin. 2012, 3, 1293-1296.

140. Khurana, J.M.; Chaudhary, A.; Nand, B.; Lumb, A. Aqua mediated indium(III) chloride catalyzed synthesis of fused pyrimidines and pyrazoles. Tetrahedron Lett. 2012, 53, 3018-3022. [CrossRef]

141. Kumar, N.; Verma, S.; Jain, S.L. Combined Thiourea DioxideWater: An Effective Reusable Catalyst for the Synthesis of Polyhydroquinolines via Hantzsch Multicomponent Coupling. Chem. Lett. 2012, 41, 920-922. [CrossRef]

142. Rahmati, A.; Khalesi, Z. Catalyst free synthesis of fused pyrido[2,3-d]pyrimidines and pyrazolo[3,4-b] pyridines in water. Chin. Chem. Lett. 2012, 23, 1149-1152. [CrossRef] 
143. Shen, Q.; Wang, L.; Yu, J.; Liu, M.; Qiu, J.; Fang, L.; Guo, F.; Tang, J. Synthesis of Quinolines via Friedländer Reaction in Water and under Catalyst-Free Conditions. Synthesis 2012, 44, 389-392. [CrossRef]

144. Xu, F.; Wang, C.; Li, X.; Wan, B. Ruthenium-catalyzed [2+2+2] Cycloaddition of Diynes with Nitriles in Pure Water. ChemSusChem 2012, 5, 854-857. [CrossRef]

145. Mukhopadhyay, C.; Das, P.; Butcher, R.J. An Expeditious and Efficient Synthesis of Highly Functionalized [1,6]-Naphthyridines under Catalyst-Free Conditions in Aqueous Medium. Org. Lett. 2011, 13, 4664-4667. [CrossRef] [PubMed]

146. Paul, N.; Muthusubramanian, S.; Bhuvanesh, N. A green protocol for the synthesis of conformationally rigid sulfur linked bisquinolines by double Friedlander reaction in water. New J. Chem. 2011, 35, 2607-2613. [CrossRef]

147. Das, B.; Jangili, P.; Kashanna, J.; Kumar, R.A. Organic Reactions in Water: A Distinct Approach for the Synthesis of Quinoline Derivatives Starting Directly from Nitroarenes. Synthesis 2011, 20, 3267-3270. [CrossRef]

148. Madhav, B.; Murthy, S.N.; Rao, K.R.; Nageswar, Y.V.D. An Improved Protocol for the Synthesis of Quinoline-2,3-dicarboxylates under Neutral Conditions via Biomimetic Approach. Helv. Chim. Acta 2010, 93, 257-260. [CrossRef]

149. Wu, L.Q.; Dong, R.-Y.; Yang, C.-G.; Yan, F.-L. Synthesis of 4-Aryl-3-methyl-1-phenyl-1Hbenzo[h] pyrazolo[3,4-b]quinoline-5,10-diones Using Diammonium Hydrogen Phosphate as an Efficient and Versatile Catalyst in Water. J. Chin. Chem. Soc. 2010, 57, 19-23. [CrossRef]

150. Akbari, J.; Heydari, A.; Kalhor, H.R.; Kohan, S.A. Sulfonic Acid Functionalized Ionic Liquid in Combinatorial Approach, a Recyclable and Water Tolerant-Acidic Catalyst for One-Pot Friedlander Quinoline Synthesis. J. Comb. Chem. 2010, 12, 137-140. [CrossRef]

151. Shi, D.-Q.; Yao, H. Facile and Clean Synthesis of Furopyridine Derivatives via Three-Component Reaction in Aqueous Media Without Catalyst. Synth. Commun. 2009, 39, 2481-2491. [CrossRef]

152. Shi, F.; Wang, Q.; Tu, S.; Zhou, J.; Jiang, B.; Li, C.; Zhou, D.; Shao, Q.; Cao, L. A Green and Efficient Synthesis of Furo[3,4-e]pyrazolo[3,4-b]-pyridine Derivatives in Water under Microwave Irradiation without Catalyst. J. Heterocycl. Chem. 2008, 45, 1103-1108. [CrossRef]

153. Shi, F.; Zhou, D.; Tu, S.; Shao, Q.; Li, C.; Cao, L. An Efficient Microwave-assisted Synthesis Furo[3,4-b][4,7]phenanthroline and Indeno[2,1-b][4,7]phenanthroline Derivatives in Water. J. Heterocycl. Chem. 2008, 45, 1065-1070. [CrossRef]

154. Shi, F.; Zhou, D.; Tu, S.; Li, C.; Cao, L.; Shao, Q. Pot, Atom and Step Economic Synthesis of Fused Three Heterocyclic Ring Compounds under Microwave Irradiation in Water. J. Heterocycl. Chem. 2008, 45, 1305-1310. [CrossRef]

155. Shi, F.; Zhang, Y.; Tu, S.-J.; Zhou, D.-X.; Li, C.-M.; Shao, Q.-Q.; Cao, L.-J. A Green Approach to the Synthesis of Biologically Important Indeno[2,1-e]pyrazolo[5,4-b]pyridines via Microwave-assisted Multi-component Reactions in Water. Chin. J. Chem. 2008, 26, 1262-1266. [CrossRef]

156. Kumar, A.; Maurya, R.A. Synthesis of polyhydroquinoline derivatives through unsymmetric Hantzsch reaction using organocatalysts. Tetrahedron 2007, 63, 1946-1952. [CrossRef]

157. Wang, G.-W.; Jia, C.-S.; Dong, Y.-W. Benign and highly efficient synthesis of quinolines from 2-aminoarylketone or 2-aminoarylaldehyde and carbonyl compounds mediated by hydrochloric acid in water. Tetrahedron Lett. 2006, 47, 1059-1063. [CrossRef]

158. Tu, S.-J.; Jiang, B.; Zhang, J.-Y.; Jia, R.-H.; Zhang, Y.; Yao, C.-S. Efficient and direct synthesis of poly-substituted indeno[1,2-b]quinolones assisted by $\mathrm{p}$-toluene sulfonic acid using high-temperature water and microwave heating via one-pot, three-component reaction. Org. Biomol. Chem. 2006, 4, 3980-3985. [CrossRef] [PubMed]

159. Loncaric, C.; Manabe, K.; Kobayashi, S. AgOTf-Catalyzed Aza-Diels-Alder Reactions of Danishefsky's Diene with Imines in Water. Adv. Synth. Catal. 2003, 345, 475-477. [CrossRef]

160. Zhang, Z.; Gao, X.; Wan, Y.; Huang, Y.; Huang, G.; Zhang, G. Ammonium Acetate-Promoted One-Pot Tandem Aldol Condensation/Aza-Addition Reactions: Synthesis of 2,3,6,7-Tetrahydro-1H-pyrrolo [3,2-c]pyridin-4(5H)-ones. ACS Omega 2017, 2, 6844-6851. [CrossRef] [PubMed]

161. Maryamabadi, A.; Hasaninejad, A.; Nowrouzi, N.; Mohebbi, G.; Asghari, B. Application of PEG-400 as a green biodegradable polymeric medium for the catalyst-free synthesis of spiro-dihydropyridines and their use as acetyl and butyrylcholinesterase inhibitors. Bioorg. Med. Chem. 2016, 24, 1408-1417. [CrossRef] [PubMed] 
162. Pal, S.; Singh, V.; Das, P.; Choudhury, L.H. PEG-mediated one-pot multicomponent reactions for the efficient synthesis of functionalized dihydropyridines and their functional group dependent DNA cleavage activity. Bioorg. Chem. 2013, 48, 8-15. [CrossRef]

163. Paidepala, H.; Nagendra, S.; Saddanappu, V.; Addlagatta, A.; Das, B. Catalyst-free efficient synthesis of polyhydroquinolines using polyethylene glycol as a solvent and evaluationof their cytotoxicity. Med. Chem. Res. 2014, 23, 1031-1036. [CrossRef]

164. Wu, F.-W.; Hou, R.-S.; Wang, H.-M.; Kang, I.-J.; Chen, L.-C. Catalyst Free Indirect Friedländer Synthesis of Substituted Quinolines from Alcohols in PEG-400. J. Chin. Chem. Soc. 2012, 59, 535-539. [CrossRef]

165. Karnakar, K.; Murthy, S.N.; Ramesh, K.; Satish, G.; Nanubolu, J.B.; Nageswar, Y.V.D. Polyethylene glycol (PEG-400): An efficient and recyclable reaction medium for the synthesis of pyrazolo[3,4-b]quinoline derivatives. Tetrahedron Lett. 2012, 53, 2897-2903. [CrossRef]

166. Nalage, S.V.; Nikum, A.P.; Kalyankar, M.B.; Patil, V.S.; Patil, U.D.; Desale, K.R.; Patil, S.L.; Bhosale, S.V. One-Pot Four Component Synthesis of 4, 6-Disubstituted 3-Cyano-2-Pyridones in Polyethylene Glycol. Lett. Org. Chem. 2010, 7, 406-410. [CrossRef]

167. Manvar, A.; Karia, D.; Trangadia, V.; Vekariya, N.; Shah, A. PEG-400 mediated and microwave assisted one pot three-component coupling reactions: Expedient and rapid synthesis of Hantzsch 1,4-dihydropyridines devoid of use of catalyst. OCAIJ 2007,3, 166-169.

168. Smith, N.M.; Raston, C.L.; Smith, C.B.; Sobolev, A.N. PEG mediated synthesis of amino-functionalised 2,4,6-triarylpyridines. Green Chem. 2007, 9, 1185-1190. [CrossRef]

169. Paul, S.; Das, A.R. An efficient green protocol for the synthesis of coumarin fused highly decorated indenodihydropyridyl and dihydropyridyl derivatives. Tetrahedron Lett. 2012, 53, 2206-2210. [CrossRef]

170. Rimaz, M.; Khalafy, J. A novel one-pot, three-component synthesis of alkyl 6-aryl-3-methylpyridazine4-carboxylates in water. ARKIVOC 2010, 110-117. [CrossRef]

171. Rimaz, M.; Khalafy, J.; Moghadam, P.N. A Regioselective One-Pot, Three Component Synthesis of 6-Aryl-4-cyano-3(2H)-pyridazinones in Water. Aust. J. Chem. 2010, 63, 1396-1401. [CrossRef]

172. Yan, H.; Ma, Y.; Sun, Y.; Ma, C.; Wang, Y.; Ren, X.; Huang, G. Catalyst-free synthesis of alkyl 4-oxo-4H-pyrido[1,2-a]pyrimidine-2-carboxylate derivatives on water. Tetrahedron 2014, 70, 2761-2765. [CrossRef]

173. Siddiqui, Z.N. Bis[(L)prolinato-N,O]Zn-water: A green catalytic system for the synthesis of 3,4-dihydropyrimidin-2 (1H)-ones via the Biginelli reaction. Comptes Rendus Chim. 2013, 16, 183-188. [CrossRef]

174. Mukhopadhyay, C.; Datta, A. Synthesis of Substituted Pyrimidinones Catalyzed by Boric Acid and Glycerol in Aqueous Medium. Synth. Commun. 2013, 43, 438-449. [CrossRef]

175. Ramesh, K.; Karnakar, K.; Satish, G.; Kumar, B.S.P.A.; Nageswar, Y.V.D. A concise aqueous phase supramolecular synthesis of 2-phenyl-2,3-dihydroquinazolin-4(1H)-one derivatives. Tetrahedron Lett. 2012, 53, 6936-6939. [CrossRef]

176. Li, Q.-Y.; Ge, Z.-M.; Cheng, T.-M.; Li, R.-T. An efficient three-component, one-pot synthesis of 2-alkylthio-4-amino-5-cyano-6-aryl(alkyl)pyrimidines in water. Mol. Divers. 2012, 16, 431-439. [CrossRef] [PubMed]

177. Zhang, X.; Ye, D.; Sun, H.; Guo, D.; Wang, J.; Huang, H.; Zhang, X.; Jianga, H.; Liu, H. Microwave-assisted synthesis of quinazolinone derivatives by efficient and rapid iron-catalyzed cyclization in water. Green Chem. 2009, 11, 1881-1888. [CrossRef]

178. Xu, F.; Wang, J.J.; Tian, Y.P. New Procedure for One-Pot Synthesis of 3,4-Dihydropyrimidin-2(1H)-ones by Biginelli Reaction. Synth. Commun. 2008, 38, 1299-1310. [CrossRef]

179. Hese, S.V.; Kamble, R.D.; Mogle, P.P.; Kadam, S.S.; Hebade, M.J.; Ambhore, A.N.; Dawane, B.S. Green synthesis and antimicrobial evaluation ofpyrido[1,2-a]pyrimidine3-carbonitrile derivatives. Pharma Chem. 2015, 7, 249-256.

180. Konda, S.G. PEG-400: An efficient and recyclable reaction medium for the synthesis of pyrazolo[1,5-a] pyrimidines. Eur. J. Chem. 2014, 5, 676-680. [CrossRef]

181. Reddy, B.S.; Naidu, A.; Dubey, P.K. PEG-600-mediated, green and efficient, tandem syntheses of N-subtituted-2-styrylquinazolin-4-ones. Green Chem. Lett. Rev. 2013, 6, 254-261. [CrossRef]

182. Maddila, S.; Jonnalagadda, S.B.; Chunduri, V.; Lavanya, P. Solvent-free splendid one pot synthesis of 2-amino-6-(substitutedphenyl)-5-methylpyrimidin-4-ol using PEG-400. Heterocycl. Lett. 2012, 2, 37-42. 
183. Sharafi-Kolkeshvandi, M.; Nikpour, F. A facile and convenient approach for the one-pot synthesis of 2,4(1H,3H)-quinazolinediones. Chin. Chem. Lett. 2012, 23, 431-433. [CrossRef]

184. Kidwai, M.; Chauhan, R.; Bhatnagar, D. Amberlyst- $15^{\circledR}$ in PEG: A novel catalytic system for the facile and efficient one-pot synthesis of benzothiazolo-[2,3-b]-quinazolinone derivatives. Sci. China Chem. 2012, 55, 2154-2160. [CrossRef]

185. Nikpour, F.; Mozafari, R.; Paibast, T. A facile and convenient method to the one-pot synthesis of 2-mercapto-4(3h)-quinazolinones. Heterocycles 2009, 78, 1569-1571. [CrossRef]

186. Wang, X.; Quan, Z.; Zhang, Z. Michael additions of dihydropyrimidines and 2-amino-1,3,4-thiadiazoles to a,b-ethylenic compounds: Using polyethylene glycols as a green reaction media. Tetrahedron 2007, 63, 8227-8233. [CrossRef]

187. Khandelwal, S.; Rajawat, A.; Kumar, M. An Efficient and Environmentally Benign One-pot Three- Component Domino Protocol for the Synthesis of Structurally Diverse Spiroquinazolines. Curr. Catal. 2015, 4, $214-223$. [CrossRef]

188. Khandelwal, S.; Rajawat, A.; Tailor, Y.K.; Kumar, M. Efficient and Environmentally Benign Diversity Oriented Synthesis of 2, 3-dihydroquinazolin-4(1H)-ones Using GAAS As a Bio-based Green Solvent. Curr. Green Chem. 2015, 2, 156-162. [CrossRef]

189. Xu, Z.; Jianga, Y.; Zou, S.; Liu, Y. Bio-Based Solvent Mediated Synthesis of Dihydropyrimidinthiones Via Biginelli Reaction. Phosphorus Sulfur Silicon Relat. Elem. 2014, 189, 791-795. [CrossRef]

190. Rashidi, R.; Nasr-Esfahani, M.; Mohammadpoor-Baltork, I.; Tangestaninejad, S.; Moghadam, M.; Mirkhani, V. Highly selective synthesis of mono- and bis-4,5-dihydropyrrolo[1,2-a]quinoxalines catalyzed by sustainable supported acidic ionic liquid in water media. Monatsh. Chem. 2018, 149, 557-567. [CrossRef]

191. Liu, S.; Zhou, Y.; Sui, Y.; Liu, H.; Zhou, H. B2(OH)4-mediated one-pot synthesis of tetrahydroquinoxalines from 2-amino(nitro)anilines and 1, 2-dicarbonyl compounds in water. Org. Chem. Front. 2017, 4, 2175-2178. [CrossRef]

192. Yazdani-Elah-Abadi, A.; Mohebat, R.; Maghsoodlou, M.-T. Theophylline as the catalyst for the diastereoselective synthesis of trans-1,2-dihydrobenzo[a]furo[2,3-c]phenazines in water. RSC Adv. 2016, 6, 84326-84333. [CrossRef]

193. Bardajee, G.R.; Malakooti, R.; Abtin, I.; Atashin, H. Palladium Schiff-base complex loaded SBA-15 as a novel nanocatalyst for the synthesis of 2,3-disubstituted quinoxalines and pyridopyrazine derivatives. Micropor. Mesopor. Mat. 2013, 169, 67-74. [CrossRef]

194. Alinezhad, H.; Tajbakhsh, M.; Norouzi, M.; Baghery, S. An Efficient and Green Protocol for the Synthesis of 1,5-benzodiazepine and Quinoxaline Derivatives Using Protic Pyridinium Ionic Liquid as a Catalyst. World Appl. Sci. J. 2013, 22, 1711-1717. [CrossRef]

195. Bardajee, G.R. ZrOCl28H2O in water: An efficient catalyst for rapid one-pot synthesis of pyridopyrazines, pyrazines and 2,3-disubstituted quinoxalines. Comptes Rendus Chim. 2013, 16, 872-877. [CrossRef]

196. Feng, E.; Zhou, Y.; Zhao, F.; Chen, X.; Zhang, L.; Jiang, H.; Liu, H. Gold-catalyzed tandem reaction in water: An efficient and convenient synthesis of fused polycyclic indoles. Green Chem. 2012, 14, 1888-1895. [CrossRef]

197. Zhang, Q.-Y.; Liu, B.-K.; Chen, W.-Q.; Wu, Q.; Lin, X.-F. A green protocol for synthesis of benzo-fused N,S-, N,O- and N,N-heterocycles in water. Green Chem. 2008, 10, 972-977. [CrossRef]

198. Srinivas, C.; Kumar, C.N.S.S.P.; Rao, V.J.; Palaniappan, S. Green Approach for the Synthesis of Quinoxaline Derivatives in Water Medium Using Reusable Polyaniline-sulfate Salt Catalyst and Sodium Laurylsulfate. Catal. Lett. 2008, 121, 291-296. [CrossRef]

199. Khurana, J.M.; Chaudhary, A.; Lumb, A.; Nand, B. An expedient four-component domino protocol for the synthesis of novel benzo[a]phenazine annulated heterocycles and their photophysical studies. Green Chem. 2012, 14, 2321-2327. [CrossRef]

200. Huang, T.; Jiang, D.; Chen, J.; Gao, W.; Ding, J.; Wu, H. Silica Sulfuric Acid (SSA)/Polyethylene Glycol (PEG) as a Recyclable System for the Synthesis of Quinoxalines and Pyrazines. Synth. Commun. 2011, 41, 3334-3343. [CrossRef]

201. Nagarapu, L.; Mallepalli, R.; Arava, G.; Yeramanchi, L. Polyethylene glycol (PEG-400) mediated synthesis of quinoxalines. Eur. J. Chem. 2010, 1, 228-231. [CrossRef]

202. Abdollahi-Irandegan, A.; Hassanabadi, A. Synthesis of 4-aryl-7-methyl-3,4-dihydropyrano[3,4-e][1,3]oxazine-2, 5-dione in aqueous media. J. Chem. Res. 2016, 40, 727-728. [CrossRef] 
203. Rostami-Charati, F.; Hossaini, Z.; Gharaee, E.; Khalilzadeh, M.A. One-Pot Three-Component Synthesis of Oxazine Derivatives in Water. J. Heterocycl. Chem. 2013, 50, E174-E177. [CrossRef]

204. Paira, R.; Paira, P.; Maity, A.; Mondal, S.; Hazra, A.; Sahu, K.B.; Naskar, S.; Saha, P.; Banerjee, M.; Mondal, N.B. Amberlite IRA 402(OH): An efficient mediator for the exclusive synthesis of fused tricyclic oxaza quinolinium salts. Tetrahedron Lett. 2010, 51, 3200-3204. [CrossRef]

205. Shinde, P.V.; Kategaonkar, A.H.; Shingate, B.B.; Shingare, M.S. Polyethylene glycol (PEG) mediated expeditious synthetic route to 1,3-oxazine derivatives. Chin. Chem. Lett. 2011, 22, 915-918. [CrossRef]

206. Sridhar, R.; Yedukondalu, M.; Prasad, K.R.S.; Rao, M.V.B. Polyethylene glycol mediated catalyst-free synthesis of 5,9b-dihydro-1H-[1,2,4] triazino[5,6-b]indole-3-ols/thioles. Pharma Chem. 2014, 6, 1-8.

207. Prasad, J.V.; Prabhakar, M.; Manjulatha, K.; Rambabu, D.; Solomon, K.A.; Krishna, G.G.; Kumar, K.A. Efficient catalyst-free Domino approach for the synthesis of novel 2-benzazepine derivatives in water. Tetrahedron Lett. 2010, 51, 3109-3111. [CrossRef]

208. Mallepalli, R.; Yeramanchi, L.; Bantu, R.; Nagarapu, L. Polyethylene Glycol (PEG-400) as an Efficient and Recyclable ReactionMedium for the One-Pot Synthesis of N-Substituted Azepines under Catalyst-Free Conditions. Synlett 2011, 18, 2730-2732. [CrossRef]

209. Shaabani, A.; Maleki, A.; Mofakham, H.; Moghimi-Rad, J. A Novel One-Pot Pseudo-Five-Component Synthesis of 4,5,6,7-Tetrahydro-1H-1,4-diazepine-5-carboxamide Derivatives. J. Org. Chem. 2008, 73, 3925-3927. [CrossRef] [PubMed]

210. Dandia, A.; Singh, R.; Joshi, J.; Maheshwari, S. Green and chemoselective synthesis of pyrazolo[3,4-e] $[1,4]$ thiazepines and evaluation of their anti-infective activities. Res. Chem. Intermed. 2015, 41, 4213-4226. [CrossRef]

211. Yan, Y.; Yang, X.; Wu, L. Facile Synthesis of 1,5-Benzothiazepines in Water Using Tetrabutylammonium Tribromide. Phosphorus Sulfur Silicon Relat. Elem. 2012, 187, 573-579. [CrossRef]

212. Lingampalle, D.L.; Netankar, P.D.; Jagrut, V.B.; Mane, R.A. PEG-400 mediated synthesis of 1, 5-benzothiazepines. J. Chem. Biol. Interfaces 2014, 4, 287-291.

(C) 2020 by the authors. Licensee MDPI, Basel, Switzerland. This article is an open access article distributed under the terms and conditions of the Creative Commons Attribution (CC BY) license (http://creativecommons.org/licenses/by/4.0/). 